\title{
Uma plataforma para avaliar a degradação da vazão causada por interferência espectral em redes sem fio padrão IEEE 802.11
}

\section{Dagoberto Carvalio Junior}

Orientador: Prof. Dr. Edson dos Santos Moreira

Dissertação apresentada ao Instituto de Ciências Matemáticas e de Computação - ICMC-USP, como parte dos requisitos para obtenção do título de Mestre em Ciências - Ciências de Computação e Matemática Computacional.

USP - São Carlos

Novembro/2010 


\section{Uma plataforma para avaliar a degradação da vazão causada por interferência espectral em redes sem fio padrão IEEE 802.11}


Dedico este trabalho à minha esposa,

Emanuele e a minha filha, Julia. 


\section{AGRADECIMENTOS}

Inicialmente, agradeço a Deus que me deu saúde para investir neste desafio.

Agradeço ao orientador deste trabalho, Prof. Dr. Edson dos Santos Moreira, pela energia e generosidade dispensados no andamento deste trabalho.

Ao Instituto de Ciências Matemáticas e de Computação, pela oportunidade concedida.

Ao Sr. Luiz Carlos Dotta, chefe da Seção Técnica de Informática pela compreensão e cordialidade dispensada ao longo do tempo.

Aos meus pais, Dagoberto (in memorian) e Maria. Ao meu pai pelos ensinamentos valiosos da observação da natureza e a minha mãe pela dedicação e afetividade.

Aos amigos do grupo de pesquisa, em especial ao Roberto Sadao Yokoyama, pelos inúmeros auxílios que muito colaboraram para a finalização deste trabalho.

Finalmente, gratidão especial a minha esposa Emanuele, que dedicou grande parte de seu valioso tempo com a educação de nossa filha, principalmente em minhas ausências. Também não poderia esquecer-me da Julia, minha filha; do seu sorriso cativante e empolgante que tornou meus anseios mais fáceis de serem suportados - que lindo sorriso. 
"Os problemas significativos que enfrentamos não podem ser resolvidos no mesmo nível de pensamento em que estávamos quando os criamos".

Albert Einstein, (1879-1955) 


\section{RESUMO}

A interferência espectral gera patologias nos sistemas de comunicação sem fio (wireless), como por exemplo, quedas na comunicação e degradação na vazão. O espectro de RF (rádio frequência) é fiscalizado e controlado por órgãos governamentais, no entanto as redes sem fio padrão IEEE 802.11, conhecidas por WLANs (Wireless Local Area Networks), trabalham em faixas espectrais não licenciadas, conhecidas por ISM. Estas redes estão cada vez mais presentes nos ambientes comerciais e residenciais, contribuindo para questões de ubiquidade e acesso à Internet. Com este aumento expressivo, a cobertura espectral está cada vez mais densa. A densidade elevada de sinais aponta para a saturação do espectro ISM, causando interferências mútuas das redes IEEE 802.11. O objetivo deste trabalho é analisar a cobertura do espectro, por redes WLANs, e avaliar quedas de vazão ocasionadas por interferências espectrais, variando no espaço e no tempo. Dois cenários foram mapeados para analisar as degradações, um com baixa a média e outro com alta densidade e complexidade. $\mathrm{O}$ objetivo da criação desses cenários foi comparar as degradações causadas pelas interferências em ambientes diferentes, na ocupação, na utilização e na propagação de sinais de redes WLANs. Através dos resultados obtidos, um ciclo de vida de gerenciamento do espectro de redes padrão 802.11 foi proposto. Este ciclo contribui para avaliar e classificar o estado de uma rede em densa, não densa, complexa e não complexa, visto que alterações de ocupação do espectro - no espaço e no tempo - são plausíveis de ocorrerem. Conclui-se que os impactos da sobreposição total do canal, por fontes 802.11, não são suficientes para a substancial degradação da vazão em ambientes de baixa a média complexidade. Em ambientes com alta densidade e complexidade as degradações são mais evidentes, principalmente quando ocorrem perturbações vindas de duas fontes adjacentes.

Palavras-chave: Interferência Espectral. Rede Sem Fio. Rede Wireless. IEEE 802.11. WiFi. Banda ISM. Gerenciamento de Rede. 


\begin{abstract}
The spectral interference generates pathologies in wireless communication systems (wireless), such as declines in communication and degradation in flow. The spectrum of RF (radio frequency) is supervised and controlled by government agencies, however the wireless standard IEEE 802.11, known as WLANs (Wireless Local Area Networks), work in unlicensed spectrum bands, known as ISM. These networks are increasingly involved in commercial and residential environments, contributing to issues and ubiquity of Internet access. With the significant increase in these networks, the spectral coverage is increasingly dense. The high density of signals pointing to the saturation of the ISM spectrum, causing mutual interference of IEEE 802.11 networks. The aim of this study is to analyze the coverage of the spectrum, for WLANs, and evaluate the flow falls caused by spectral interferences, varying in space and time. Two scenarios were mapped to examine the degradations, with a low to medium and one with high density and complexity. The purpose of creating these scenarios was to compare the degradation caused by interference in different environments, occupation, use and spread of signals WLANs. Through the results, a life cycle management of the spectrum of standard 802.11 networks was proposed. This cycle helps to evaluate and classify the state of a dense network, not dense, complex and not complex, since changes in occupation of the spectrum - in space and time - are plausible to occur. It is concluded that the impacts of the complete overlap of the channel, sources 802.11 , are not sufficient to the substantial degradation of the flow in low to medium complexity. In environments with high density and complexity of the degradation is more evident, especially when there are disturbances coming from two adjacent sources.
\end{abstract}

Keywords: Espectral Interference. Wireless Network. IEEE 802.11. WiFi. ISM. Network Management. 


\section{Sumário}

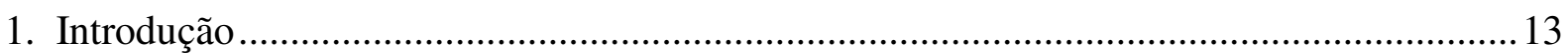

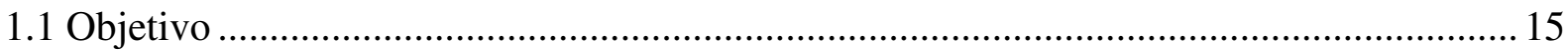

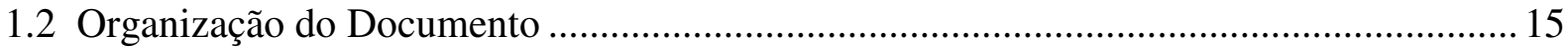

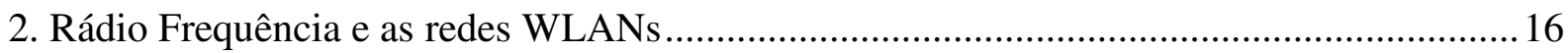

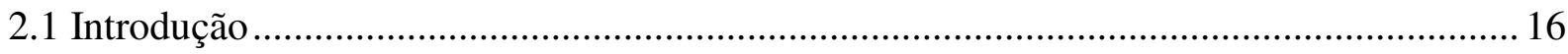

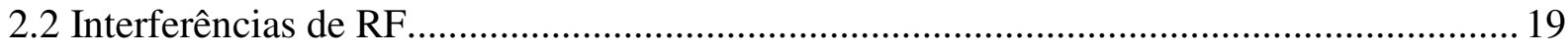

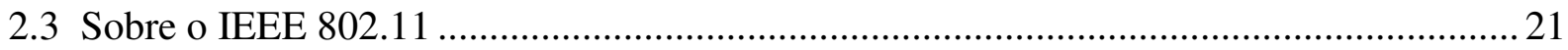

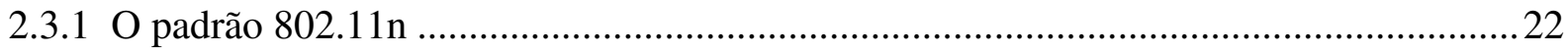

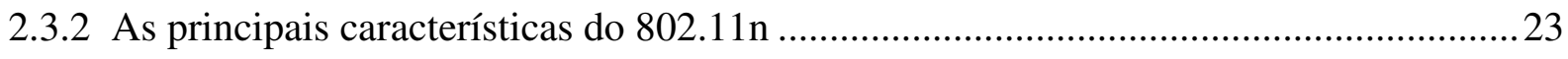

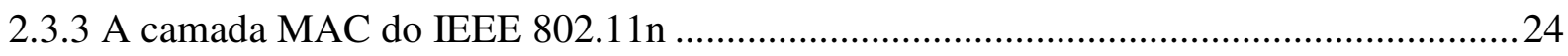

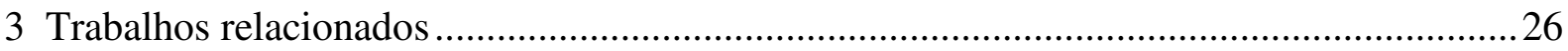

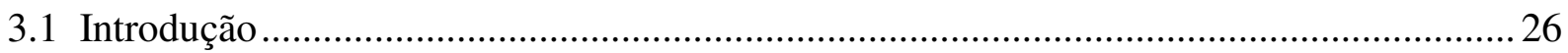

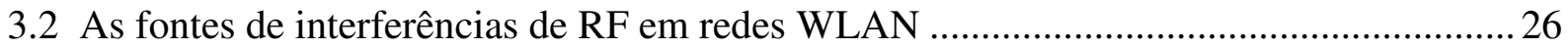

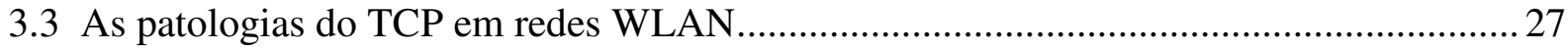

3.4 As limitações da WLAN quando exposta a interferências .............................................28

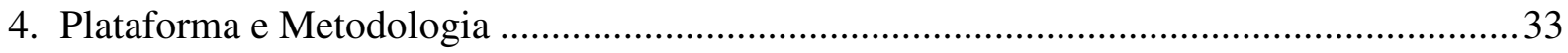

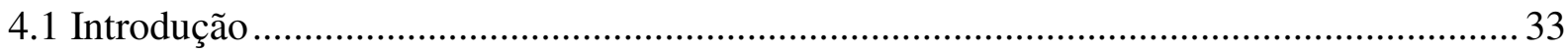

4.2 Descrição do cenário para avaliação de redes de baixa a média complexidade e

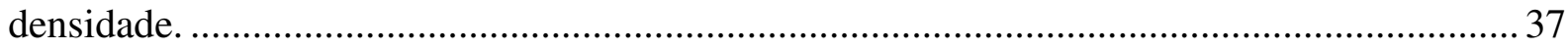

4.3 Descrição do cenário de alta complexidade e densidade................................................ 38

4.4 Descrição dos experimentos e ferramentas utilizadas ................................................... 39

4.4.1 O Simple Network Management Protocol - SNMP .................................................. 41

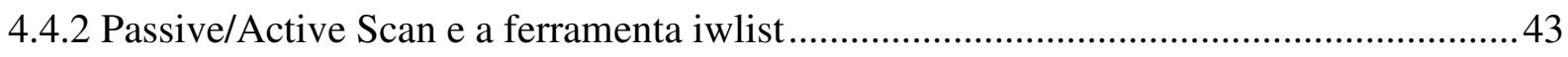

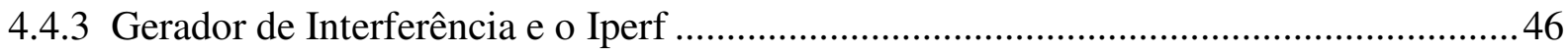


4.5 As Configurações de Hardware e Software.

4.5.1 Descrição de hardware e software do cenário de baixa a média complexidade e densidade. 48

4.5.1 Descrição de hardware e software do cenário de alta densidade e complexidade. 49

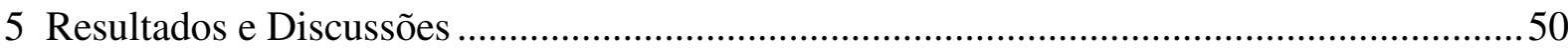

5.1 Avaliações do Ambiente de Baixa a Média Densidade e Complexidade..........................50

5.1.1 Avaliações dos Sinais Coletados no Espaço e no Tempo .............................................50

5.1.2 Avaliação da diminuição da vazão quando expostos à interferências ............................55

5.2 Avaliações do Ambiente de Alta Densidade e Complexidade .........................................58

5.2.1 Resultado e Avaliação do Experimento número 1 …...................................................58

5.2.2 Resultado e Avaliação do Experimento número 2 ...................................................59

5.2.3 Resultado e Avaliação do Experimento número 3 ........................................................ 61

6 Conclusões, Propostas e Sugestões para Trabalhos Futuros ................................................62

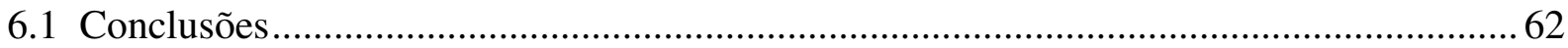

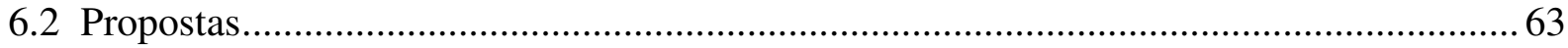

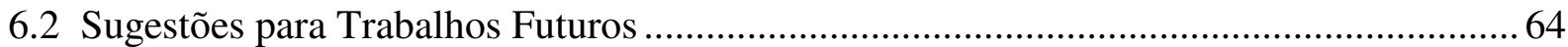

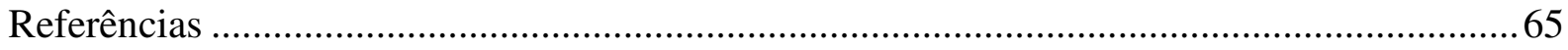




\section{Lista de Figuras}

Figura 1. A arquitetura SOHand (Moreira, et al., 2007). Em destaque a utilização da tecnologia de comunicação 802.11 como possibilidade para o processo de handover.

Figura 2 - Mapa das redes WiFi detectadas na ilha de Manhattan. (WIGLE) ..................................... 15

Figura 3 - Divisão Espectral (Adaptada de TANENBAUM, 2003)...................................................... 17

Figura 4 - Interferência entre dois APs 802.11b/g configurados na mesma frequência....................... 19

Figura 5 - Interferência de sobreposição de canais adjacentes entre dois APs $802.11 \mathrm{~b} / \mathrm{g}$.................... 20

Figura 6 - Canais sem sobreposição em APs $802.11 \mathrm{~b} / \mathrm{g}$. Os canais 1,6 e 11 não se sobrepõem, impossibilitando qualquer interferência entre eles

Figura 7 - Sobreposição de canais em ambientes WLAN: a) utilização da técnica de mitigação da não sobreposição de canais; b) interferência total de canal por APs vizinhos.

Figura 8 - Padrões IEEE 802.11, posicionados nas camadas, física e enlace, do modelo de referência OSI.

Figura 9 - Arquitetura SISO, uma única antena envia o sinal (at) no lado do transmissor

(T) e, uma única antena recebe (ar) do lado do receptor $(\mathrm{R})$.

Figura 10 - Arquitetura MIMO 3x3, três antenas enviam (at1, at2, at3) do lado do transmissor $(\mathrm{T})$ e três antenas recebem sinais do lado do receptor $(\mathrm{R})$.

Figura 11 - Throughput versus velocidade da camada PHY sem alterações do MAC, com $10 \%$ de erro sobre envio de pacotes. (PERAHIA e STACEY, 2008)

Figura 12 - Throughput versus velocidade da camada PHY com as alterações da camada MAC (frame aggregation e block acknowledgement), com 10\% de erro sobre envio de pacotes. (PERAHIA e STACEY, 2008)

Figura 13 - Resultados obtidos através dos cenários. (E.BENJAMIN, 2001)

Figura 14 - Configuração do Cenário para Experimento - Três Interfaces

(RAMAKRISHNA, DAVID, et al., 2007).

Figura 15 - Diagrama de comunicação da camada PHY entre remetente e destinatário. Os componentes vulneráveis no destinatário são ilustrados em itálico. (RAMAKRISHNA, DAVID, et al., 2007).

Figura 16 - Vazão e latência versus potência da interferência, afetando o timing recovery.

(RAMAKRISHNA, DAVID, et al., 2007)

Figura 17 - Encapsulamento 802.11 PHY e o seu uso no receptor. (RAMAKRISHNA,

DAVID, et al., 2007)

Figura 18 - Vazão e latência versus potência da interferência afetando o processamento

do cabeçalho. (RAMAKRISHNA, DAVID, et al., 2007).

Figura 19 - Vazão e latência versus interferências. (RAMAKRISHNA, DAVID, et al., 2007). 
Figura 20 - Percentual de retransmissões e média das latências versus interferência.

(RAMAKRISHNA, DAVID, et al., 2007).

Figura 21 - Plataforma para estudos dos efeitos das interferências causadas por redes

WLANs na vazão de redes sem fio. 34

Figura 22 - Modelo centralizado de arquitetura de gerenciamento de rede sem fio. 35

Figura 23 - Modelo distribuído de arquitetura de gerenciamento de rede sem fio. 36

Figura 24 - Modelo híbrido de arquitetura de gerenciamento de rede sem fio. 36

Figura 25 - Distribuição dos Pontos de Acesso do ambiente do Campus Universitário. A escala apresenta valores em metros. 38

Figura 26 - Cenário com alta densidade de dispositivos $802.11 \mathrm{~b} / \mathrm{g}$. 39

Figura 27 - Fluxo da solicitação e resposta do protocolo SNMP na plataforma...... 40

Figura 28 - Relacionamento entre o NMS e o agente (adaptado de MAURO e SCHMIDT, 2005).

Figura 29 - Padrão de comunicação entre o NMS e o agente (adaptado de MAURO e SCHMIDT, 2005).

Figura 30 - Estrutura de árvore de objetos, o nó no topo é chamado de root e os nós subsequentes são chamados de filhos, todos os nós filhos fazem parte da sub-árvore (STALLINGS, 1999). 43

Figura 31 - Imagem do sensor utilizado no experimento.

Figura 32 - Processo passive scan, APs anunciam beacons frames. 44

Figura 33 - Cliente requisita informações dos APs através de Probe Request. A resposta dos APs é através de mensagens de Probe Response. 45

Figura 34 - Fluxo da solicitação e resposta da ferramenta $i$ wlist na plataforma................................... 46

Figura 35 - Resultado do comando iwlist executado em Linux. ........................................................ 46

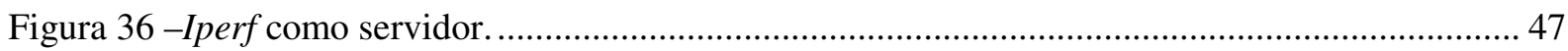

Figura 37 -Iperf como cliente.

Figura 38 - Gerador de Interferência, utilizado para geração de cargas de rede em ambos os cenários.

Figura 39 - Total de pontos de acesso, média total geral de associações por dia e média de associações por ponto de acesso no período de 24 horas.

Figura 40 - Mapa do Campus Universitário e suas divisas, com o posicionamento preciso dos sensores e suas respectivas distâncias.

Figura 41 - Quantidade de sinais coletados pelo sensor posicionado no bloco 1, distribuídos em dias e qualificados pelos canais de operação (Latitude $=22^{\circ} 0^{\prime} 26.91 " \mathrm{~S}$ e Longitude $\left.=47^{\circ} 53^{\prime} 44.54^{\prime \prime} \mathrm{O}\right)$. 
Figura 42 - Quantidade de sinais coletados pelo sensor posicionado no bloco 2, distribuídos em dias e qualificados pelos canais de operação (Latitude $=22^{\circ} 0{ }^{\prime} 27.53 " \mathrm{~S}$ e Longitude $=47^{\circ} 53^{\prime} 42.92^{\prime \prime} \mathrm{O}$ )

Figura 43 - Quantidade de sinais coletados pelo sensor posicionado no bloco 4, distribuídos em dias e qualificados pelos canais de operação (Latitude $=22^{\circ} 0{ }^{\prime} 25.91$ "S e Longitude $=47^{\circ} 53^{\prime} 41.13^{\prime \prime} \mathrm{O}$ ).

Figura 44 - Quantidade de sinais coletados pelos sensores posicionados nos blocos 1, 2 e 4, distribuídos em dias e qualificados pelos canais de operação.

Figura 45 - Média dos sinais coletados pelos sensores posicionados nos blocos 1, 2 e 4, qualificados pelos canais de operação.

Figura 46 - Distribuição dos sinais coletados no tempo, qualificados por canais e dias da semana.

Figura 47 - Comportamento da vazão da rede sem fio no Campus Universitário, Ponto de Acesso bloco1, bloco2 e bloco4.

Figura 48 - Média percentual dos erros (pacotes perdidos), com e sem interferência da fonte geradora. Intervalo de confiança de 5\% para mais e para menos

Figura 49 - Projeção da média percentual dos erros sobre o comportamento da vazão dos pontos de acesso.

Figura 50 - Comportamento da vazão nos três APs no cenário de alta densidade e complexidade. O AP1 operava no canal 1, o AP2 no canal 6 e o AP3 no canal 11.

Figura 51 - Comportamento da vazão do AP3 quando exposto a uma fonte geradora de interferência sem atividade, alocada no mesmo canal.

Figura 52 - Comportamento da vazão do AP3 quando exposto a uma fonte geradora de interferência com atividade, alocada no mesmo canal.

Figura 53 - Comportamento compilado das vazões dos APs 1, 2 e 3 . O canal de operação do AP3 variou no tempo.

Figura 54 - Proposta de um ciclo de vida da rede sem fio, padrão 802.11. 


\section{Lista de Tabelas}

Tabela 1 - Faixas registradas para equipamentos de radiocomunicação de uso restrito.

Tabela 2 - Divisão de canais pelo IEEE 802.11 para os padrões b/g (CISCO SYSTEMS, 2010)

Tabela 3 - Divisão de canais pelo IEEE 802.11 para o padrão 802.11a (CISCO

SYSTEMS, 2010).

Tabela 4 - Cenários dos testes realizados (Adaptado de E.BENJAMIN, 2001). 27

Tabela 5 - Relação entre metros quadrados e números de APs.

Tabela 6 - Resumo dos hardwares utilizados no cenário de baixa a média complexidade e densidade.

Tabela 7 - Resumo dos hardwares utilizados no cenário de baixa a média complexidade e densidade.

Tabela 8 - Distribuição dos sinais coletados e o percentual de ocupação espectral. 55

Tabela 9 - Combinações de canais nos APs 1, 2, 3 e Gerador de Interferência, no experimento número 3 


\section{Lista de Acrônimos}

ACI : $\quad$ Adjacent-Channel Interference;

ACK : $\quad$ Acknowledgment;

ADC : $\quad$ Analog-To-Digital Converter;

A-MPDU : Aggregated-Mac Packet Data Unit;

A-MSDU : Aggregated-Mac Service Data Unit;

ANATEL : Agência Nacional de Telecomunicações;

AP : $\quad$ Access Point;

CCI : $\quad$ Co-Channel Interference;

DS-SS : $\quad$ Direct Sequence Spread Spectrum;

FCC : $\quad$ Federal Communications Commission;

FH-SS : $\quad$ Frequency Hopping Spread Spectrum;

HTSG : $\quad$ High Throughput Study Group;

IEEE : $\quad$ Institute Of Electrical And Electronic Engineers;

ISM : $\quad$ Industrial, Scientific, Medical;

MAC : $\quad$ Media Access Control;

MIB : $\quad$ Management Information Base;

MIMO : $\quad$ Multiple Input Multiple Output;

MTU : $\quad$ Maximum Transmission Unit;

NGN : $\quad$ Next Generation Network;

NIC : $\quad$ Network Interface Card;

NMS : $\quad$ Network Management Station;

OFDM : $\quad$ Orthogonal Frequency-Division Multiplexing;

OID : $\quad$ Object Identifier;

OSI : $\quad$ Open Systems Interconnection;

PC : $\quad$ Personal Computer; 
PHY : $\quad$ Physical;

PLCP : $\quad$ Physical Layer Convergence Protocol;

RAM : $\quad$ Random Access Memory;

RF : $\quad$ Radio Frequência;

RFID : $\quad$ Radio-Frequency Identification;

SFD : $\quad$ Start Frame Delimiter;

SISO : $\quad$ Single Input Single Output;

SMI : $\quad$ Structure Of Management Information;

SNMP : $\quad$ Simple Network Management Protocol;

SOHand : $\quad$ Service Oriented Handover;

SQL : $\quad$ Structured Query Language;

SSID : $\quad$ Service Set Identifier;

TCP : $\quad$ Transmission Control Protocol;

UDP : $\quad$ User Datagram Protocol;

WLAN : $\quad$ Wireless Local Area Network;

WNGSC : $\quad$ Wireless Next Generation Standing Committee; 


\section{Introdução}

Nos últimos anos, grandes avanços proporcionados por pesquisas em redes locais sem fio impulsionaram novo paradigma de comunicação. Novos conceitos de utilização de dispositivos sem fio contribuíram para diversas áreas da computação e automação, por exemplo, a computação ubíqua (ARAUJO, 2003). A comunicação sem fio colabora com a mobilidade dos usuários da rede computacional e um de seus pontos fortes é a comunicação onipresente (WEISER, 1991).

Além da computação ubíqua podemos destacar as redes de $4^{\mathrm{a}}$ Geração (4G) ou redes de próxima geração (NGN - Next Generation Network), (HUI e YEUNG, 2003), (MATEUS e LOUREIRO, 2005), (VIDALES, MAPP, et al., 2005), (FRATTASI, FATHI, et al., 2006), que trouxeram uma arquitetura de convergência global em torno do IP (Internet Protocol). O IP cria uma forma de agregação convergente de voz e dados. A computação ubíqua unida pela convergência através das redes NGN trará relevante contribuição para a população em geral.

Ultimamente houve um crescimento das redes WLAN (Wireless Local Area Network), principalmente em locais considerados importantes em aspectos de mobilidade (ERIKSSON, AGARWAL, et al., 2006), por exemplo: aeroportos, conferências, escritórios, universidades e locais públicos denominados hotspots. Segundo a Wi-Fi Alliance (WI-FI ALLIANCE, 2008) - organização formada pelos fabricantes de equipamentos compatíveis com o padrão IEEE 802.11 - em 2008 foram certificados mais de 5000 produtos e 99\% das universidades americanas terão redes WLANs até 2013.

Para apoiar os requisitos de escolha de conectividade em redes 4G, Moreira et al. (2007) propuseram uma arquitetura que controla e apóia aplicações que utilizam interfaces 4G de conexão. Este é um ponto importante para que as redes WLANs sejam inseridas no contexto global de conectividade. Uma malha física de cobertura cada vez maior possibilita o acesso de clientes em diversos pontos de intercâmbio com outras tecnologias 4G.

A arquitetura proposta por Moreira et al. (2007) é dita SOHand (Service Oriented Handover) (Figura 1). Esta arquitetura prevê a possibilidade de troca de tecnologia de comunicação em um sistema $4 \mathrm{G}$, de forma transparente ou controlada pelo usuário. $\mathrm{O}$ processo de troca de tecnologia em determinado momento ou a troca de células de comunicação na mesma tecnologia é chamado handover. A criação de uma arquitetura que 
facilite os usuários migrarem de uma tecnologia para outra - através de processo de handover - provavelmente colaborará para o aumento de redes WLANs. Os locais considerados públicos, com abrangência metropolitana ou setorial em determinada região ou cidade, poderão prover conectividade através do padrão 802.11 (WiFi).

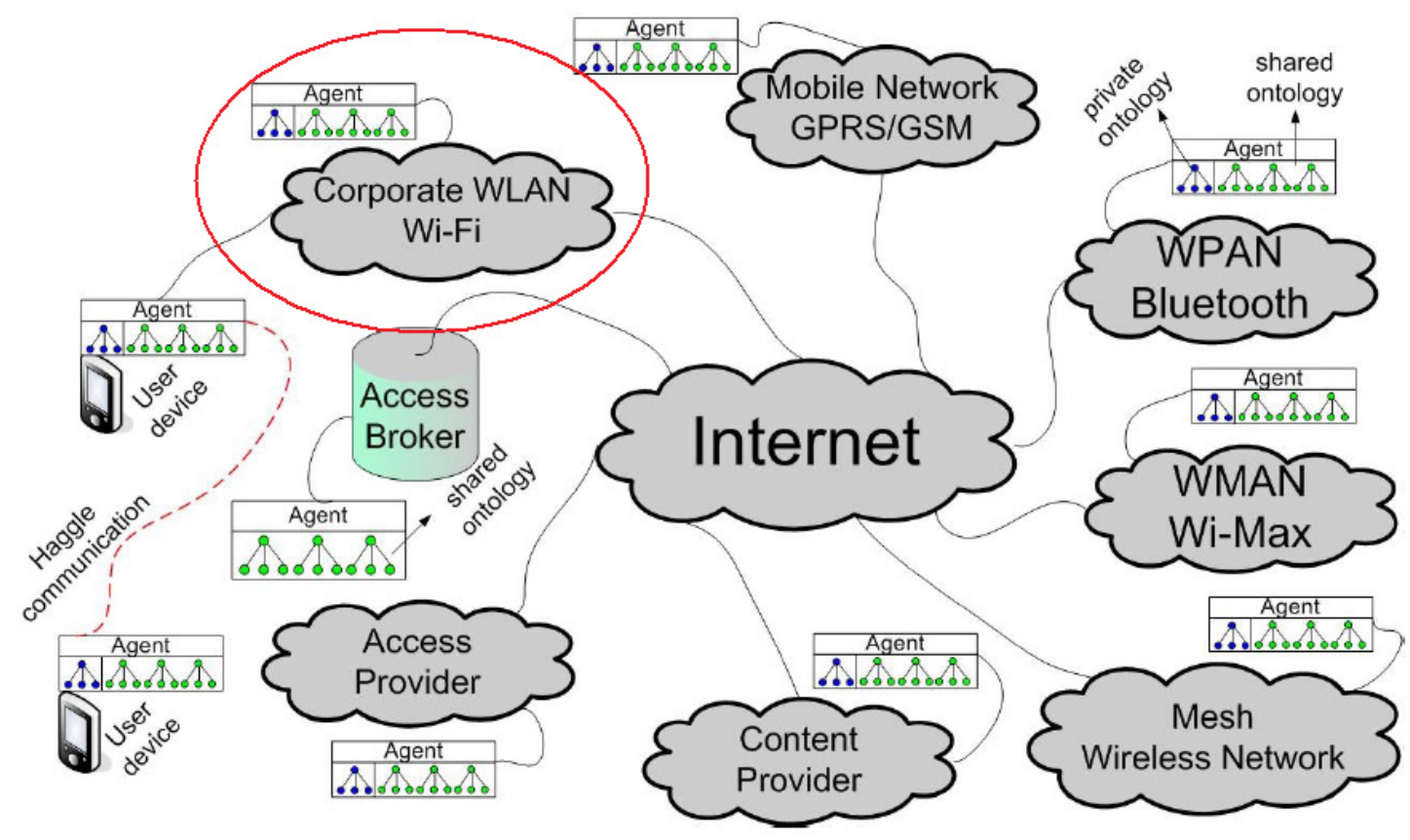

Figura 1. A arquitetura SOHand (Moreira, et al., 2007). Em destaque a utilização da tecnologia de comunicação 802.11 como possibilidade para o processo de handover.

Em decorrência do crescimento das redes WLANs os efeitos negativos causados nas taxas de vazão precisam ser entendidos. As redes IEEE 802.11 utilizam faixas de frequências não licenciadas (ISM). A intersecção de faixas espectrais de frequência pode causar patologias na comunicação, uma dessas patologias é a queda de vazão (throughput) (WANG, CUTHBERT e BIGHAM, 2004) , (CHENG, BELLARDO, et al., 2006) , (RAMAKRISHNA, DAVID, et al., 2007). Devido à alternativa de infra-estrutura de comunicação sem fio e da baixa complexidade de instalação, diversos espaços corporativos e residenciais estão utilizando a tecnologia WLAN (Figura 2). Em qualquer caso que utilize à tecnologia WLAN, é importante a taxa de vazão do sistema de comunicação. 


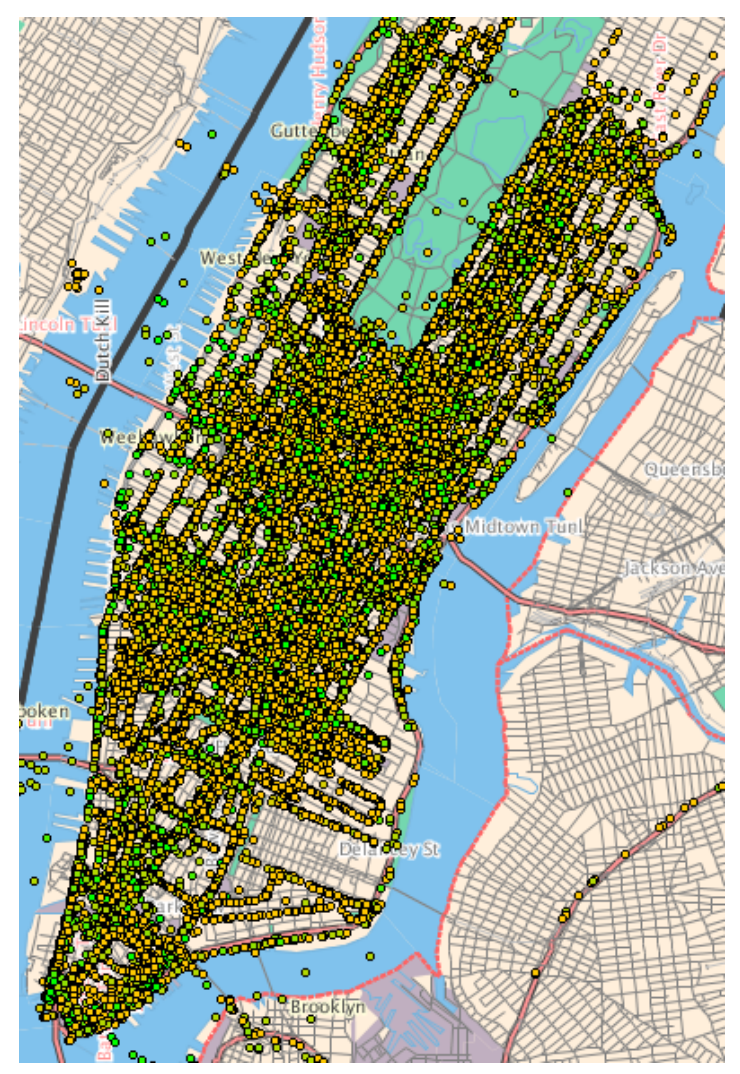

Figura 2 - Mapa das redes WiFi detectadas na ilha de Manhattan. (WIGLE)

\subsection{Objetivo}

O objetivo deste trabalho é avaliar as quedas de vazão em uma rede $802.11 \mathrm{~b} / \mathrm{g}$ quando expostas às interferências espectrais geradas por outras redes WiFi. As avaliações serão realizadas em um ambiente que provê comunicação aos alunos da Universidade de São Paulo no campus de São Carlos, mais especificamente no Instituto de Ciências Matemáticas e de Computação.

Para avaliar os efeitos na vazão, o trabalho propõe uma plataforma de gerenciamento espectral específica para redes $802.11 \mathrm{~b} / \mathrm{g}$ e um ciclo de vida da rede. A plataforma coleta informações relevantes para o gerenciamento do espectro de rádio frequência $(\mathrm{RF})$ em redes WiFi e canaliza as informações para uma estação de processamento. $\mathrm{O}$ ciclo de vida de uma rede sem fio é importante para esquematizar as etapas de vida da rede, desde sua concepção até suas adaptações.

\subsection{Organização do Documento}

Este documento está organizado da seguinte maneira: no capítulo 2 é realizada a abordagem dos temas relacionados aos fatores de interferência espectral, além de 
contextualizar as redes locais sem fio (WLAN). Explorar os tipos de interferências espectrais e as respectivas faixas de frequência utilizadas pelo padrão IEEE 802.11. O capítulo 3 apresenta os trabalhos relacionados. Estes trabalhos apresentam os problemas e patologias ocasionados pela interferência espectral em redes WLAN e, de forma sistemática, aborda as quedas de vazão, tema desta dissertação. No capítulo 4 é apresentada a plataforma para estudos da degradação de vazão, além das metodologias utilizadas para desenvolvimento deste trabalho. As ferramentas utilizadas para a extração dos dados também são apresentadas nesse capítulo. Por sua vez, o capítulo 5 apresenta os resultados obtidos. Os resultados do cenário, qualificado como de baixa a média complexidade e densidade, são apresentados e comparados aos resultados do cenário de alta densidade e complexidade. Finalmente as conclusões, propostas e sugestões para trabalhos futuros são apresentados no capítulo 6.

\section{Rádio Frequência e as redes WLANs}

\subsection{Introdução}

As redes sem fio padrão IEEE $802.11 \mathrm{a} / \mathrm{b} / \mathrm{g} / \mathrm{n}$ trabalham em faixa de banda espectral conhecida por ISM (Industrial, Scientific, Medical). Diversos outros dispositivos operam nesta mesma faixa de frequência - não somente os dispositivos 802.11. Desta forma, a poluição espectral ISM é ampla, visto que dispositivos comuns, como telefones sem fio, Bluetooth, Zigbee (IEEE 802.15.4), RFID tags e diversos outros mais específicos acabam por compartilhar o mesmo ambiente de cobertura de RF dos pontos de acesso (APs) de rede WLAN. Além de a rede WLAN compartilhar o espectro de RF com dispositivos comuns, há interferências causadas pelos próprios APs no mesmo ambiente.

As agências reguladoras cuidam da normatização aplicada às faixas não licenciadas de RF que, a princípio, são fundamentadas nas recomendações da Federal Communications Commission (FCC) (RAMAKRISHNA, DAVID, et al., 2007). Apesar da faixa espectral ISM não ser licenciada, os dispositivos que operam nestas faixas de frequência devem operar em uma faixa restrita de cobertura, conseguida através da limitação da potência de irradiação dos sinais. Os limites das potências de irradiação são descritos pelas agências reguladoras que, no caso do Brasil, é a ANATEL (Agência Nacional de Telecomunicações http://www.anatel.gov.br). Os atos regulatórios do espectro de radio frequência no Brasil são de responsabilidade da ANATEL que, em 2004, publicou a resolução 365/2004. Esta resolução basicamente criou regras para a utilização das faixas não licenciadas (livres e de uso 
restrito), sendo que, algumas observações foram mapeadas para que o espectro pudesse ser preservado. Primeiramente, rede local sem fio (WLAN) é uma aplicação considerada livre, portanto não necessita homologação na ANATEL. No entanto, se houver exploração comercial da faixa livre, o prestador de serviço terá que adequar suas atribuições de acordo com a Resolução 73, de 25 de novembro de 1998. As faixas de frequência livres registradas pela ANATEL são: 902-907,5 MHz, 915-928 MHz, 2400-2483,5 MHz e 5725-5850 MHz (Tabela 1).

Tabela 1 - Faixas registradas para equipamentos de radiocomunicação de uso restrito.

\begin{tabular}{l|l|l|l}
\hline Faixa 1 & Faixa 2 & Faixa 3 & Faixa 4 \\
\hline $902-907,5 \mathrm{MHz}$ & $915-928 \mathrm{MHz}$ & $2400-2483,5 \mathrm{MHz}$ & $5725-5850 \mathrm{MHz}$. \\
\hline
\end{tabular}

Em redes locais sem fio as faixas utilizadas e comercializadas em equipamentos padrão 802.11 são: $2400-2483,5 \mathrm{MHz}$ e $5725-5850 \mathrm{MHz}$ (Figura 3). As tecnologias que trabalham na primeira faixa são $802.11 \mathrm{~b} / \mathrm{g} / \mathrm{n}$ e na segunda faixa $802.11 \mathrm{a} / \mathrm{n}$. As especificações do IEEE 802.11 controlam o espectro de rádio frequência de forma a criar uma divisão de canais (CISCO SYSTEMS, 2010). Estes canais são utilizados para separar as interferências que ocorrem entre rádios distintos.

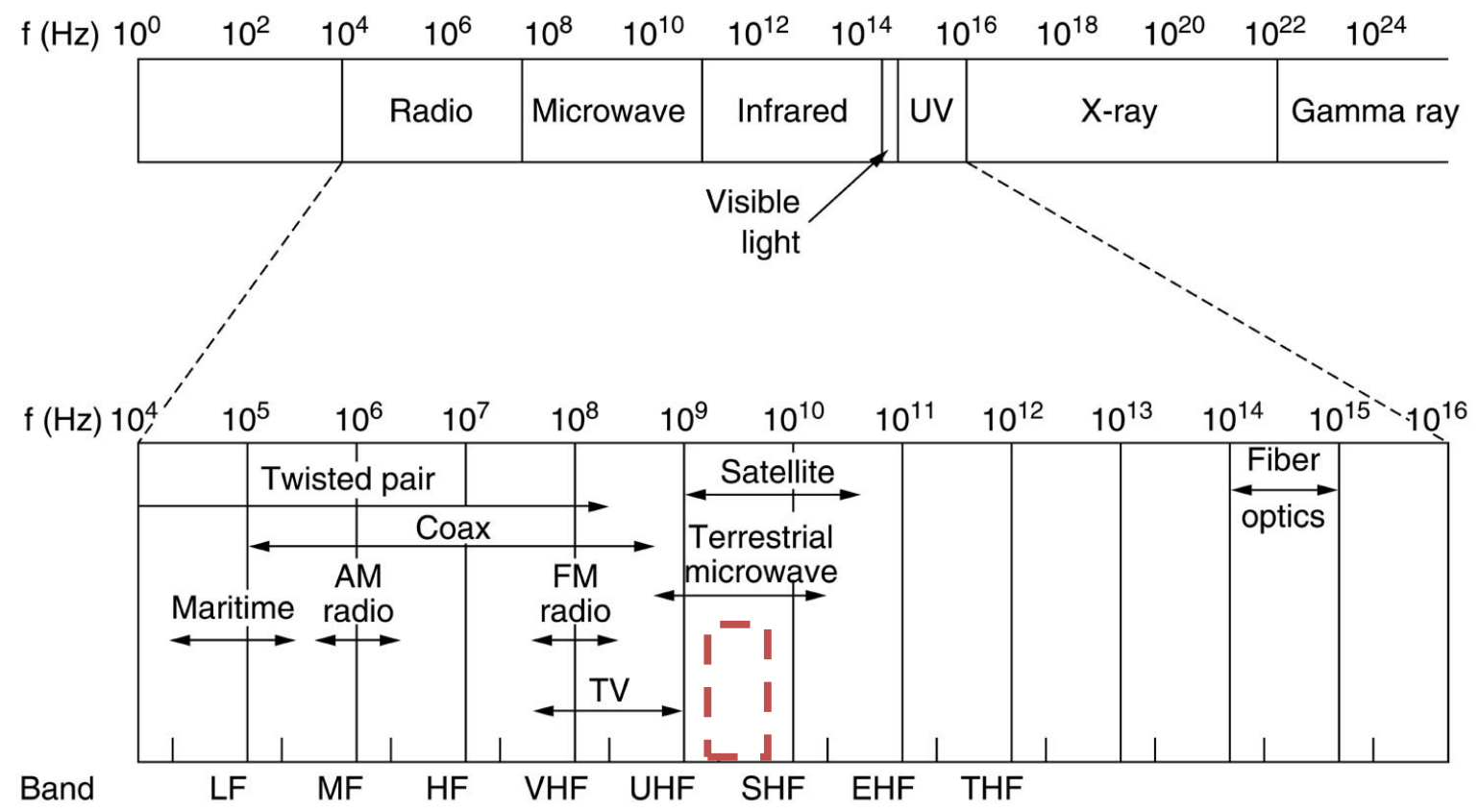

Figura 3 - Divisão Espectral (Adaptada de TANENBAUM, 2003). 
A Tabela 2 relaciona canais utilizados nas tecnologias $802.11 \mathrm{~b} / \mathrm{g}$ classificados por domínios reguladores. Na Tabela 3, as representações são relativas ao padrão 802.11a

Tabela 2 - Divisão de canais pelo IEEE 802.11 para os padrões b/g (CISCO SYSTEMS, 2010).

\section{Divisão de Canais para IEEE 802.11b/g}

\begin{tabular}{c|l|l|l|l|l}
\hline \multirow{2}{*}{$\begin{array}{l}\text { Identificador } \\
\text { do Canal }\end{array}$} & Frequência & \multicolumn{5}{|c}{ Domínios Reguladores } \\
\cline { 3 - 6 } & & América & \multicolumn{1}{|c}{ EMEA } & Japan & $\begin{array}{c}\text { Resto do } \\
\text { Mundo }\end{array}$ \\
\hline $\mathbf{1}$ & 2412 & & & & \\
\hline $\mathbf{2}$ & 2417 & Sim & Sim & Sim & Sim \\
\hline $\mathbf{3}$ & 2422 & Sim & Sim & Sim & Sim \\
\hline $\mathbf{4}$ & 2427 & Sim & Sim & Sim & Sim \\
\hline $\mathbf{5}$ & 2432 & Sim & Sim & Sim & Sim \\
\hline $\mathbf{6}$ & 2437 & Sim & Sim & Sim & Sim \\
\hline $\mathbf{7}$ & 2442 & Sim & Sim & Sim & Sim \\
\hline $\mathbf{8}$ & 2447 & Sim & Sim & Sim & Sim \\
\hline $\mathbf{9}$ & 2452 & Sim & Sim & Sim & Sim \\
\hline $\mathbf{1 0}$ & 2457 & Sim & Sim & Sim & Sim \\
\hline $\mathbf{1 1}$ & 2462 & Sim & Sim & Sim & Sim \\
\hline $\mathbf{1 2}$ & 2467 & - & Sim & Sim & Sim \\
\hline $\mathbf{1 3}$ & 2472 & - & Sim & Sim & Sim \\
\hline $\mathbf{1 4}$ & 2484 & - & - & Sim & - \\
\hline
\end{tabular}

Tabela 3 - Divisão de canais pelo IEEE 802.11 para o padrão 802.11a (CISCO SYSTEMS, 2010).

\section{Divisão de Canais para IEEE 802.11a}

\begin{tabular}{|c|c|c|c|c|c|}
\hline \multirow{2}{*}{$\begin{array}{l}\text { Identificador } \\
\text { do Canal }\end{array}$} & \multirow{2}{*}{$\begin{array}{l}\text { Frequência } \\
\text { em MHz }\end{array}$} & \multicolumn{4}{|c|}{ Domínios Reguladores } \\
\hline & & América & EMEA & Japan & $\begin{array}{l}\text { Resto do } \\
\text { Mundo }\end{array}$ \\
\hline 34 & 5170 & - & - & Sim & - \\
\hline 36 & 5180 & Sim & Sim & Sim & Sim \\
\hline 38 & 5190 & - & - & Sim & - \\
\hline 40 & 5200 & Sim & Sim & Sim & Sim \\
\hline 42 & 5210 & - & - & Sim & - \\
\hline 44 & 5220 & Sim & Sim & Sim & Sim \\
\hline 46 & 5230 & - & - & Sim & - \\
\hline 48 & 5240 & Sim & Sim & Sim & Sim \\
\hline 52 & 5260 & Sim & Sim & Sim & Sim \\
\hline 56 & 5280 & Sim & Sim & Sim & Sim \\
\hline 60 & 5300 & Sim & Sim & Sim & Sim \\
\hline
\end{tabular}




\begin{tabular}{l|l|l|l|l|l}
\hline 64 & 5320 & Sim & Sim & Sim & Sim \\
\hline 100 & 5500 & - & Sim & - & Sim \\
\hline 104 & 5520 & - & Sim & - & Sim \\
\hline 108 & 5540 & - & Sim & - & Sim \\
\hline 116 & 5560 & - & Sim & - & Sim \\
\hline 120 & 5580 & - & Sim & - & Sim \\
\hline 124 & 5600 & - & Sim & - & Sim \\
\hline 128 & 5620 & - & Sim & - & Sim \\
\hline 132 & 5640 & - & Sim & - & Sim \\
\hline 136 & 5660 & - & Sim & - & Sim \\
\hline 140 & 5680 & - & Sim & - & Sim \\
\hline 149 & 5700 & - & Sim & - & Sim \\
\hline 153 & 5745 & Sim & - & - & Sim \\
\hline 157 & 5765 & Sim & - & - & Sim \\
\hline 161 & 5785 & Sim & - & - & Sim \\
\hline & 5805 & Sim & - & - & Sim \\
\hline
\end{tabular}

\subsection{Interferências de $R F$}

No padrão 802.11a cada canal ocupa uma faixa espectral de $20 \mathrm{MHz}$ e no padrão b/g a faixa espectral do canal é de $22 \mathrm{MHz}$. Interferência espectral ocorre quando dois sinais distintos são gerados na mesma faixa de frequência e enviados ao mesmo espaço temporal (E.BENJAMIN, 2001). As interferências de RF em redes locais podem ser basicamente classificadas de duas formas: quando ocorrem no mesmo canal (CCI - Co-Channel Interference) ou quando ocorrem em canais adjacentes (ACI - Adjacent-Channel Interference). As interferências CCI (Figura 4) ocorrem quando dois sinais ocupam a mesma faixa espectral, por exemplo, dois APs transmitindo e recebendo dados no mesmo intervalo de espectro. Por outro lado, a interferência ACI ocorre quando existe sobreposição de canais adjacentes, vale dizer, muito próximos, porém não totalmente sobrepostos (Figura 5).

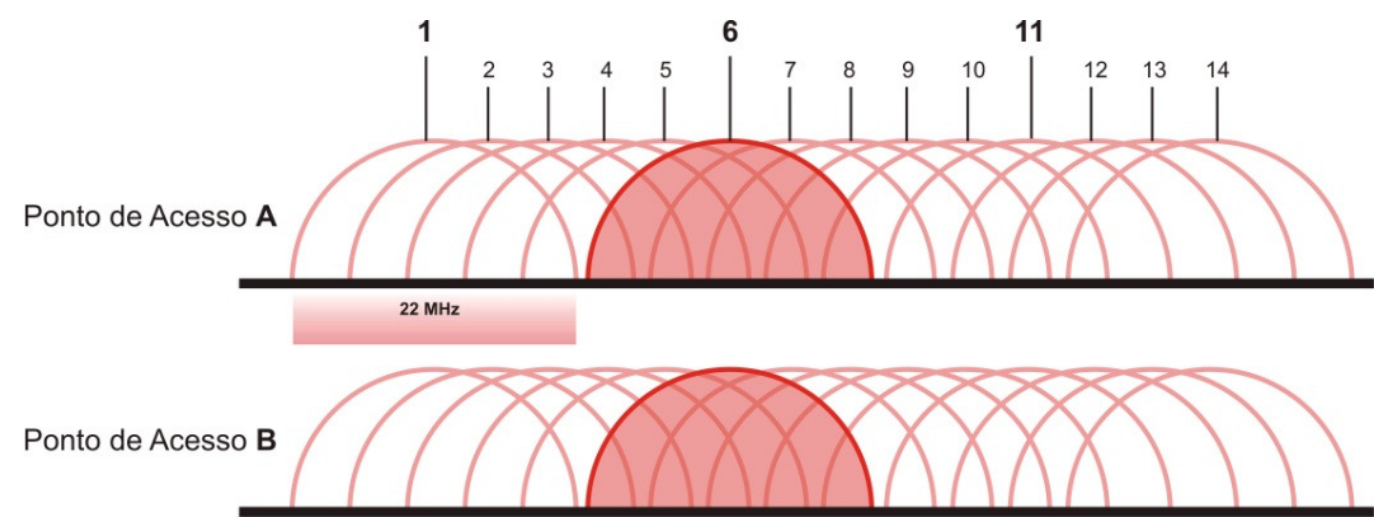

Figura 4 - Interferência entre dois APs 802.11b/g configurados na mesma frequência. 


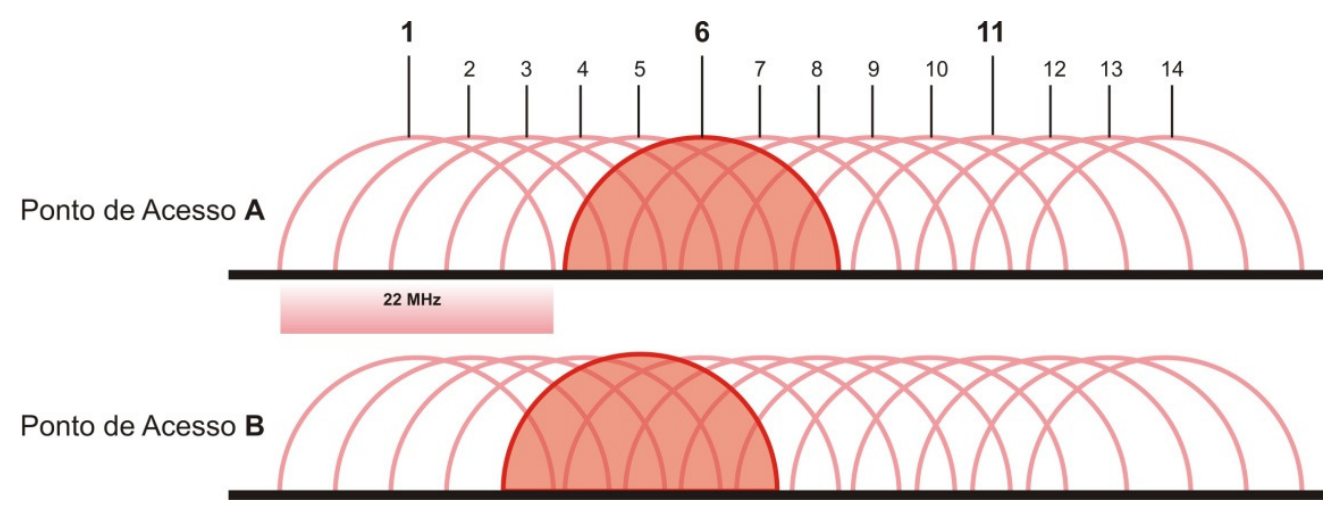

Figura 5 - Interferência de sobreposição de canais adjacentes entre dois APs 802.11b/g.

A interferência causada pela sobreposição total do espectro (CCI) é frequente em ambientes que possuem um número elevado de dispositivos WLAN. Na América, três canais no padrão 802.11b/g não se sobrepõem, os canais 1,6 e 11 (Figura 6), o que possibilita o arranjo em células (Figura 7) que criam uma estrutura de não sobreposição. Rappaport (2009) refere conceitualmente o arranjo em células como forma de reutilização de frequência. A técnica de utilizar canais diferentes entre os pontos de acesso vizinhos cria a possibilidade de mitigação dos problemas de interferência; no entanto, necessita um acompanhamento constante da sobreposição espectral (MARY, GORCE, et al., 2007) e sua eficiência é minimizada se o ambiente não for totalmente controlado, fato comum em situações em que as WLANs provêem comunicação em ambientes externos (outdoor).

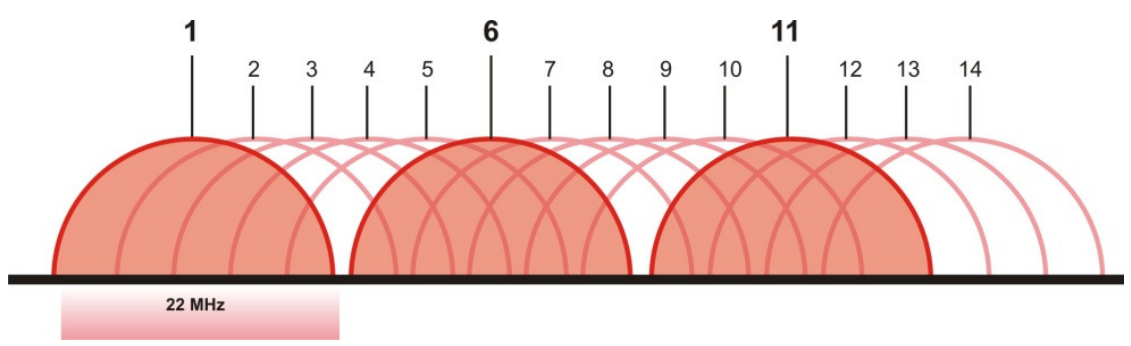

Figura 6 - Canais sem sobreposição em APs 802.11b/g. Os canais 1,6 e 11 não se sobrepõem, impossibilitando qualquer interferência entre eles. 

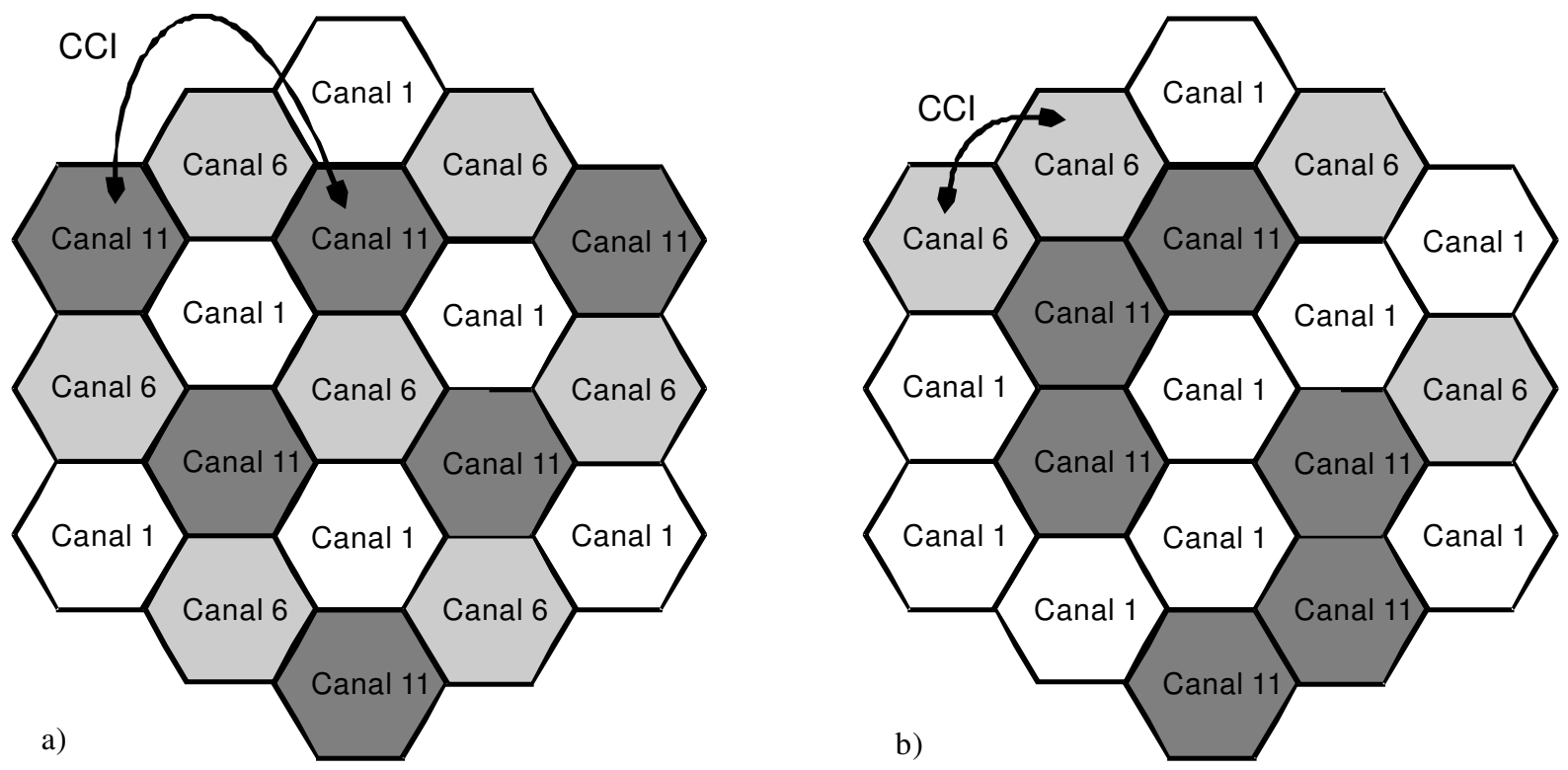

Figura 7 - Sobreposição de canais em ambientes WLAN: a) utilização da técnica de mitigação da não sobreposição de canais; b) interferência total de canal por APs vizinhos.

\subsection{Sobre o IEEE 802.11}

Após o estabelecimento dos espectros não licenciados ISM pela FCC (Federal Communications Commission - http://www.fcc.org) no final dos anos 80, essa comissão tinha esperança que as indústrias se encorajariam a desenvolver projetos para explorar as bandas ISM, principalmente nas questões voltadas a WLAN. O grupo de trabalho IEEE 802.11 Wireless LAN foi fundado em 1987, com o intuito de iniciar a padronização do espectro espalhado em bandas ISM. No entanto, os resultados positivos na padronização dos 802.11 vieram somente em 1990, quando a massificação e popularidade da internet juntamente com o crescimento de dispositivos móveis alavancaram o crescimento de projetos em WLAN (RAPPAPORT, 2009). Finalmente, em 1997 o IEEE 802.11 foi padronizado e os fabricantes receberam diretrizes de interoperabilidade usando espalhamento Direct Sequence Spread Spectrum (DS-SS) a uma taxa de transmissão de 11Mbps e 2Mbps. Após a padronização, os fabricantes começaram a produzir equipamentos para o padrão 802.11. Isto acelerou o desenvolvimento do setor. Em 1999, o padrão 802.11b (chamado de High Rate) teve aprovação, com taxas de 11Mbps, 5,5 Mbps, 2Mbps e 1Mbps. Em 2001, o padrão 802.11b admitiu o salto de frequência Frequency Hopping Spread Spectrum (FH-SS). Os padrões 802.11a, 802.11g e 802.11n descrevem as características da camada PHY (física) baseada em Orthogonal Frequency Division Multiplexing (OFDM), na faixa de $5 \mathrm{GHz}$ para o padrão $802.11 \mathrm{a} / \mathrm{n}$ e 2,4GHz para 802.11 g/n, com taxas de 54Mbps (GAST, 2005). 


\subsubsection{O padrão 802.11n}

Em janeiro de 2002 o IEEE criou o Wireless Next Generation Standing Committee (WNGSC) com o desafio de melhorar a taxa de transmissão dos sistemas WLAN, cujo principal motivador foi o padrão 802.11a. Em setembro do mesmo ano, o High Throughput Study Group (HTSG) realizou a primeira reunião, com o objetivo de extrair documentos para a elevação das taxas de transmissão. Após várias definições, o IEEE concluiu quais modificações deveriam ocorrer na camada física (PHY) e de controle (MAC), com o objetivo de atingir taxa de transmissão de pelo menos 100Mbps, mantendo a compatibilidade com os padrões existentes (PERAHIA e STACEY, 2008).

A grande maioria dos dispositivos de acesso às redes sem fio está baseada nos padrões 802.11b/g; porém, pela crescente demanda dos sistemas WLANs a procura por melhoria de vazão é inevitável. O padrão 802.11n aumentou sua capacidade de taxa de transmissão com a inclusão da arquitetura Multiple Input Multiple Output (MIMO). A concepção original de MIMO foi descrita em 1996 pelo Bell Labs (DRIESSEN e FOSCHINI, 1999). Em 2004 a Atheros demonstrou que, em custo, a produção de dispositivos de $40 \mathrm{MHz}$ ficava muito próxima à dos dispositivos de $20 \mathrm{MHz}$, fato que abriu a oportunidade de estudos com dispositivos de $40 \mathrm{MHz}$ com inclusão de Spatial Division Multiplexing. Outra alteração proposta foi a modificação da camada MAC.

O IEEE, após unificação de três grupos de trabalho, convergiu para a criação do padrão draft 802.11 (High Throughput). O projeto draft 1.0 entrou em vigência a partir de março de 2006 e, após várias votações, foi criado o draft 2.0 em fevereiro de 2007. A Figura 8 ilustra uma visão geral dos padrões IEEE 802.11, posicionados nas duas camadas inferiores (física e enlace) do modelo de referência Open Systems Interconnection (OSI).

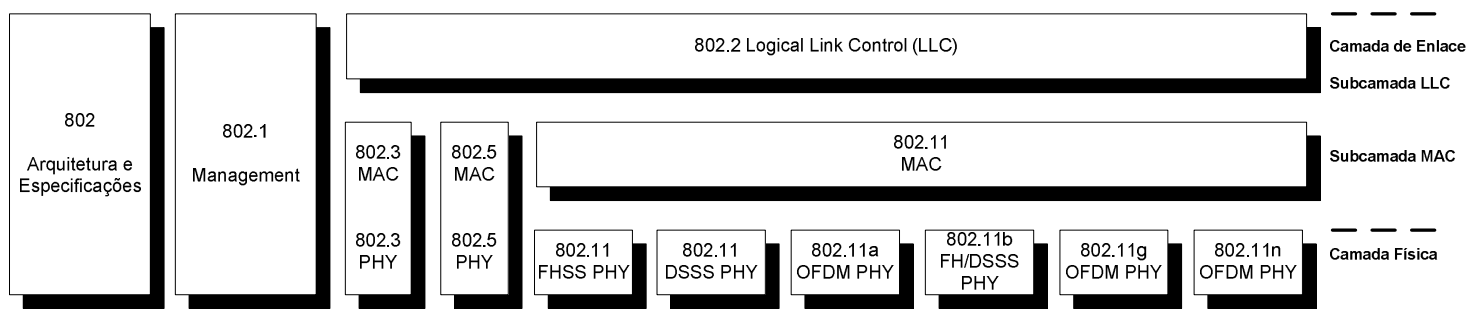

Figura 8 - Padrões IEEE 802.11, posicionados nas camadas, física e enlace, do modelo de referência OSI. 


\subsubsection{As principais características do 802.11n}

O 802.11n sofreu grandes modificações em sua camada PHY. Em comparação com o 802.11a/g as alterações foram mais direcionadas para as questões voltadas para o MIMO e os $40 \mathrm{MHz}$ de canal. Para aproveitar melhor as características melhoradas da camada PHY, algumas modificações foram feitas também na camada MAC, das quais a agregação de quadro e a confirmação em blocos foram as principais ações de melhoria da camada MAC. A confiabilidade é uma questão muito importante que foi conseguida pelo aumento da capacidade de diversidade espacial, com a implantação da arquitetura MIMO agregada à modulação OFDM. As Figuras 9 e 10 mostram as arquiteturas de SISO e MIMO, respectivamente. Single Input Single Output (SISO) é uma arquitetura muito usada em sistemas mais simples de comunicação WLAN, normalmente encontrada em equipamentos padrão $802.11 \mathrm{~b} / \mathrm{g}$.

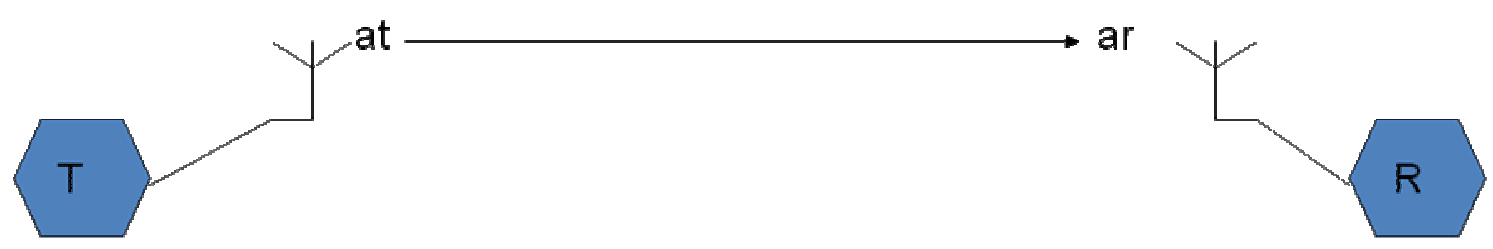

Figura 9 - Arquitetura SISO, uma única antena envia o sinal (at) no lado do transmissor (T) e, uma única antena recebe (ar) do lado do receptor $(\mathbf{R})$.

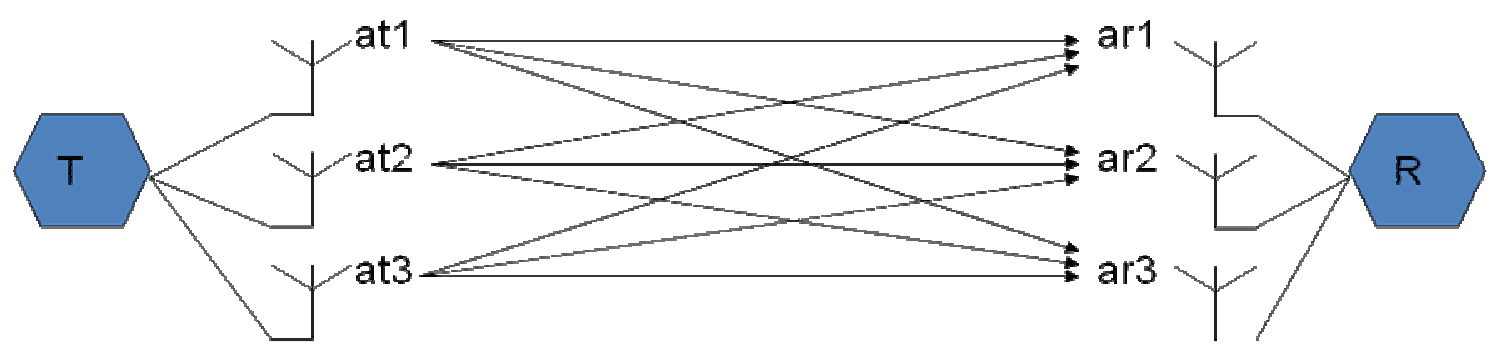

Figura 10 - Arquitetura MIMO 3x3, três antenas enviam (at1, at2, at3) do lado do transmissor (T) e três antenas recebem sinais do lado do receptor $(\mathbf{R})$.

A arquitetura MIMO exige no mínimo duas antenas para transmitir e duas antenas para receber, em uma relação de $2 \times 2$ transceptores ativos, isto é, dois transceptores ativos enviam e recebem sinais. Podemos ter outras relações de antenas em MIMO, por exemplo, $2 \times 3,3 \times 2,4 \times 4 \ldots$. 
Quando as antenas são adicionadas na arquitetura MIMO a qualidade do sinal é melhorada, melhora que fornece subsídio para a Spatial Division Multiplexing. A multiplexação por divisão espacial, como o nome indica, multiplexa de forma espacial um número de sinais transmitidos simultaneamente dentro de um canal em uma determinada banda espectral (PETROVA, WU, et al., 2007). Os transmissores e receptores TX/RX são necessários em uma relação MIMO para cada extremidade dos elementos envolvidos, que podem ser: um notebook e um AP, um AP e outro AP etc.

\subsubsection{A camada MAC do IEEE 802.11n}

Além das questões para aumento da eficiência, fomentados pela arquitetura MIMO, outro fator que contribui para o padrão 802.11 n possuir elevada taxa de transmissão é a camada MAC, que sofreu pequenas alterações com o propósito de conseguir melhorias nas quantificações das taxas de transmissão. Dois são mecanismos para aumentar a eficiência nas taxas de transmissão na camada MAC: frame aggregation e block acknowledgement (PERAHIA e STACEY, 2008).

O recurso de frame aggregation (agregação de quadros) foi proposto no último draft do IEEE, que tem por função agregar vários quadros (frames) antes de transmitir. Duas técnicas de agregação de frames foram propostas, a Aggregated-MAC Packet Data Unit (AMPDU) e a Aggregated-MAC Service Data Unit (A-MSDU), nas quais as simulações mostraram muita eficiência quando conjugadas (SKORDOULIS, NI, et al., 2008). O frame aggregation aceita que as estações móveis concatenem pequenos frames em frames maiores. Este recurso minimiza o impacto da latência do padrão IEEE 802.11 quando comparado com sua forma original, uma vez que quando as estações móveis enviam os frames, elas necessitam um tempo de espera, fato que ocasiona desperdício de banda quando existi quantidade considerável de pequenos frames. Com a agregação dos frames - recurso intitulado frame aggregation - o tempo de espera é mantido, porém, é menor a quantidade de vezes que o tempo de espera é utilizado.

O block acknowledgement é um recurso que agrega as confirmações dos quadros através de blocos, diminuindo substancialmente o overhead dispensado para este fim. Quando um frame é enviado, o emissor espera do destinatário uma confirmação (acknowledgement ACK) para poder enviar outros frames. Com as melhorias da camada PHY estipuladas pelo IEEE 802.11n, o ACK pode ser enviado para um bloco de frames MAC recebidos. Assim, a confirmação será para um bloco de frames e, por consequiência, haverá substancial 
diminuição da quantidade de ACKs e aumento da eficiência do sistema pela diminuição do overhead.

Para verificação da eficiência dos 802.11 n, com e sem as alterações da camada MAC, Perahia, et al. (2008) compilaram os valores de desempenho. A Figura 11 ilustra a eficiência do padrão $802.11 \mathrm{n}$, em taxa de transferência e velocidade, com melhorias na camada PHY, utilizando a arquitetura MIMO. A Figura 12 ilustra a eficiência do padrão 802.11n, em taxa de transmissão e velocidade, com melhorias nas camadas PHY e MAC (frame aggregation e block acknowledgement).

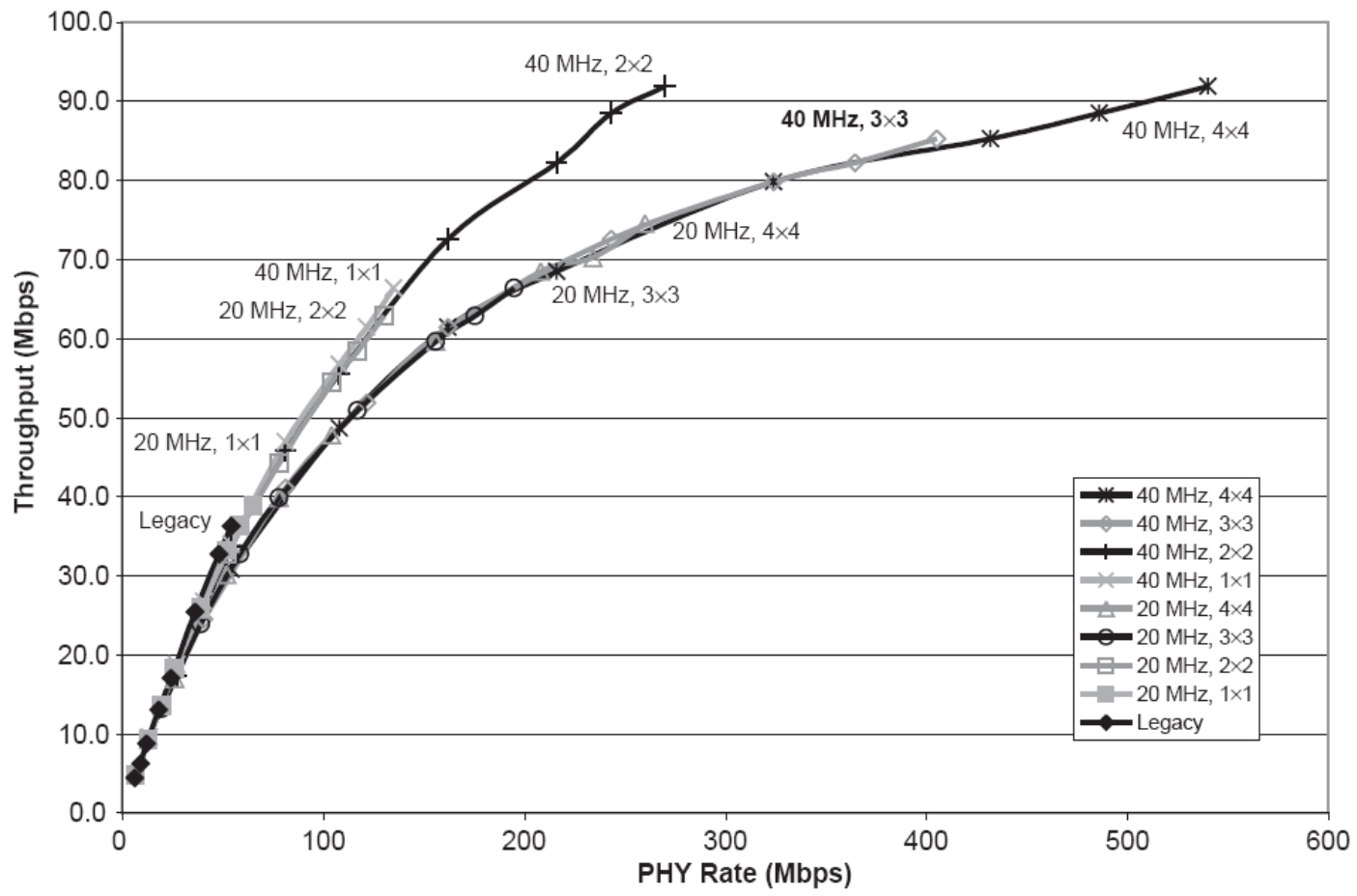

Figura 11 - Throughput versus velocidade da camada PHY sem alterações do MAC, com 10\% de erro sobre envio de pacotes. (PERAHIA e STACEY, 2008) 


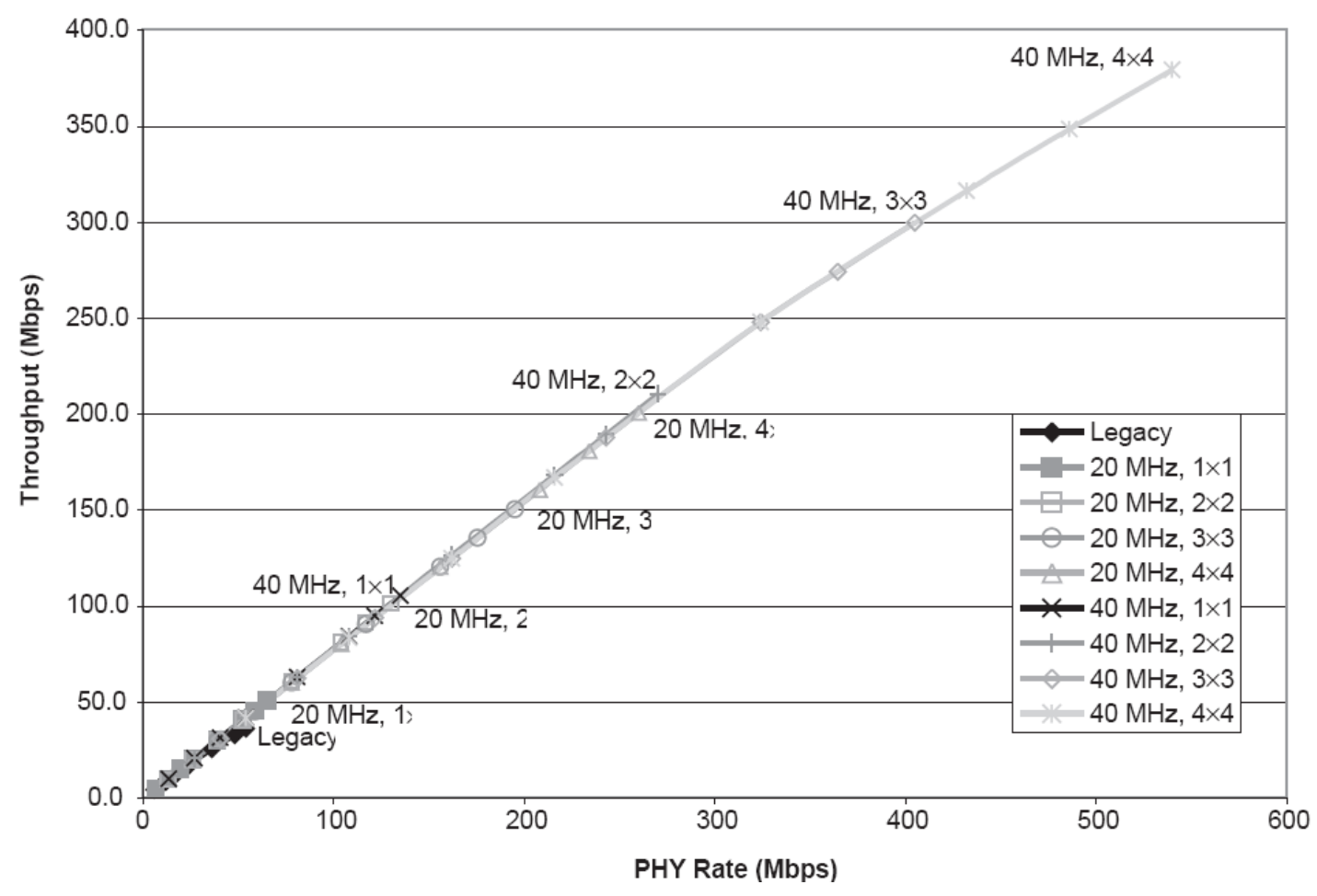

Figura 12 - Throughput versus velocidade da camada PHY com as alterações da camada MAC (frame aggregation e block acknowledgement), com $10 \%$ de erro sobre envio de pacotes. (PERAHIA e STACEY, 2008)

\section{Trabalhos relacionados}

\subsection{Introdução}

É fundamental que os efeitos causados por interferência espectral em redes WLAN sejam entendidos, pois, tais efeitos causam degradação efetiva nos sistemas computacionais que utilizam a conectividade WLAN. Foram publicados diversos trabalhos que estudaram os efeitos dos problemas causados pela interferência espectral em redes WLAN.

\subsection{As fontes de interferências de RF em redes WLAN}

Benjamin (2001) estudou os efeitos das interferências espectrais nas redes WLAN no quesito desempenho. Os testes foram gerados e compilados com base em interferências provocadas por fontes variadas, as quais basicamente foram expostas simultaneamente com a comunicação de um dispositivo cliente que estava associado a um ponto de acesso (AP) padrão 802.11b. Nessa pesquisa, o autor mediu a latência e a perda de pacotes quando são geradas interferências resultantes das seguintes fontes: Bluetooth, microondas e telefone sem fio de 2,4GHz. O resultado obtido pelo autor enfatiza a propensão de aumento de latência e perda de pacotes quando interferências ocorrem no ambiente de comunicação WLAN. A 
Tabela 4 ilustra a combinação dos geradores de interferência que concorreram com a frequência de 2,4GHz utilizados como cenários para os testes. A Figura 13 apresenta os resultados obtidos para cada cenário, ao qual, o cenário 0 é o baseline ${ }^{1}$.

Tabela 4 - Cenários dos testes realizados (Adaptado de E.BENJAMIN, 2001).

\begin{tabular}{|c|l}
\hline $\begin{array}{l}\text { Número do } \\
\text { Cenário de Teste }\end{array}$ & Descrição do Cenário de Teste \\
\hline $\mathbf{0}$ & Ambiente Baseline para $2,4 \mathrm{GHz}$ \\
\hline $\mathbf{1}$ & Laptop com Bluetooth habitado comunicando através do Bluetooth habilitado \\
\hline $\mathbf{2}$ & Forno microondas \\
\hline $\mathbf{3}$ & Fone sem fio de $2,4 \mathrm{GHz}$ \\
\hline $\mathbf{4}$ & Telefone sem fio de $2,4 \mathrm{GHz}$ \\
\hline $\mathbf{5}$ & Fone de ouvido sem fio Bluetooth comunicando com Bluetooth do telefone \\
\hline $\mathbf{6}$ & Todas as fontes de interferência de uma só vez \\
\hline
\end{tabular}

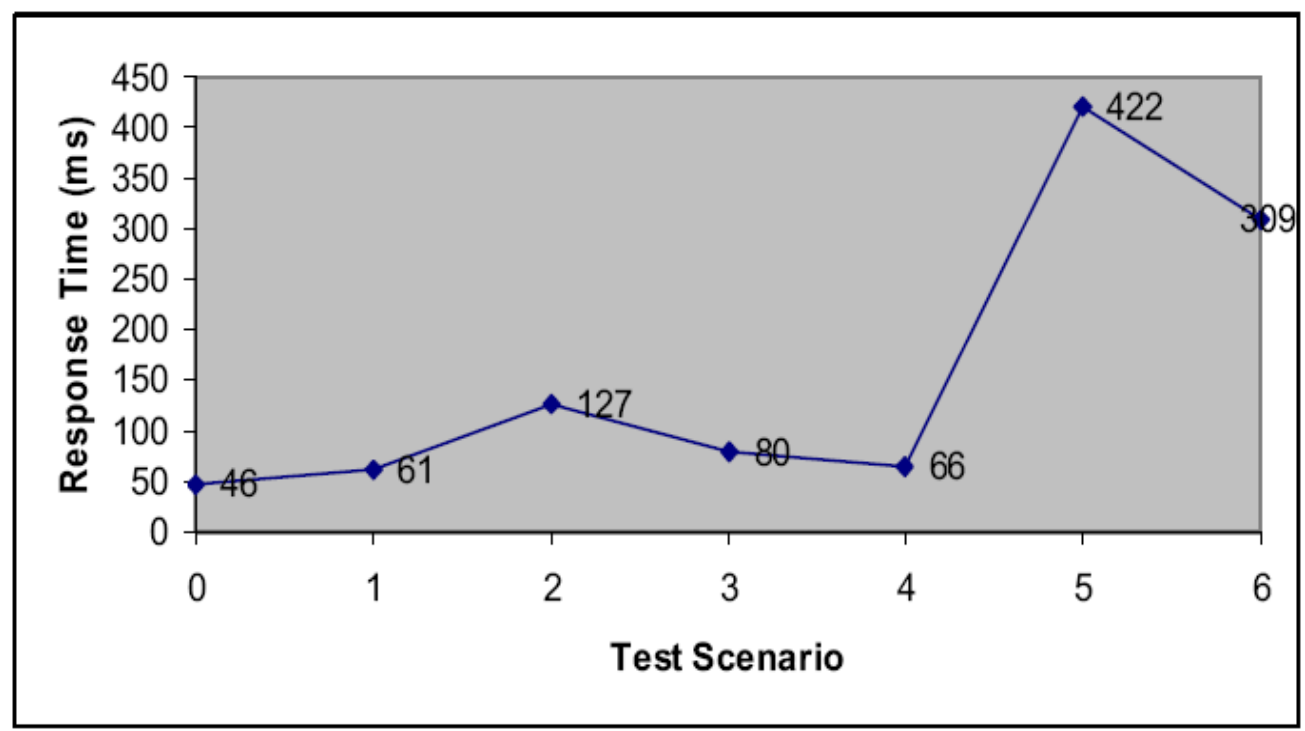

Figura 13 - Resultados obtidos através dos cenários. (E.BENJAMIN, 2001)

Desta forma, aumentos na latência foram conseqüentes da poluição espectral causada por agentes que operam na mesma frequência de trabalho das redes padrão 802.11.

\subsection{As patologias do TCP em redes WLAN}

Choi, Park e Kim (2005) estudaram os efeitos que degradam a vazão de dados em uma rede WLAN. O estudo basicamente observou a patologia que degrada o desempenho do TCP quando ocorrem problemas na camada PHY das redes WLAN. Segundo o estudo, efeitos

\footnotetext{
${ }^{1}$ Baseline é um termo em inglês utilizado para sinalizar a linha de base de um sistema de comunicação, isto é, o valor de referência inicial do sistema de comunicação para comparações e análises posteriores.
} 
recorrentes da concorrência de usuários (multiusuários) associados a uma rede WLAN são sentidos por conta da limitação da vazão de dados que pode ser sentida pela diminuição das taxas de transferência. O autor também enfatizou a camada PHY como uma camada que se correlaciona com os problemas de desempenho de vazão, porque o TCP entende como congestionamento o que, consequentemente, diminui a possibilidade de vazão a fim de equilibrar o congestionamento. Como consequência dos problemas de interferência, quando pacotes são perdidos, o TCP diminui sua taxa por entender que naquele determinado momento vários usuários utilizavam o sistema e o entendeu congestionado.

\subsection{As limitações da WLAN quando exposta a interferências}

Um estudo mais aprofundado sobre as limitações das redes 802.11, quando expostas às interferências de RF no ambiente, foi realizado por Ramakrishna, David, et al. (2007). O estudo apresentou resultados e técnicas precisas para a coleta de informações que quantificam as interferências causadas por agentes que trabalham em frequências próximas ou exatas às frequências utilizadas em redes WLAN. Basicamente, é criado um modelo de $n^{2}$ combinações, no qual $n$ é o número de dispositivos que trabalham em frequências próximas ou exatas e, desta forma, interferem entre si.

O experimento utilizado pelo autor basicamente era composto por um ponto de acesso (AP), uma estação com interfaces utilizadas para o teste de vazão e outras para gerar a interferência maliciosa (Figura 14).

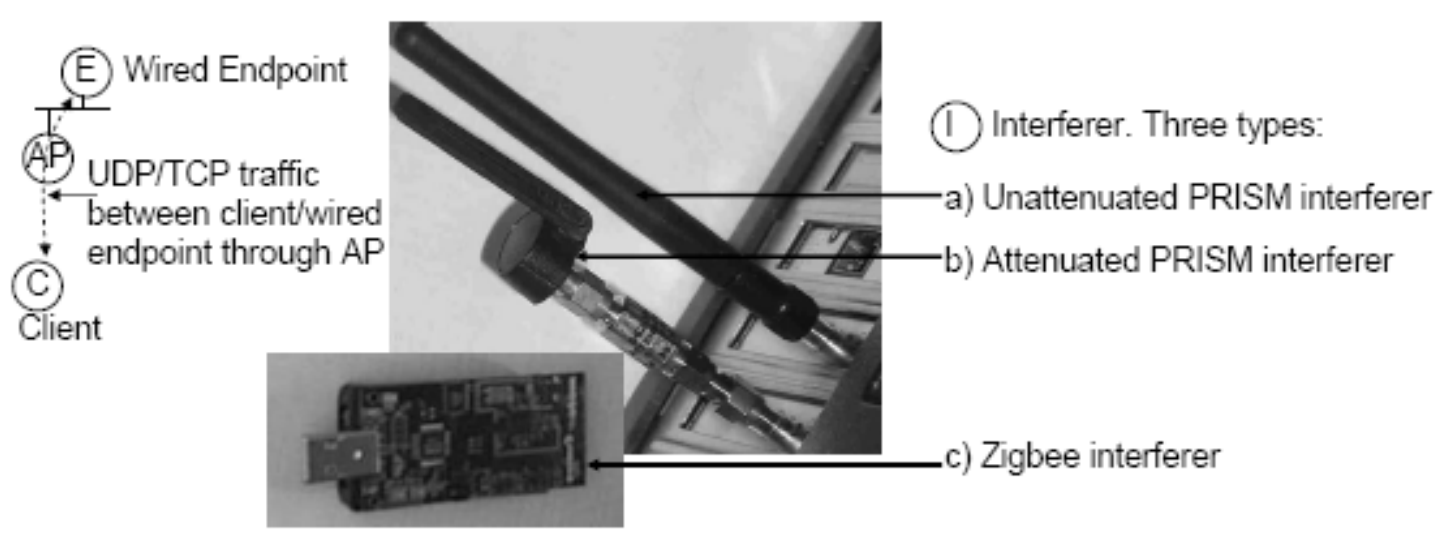

Figura 14 - Configuração do Cenário para Experimento - Três Interfaces (RAMAKRISHNA, DAVID, et al., 2007).

A contribuição do trabalho de Ramakrishna, David, et al. (2007) foi mapear as limitações dos sistemas WLAN quando expostos às interferências de alto e baixo impacto, 
bem como classificá-las em limitações de camada MAC e PHY. Durante os experimentos, o autor cita que as placas de rede sem fio (Network Interface Card - NIC) são altamente sensíveis às perdas de beacons e particularmente durante o tempo destas perdas, os NICs rapidamente começam a procurar por outros APs para associar-se, o que pode causar lacunas temporais.

Para efeitos de organização, o autor dividiu causas e efeitos das interferências em três classes: limitações do tempo de recuperação, limitações relacionadas à gama de seleção dinâmica e limitações relacionadas ao processamento do cabeçalho do Protocolo de Convergência da Camada Física (Physical Layer Convergence Protocol - PLCP).

O tempo de recuperação é importante mecanismo em redes 802.11. Existe um módulo na camada física denominado Timing Recovery (Figura 15), que tem a função de sincronizar as transmissões entre o remetente e o destinatário. Assim, se existir uma interferência de RF no meio, os tempos de sincronismo são quebrados e, consequentemente, a transmissão é prejudicada. Quando os sinais chegam ao receptor e este não consegue estabelecer o SYNC bits $^{2}$ (128 bits para preâmbulo longo e 56 bits para preâmbulo curto) com o remetente, ele simplesmente não consegue detectar qualquer pacote de transmissão. Este fator elevará a taxa de erros da camada física (PHY) contabilizando erros em seu contador.

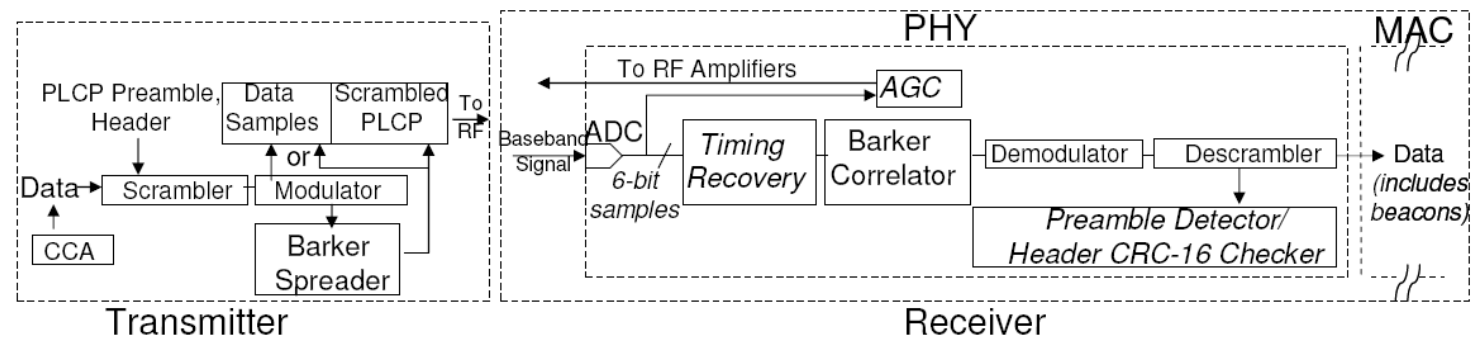

Figura 15 - Diagrama de comunicação da camada PHY entre remetente e destinatário. Os componentes vulneráveis no destinatário são ilustrados em itálico. (RAMAKRISHNA, DAVID, et al., 2007).

A Figura 16 apresenta os resultados obtidos através da comparação entre vazão (throughput) e latência, para um intervalo de confiança de 95\%. O gráfico (Figura 16) apresenta as curvas que imprimem os valores da potência da interferência e vazão; é possível notar claramente que a partir de uma potência de $12 \mathrm{dBm}^{3}$ ou $16 \mathrm{~mW}^{4}$ a vazão cai a zero.

\footnotetext{
${ }^{2} \mathrm{O}$ "SYNC bits" é um subcampo da camada MAC (Media Access Control) responsável por sinalizar o início de um frame, ele tem a função de delimitador.

${ }^{3}$ Decibel é uma unidade logarítmica para mensurar expressões de magnitude de uma quantidade física.

${ }^{4}$ A relação entre $\mathrm{dBm}$ e miliwatts é: $\mathrm{P}=10^{(\mathrm{x} / 10)} \mathrm{mW}$, portanto $\mathrm{P}$ é a potência em $\mathrm{mW}$ e $\mathrm{x}$ é em $\mathrm{dB}$.
} 


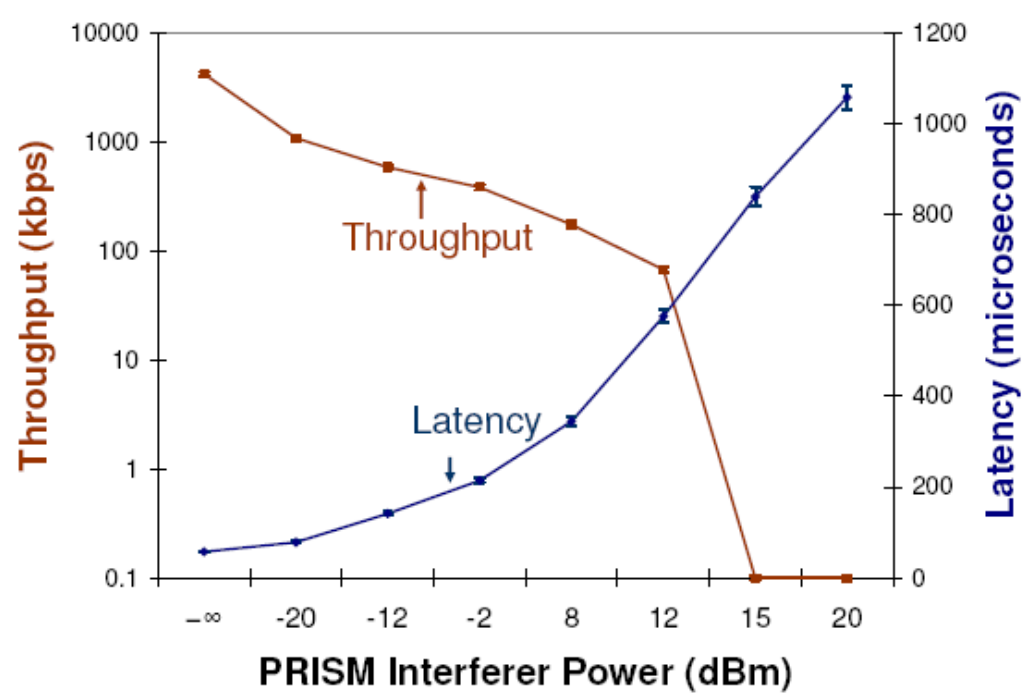

Figura 16 - Vazão e latência versus potência da interferência, afetando o timing recovery. (RAMAKRISHNA, DAVID, et al., 2007)

Gama de seleção dinâmica é outro mecanismo cuja interferência é estudada pelo autor. Este fator é conhecido por Dynamic Range Limitation, que compreende a gama de seleção de potência de sinais. Um sinal considerado forte pode estar em torno de $-10 \mathrm{dBm}$; no entanto os mais fracos podem estar em torno de $-70 \mathrm{dBm}$; desta forma, temos uma gama de 60dB. Após ajuste interno na camada PHY o receptor consegue um valor limiar de ruído e, por consequência, cria um limiar através da gama experimentada pelo NIC. Após esta calibragem, o módulo AGC (Figura 15) que faz parte do Analog-to-Digital Converter (ADC), verifica se o nível de tensão é superior à tensão limiar experimentada. O problema é verificado quando as interferências são introduzidas antes ou após a construção do limiar, impactando a vazão e a latência. Segundo o autor, estas anomalias podem ser injetadas maliciosamente através de diversas tecnologias que transmitem RF em frequências ISM, causando problemas de comunicação nas redes WLAN.

Outra análise realizada por Ramakrishna, David, et al. (2007) foi o estudo dos efeitos causados no processamento do cabeçalho do PLCP. O campo SFD (Start Frame Delimiter) (Figura 17) expressa ao receptor que o cabeçalho PLCP está prestes a ser enviado. Isto alavanca no receptor a necessidade de ter os módulos de transformação prontos. No entanto, o SYNC bit marca um tempo hábil para que os módulos de transformação estejam prontos. Se houver uma interferência enquanto o SFD está sendo recebido, haverá uma inversão na lógica a qual fará com que o receptor calcule uma CRC errada, o que resulta um PHY checksum error, resultando uma latência alta e uma baixa vazão (Figura 18). 


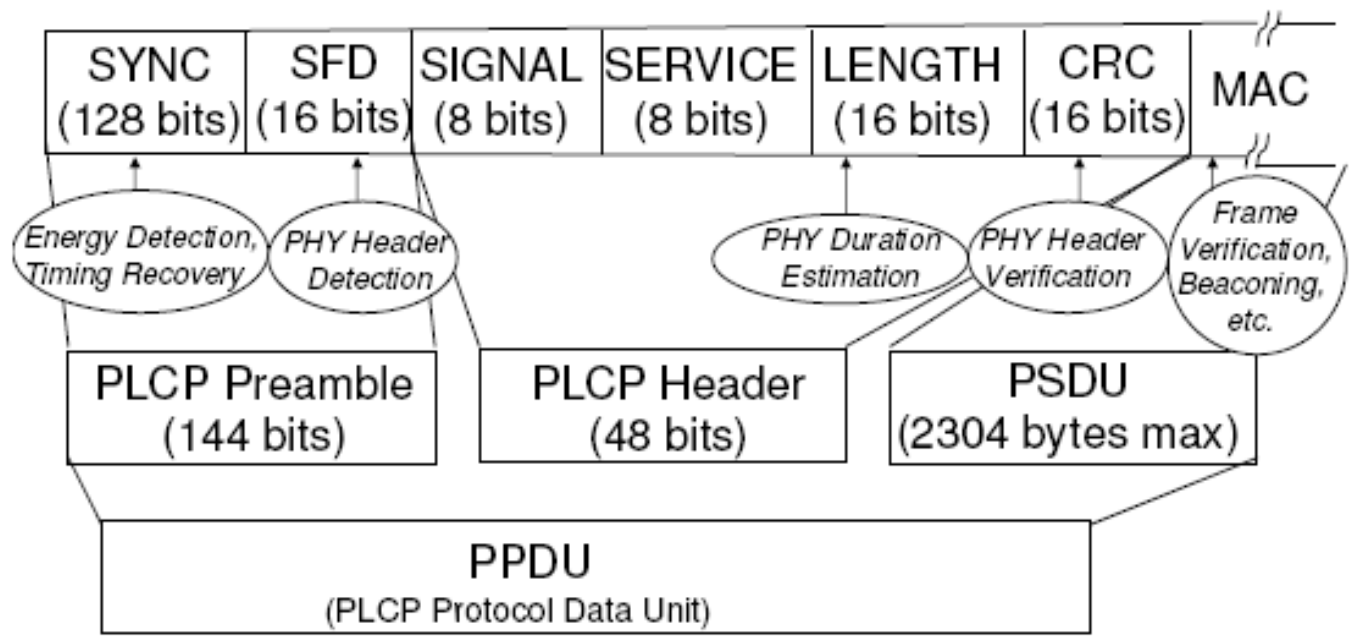

Figura 17 - Encapsulamento 802.11 PHY e o seu uso no receptor. (RAMAKRISHNA, DAVID, et al., 2007).

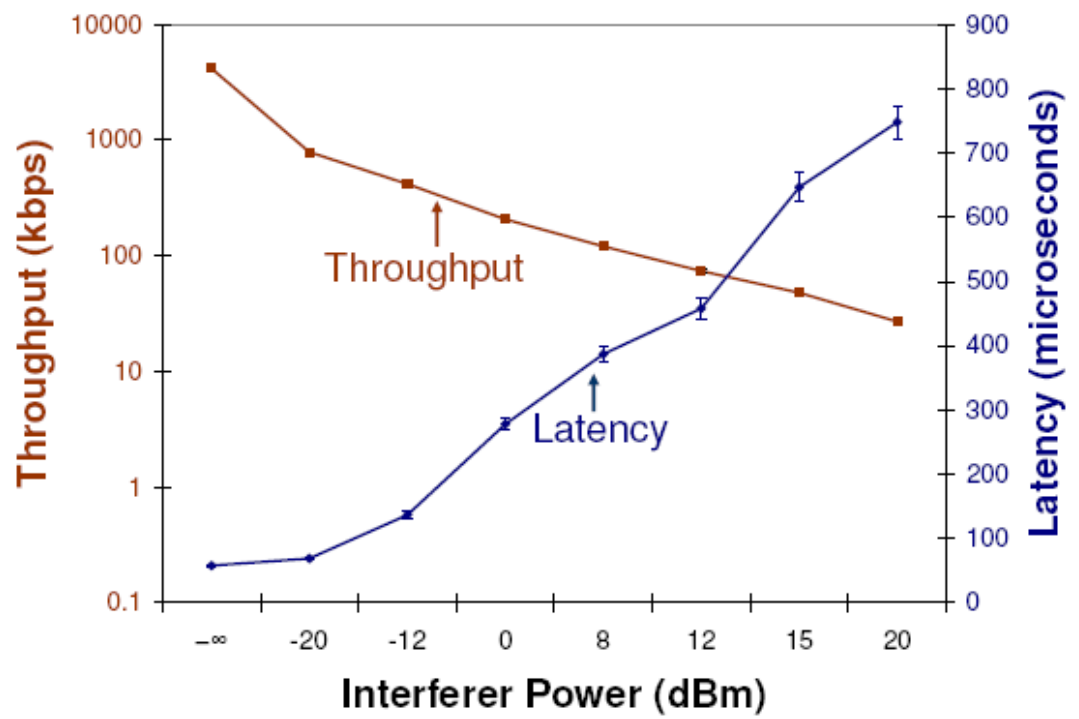

Figura 18 - Vazão e latência versus potência da interferência afetando o processamento do cabeçalho. (RAMAKRISHNA, DAVID, et al., 2007).

Os resultados do estudo de Ramakrishna, David, et al. (2007) apontaram para uma uniformidade dos resultados das interferências causadas por fontes diversas (interface 802.11b/g, telefone sem fio, interface zigbee e câmera de vídeo 802.11). O baseline de desempenho sem interferência para a comunicação de um AP e um cliente 802.11b é de 4,4Mbit/s sem salto de canal e 3,6Mbit/s com salto de canal utilizando frame de 1500 bytes e comunicação unidirecional UDP. Quando as interferências foram provocadas simultaneamente através dos dispositivos (interface $802.11 \mathrm{~b} / \mathrm{g}$, telefone sem fio, interface 
zigbee e câmera de vídeo 802.11), os testes resultaram em vazão em torno de 600kbps (Figura 19) para a comunicação UDP e o TCP fica em torno de $20 \%$ a $40 \%$ pior que o UDP.

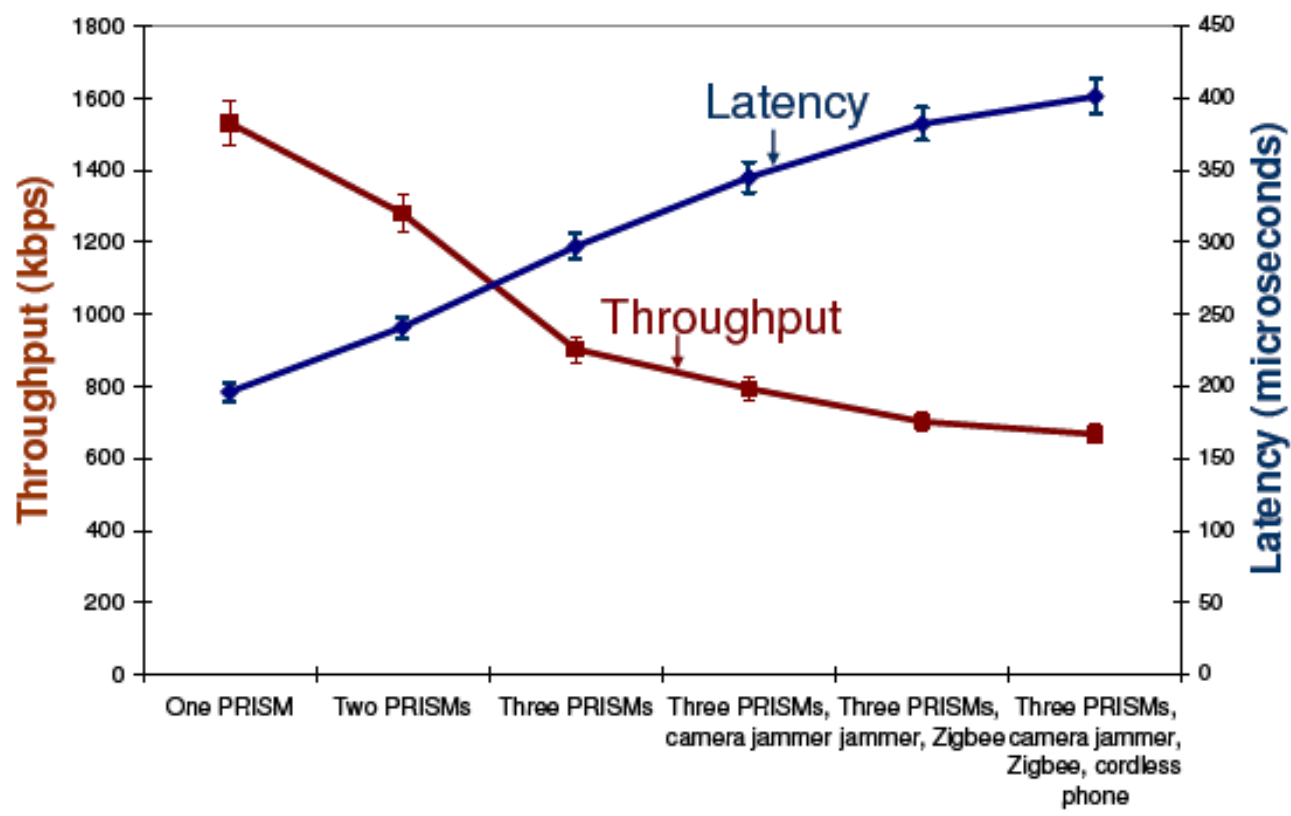

Unattenuated Interferers

Figura 19 - Vazão e latência versus interferências. (RAMAKRISHNA, DAVID, et al., 2007).

Outro importante fator mapeado foi o percentual das retransmissões que ocorrem no TCP, que são causadas por aumento na latência da comunicação, provocando perda de pacotes. Podemos analisar através da Figura 20 o limite entre as retransmissões esporádicas e as retransmissões massivas. 


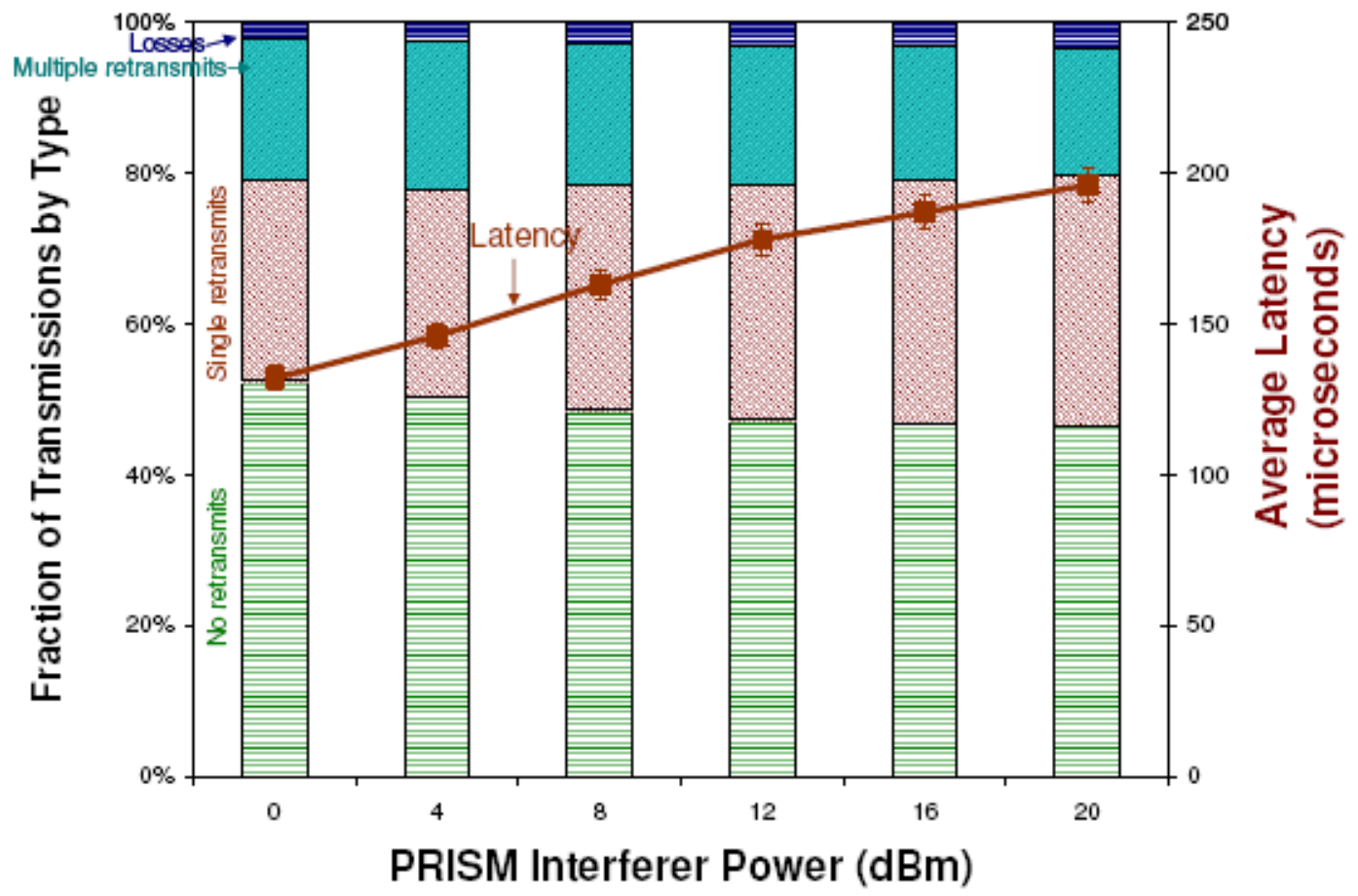

Figura 20 - Percentual de retransmissões e média das latências versus interferência. (RAMAKRISHNA, DAVID, et al., 2007).

A conclusão enfatiza os problemas das interferências causadas por fontes não compatíveis com o 802.11 e, desta forma, mapeia os problemas das interfaces de rede 802.11, que não possuem mecanismos na camada PHY para mitigar os efeitos causados pelas interferências de RF.

Nos trabalhos relacionados aqui, mencionados, não foram encontradas medidas da degradação da vazão em ambiente de média e alta complexidade e densidade. Estes ambientes são importantes por sinalizarem a realidade da utilização espectral por empresas, residências e universidades.

\section{Plataforma e Metodologia}

\subsection{Introdução}

O objetivo do trabalho é analisar a degradação da vazão em redes padrão $802.11 \mathrm{~b} / \mathrm{g}$, quando expostas às interferências ocasionadas por outras redes do mesmo padrão. Para esta análise foi proposta e implantada uma plataforma de coleta de informações (Figura 21). A plataforma é baseada no modelo de gerenciamento centralizado, no entanto não há ações de gerenciamento; são realizadas apenas as ações de coleta e armazenagem de informações. Um 
banco de dados centralizado recebe as informações da plataforma, porém as análises dos efeitos negativos, causados pela interferência de outras redes WLANs na vazão da rede, são compiladas posteriormente.

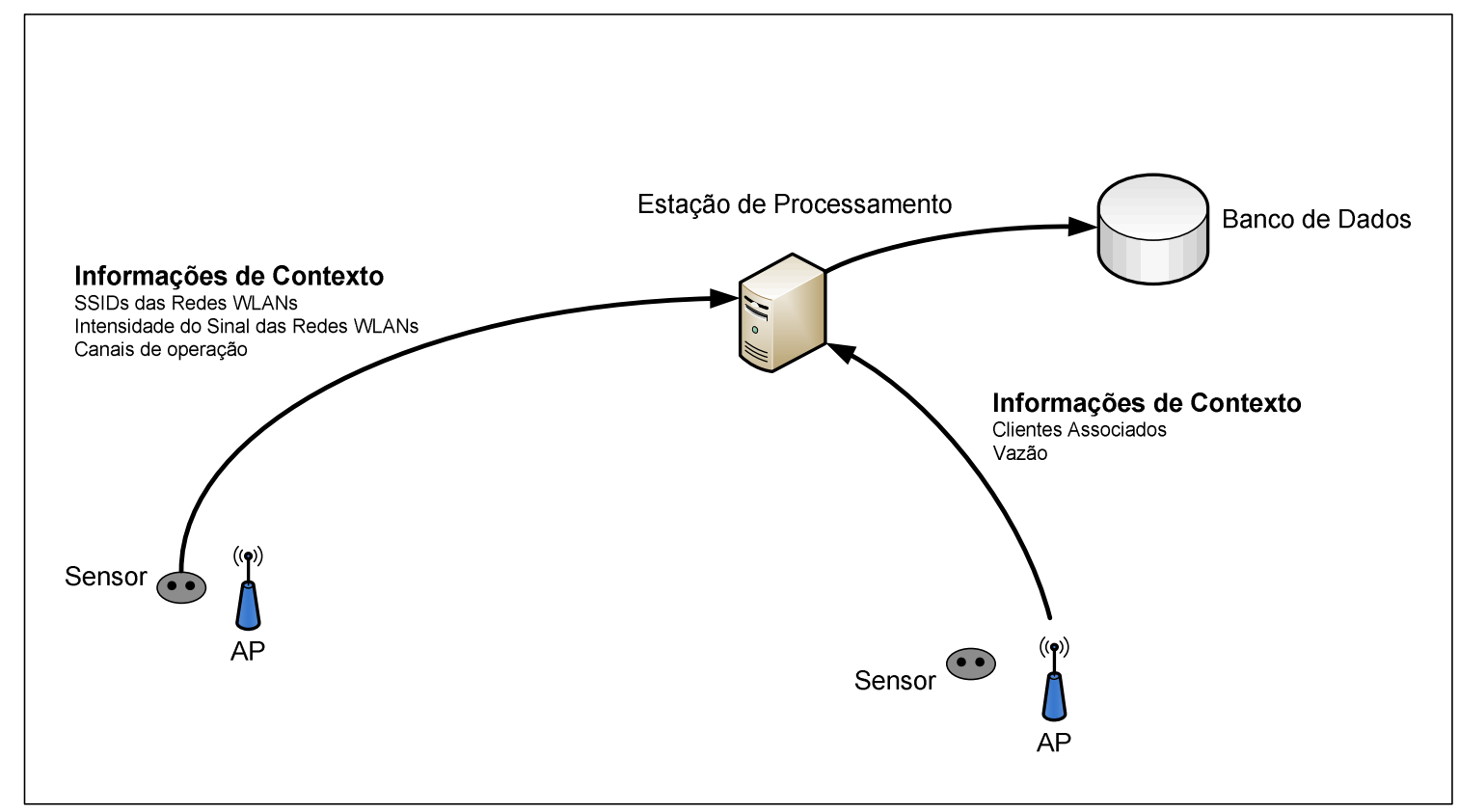

Figura 21 - Plataforma para estudos dos efeitos das interferências causadas por redes WLANs na vazão de redes sem fio.

A plataforma emprega algumas interfaces/recursos que são responsáveis pela coleta, distribuição e armazenamento de informações. As informações coletadas são distribuídas para um único ponto de controle denominado Estação de Processamento. Para melhorar a compreensão dos elementos envolvidos na plataforma, uma pequena explicação é apresentada:

((p)) Ponto de Acesso: estação base de comunicação padrão 802.11 b/g que provê a comunicação entre os dispositivos sem fio através de uma rede estruturada padrão ethernet. Os pontos de acesso fornecem informações contextuais através do protocolo SNMP (Simple Network Management Protocol).

- Sensor: dispositivo formado por um PC (Personal Computer) munido de uma interface de rede sem fio padrão $802.11 \mathrm{~b} / \mathrm{g}$. Este dispositivo coleta as informações de RF do ambiente e as envia através de script de inserção de dados em uma base SQL (Structure Query Language). 
Estação de Processamento: microcomputador que recebe as informações contextuais dos sensores, pontos de acesso e servidor de autenticação. O coletor fornece informações para a interface de gerenciamento. As informações são armazenadas em um banco de dados instanciado nele próprio; desta forma, os dados ficam preservados para futuras comparações.

Banco de Dados: repositório das informações coletadas pelos sensores.

O gerenciamento ou monitoramento de redes sem fio pode ser classificado como: centralizado, distribuído e híbrido (ZIMMERMANN, FELIS, et al., 2005). O centralizado é caracterizado por um único equipamento mestre que concentra todas as ações do processo. Neste modelo de arquitetura a eficácia do processo é concentrada em um único ponto de controle, permitindo maior facilidade de atualização (Figura 22). O desafio em qualquer um dos modelos é fazer com que as informações sejam tratadas e/ou as ações corretivas sejam realizadas.

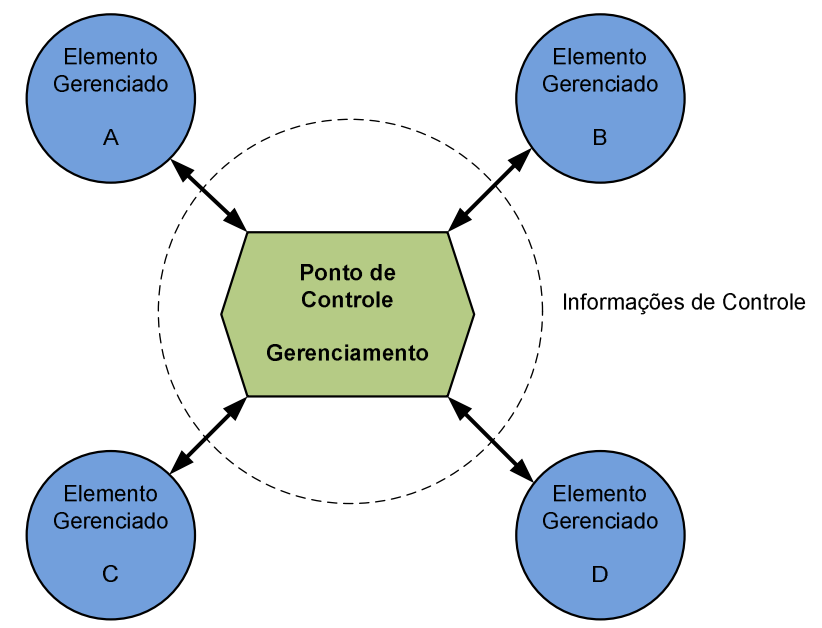

Figura 22 - Modelo centralizado de arquitetura de gerenciamento de rede sem fio.

No modelo distribuído, os pontos de acesso necessitam uma interoperabilidade pontoa-ponto entres eles, definindo uma malha de comunicação na qual as informações são repassadas. Neste modelo a escalabilidade é melhorada, pois os gargalos de comunicação 
podem ser equacionados para não haver sobrecarga na arquitetura (Figura 23). O trabalho de Mullany, et al. (2005) abordou a eficiência do gerenciamento distribuído, no qual cada ponto de acesso através de algoritmos de auto-configuração tomam decisões para gerir funções de organização, adaptação, proteção e resiliência, formando um autômato.

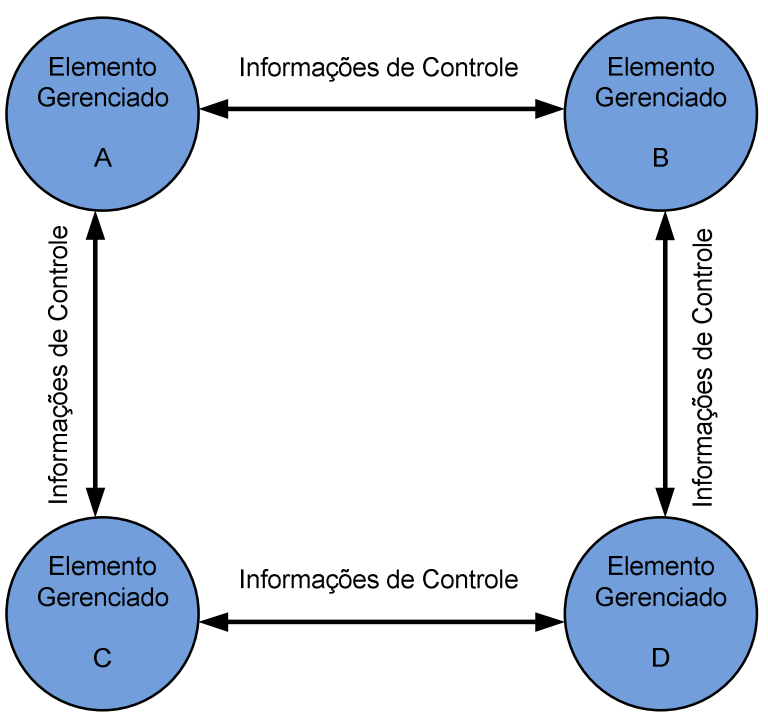

Figura 23 - Modelo distribuído de arquitetura de gerenciamento de rede sem fio.

O modelo híbrido (Figura 24) mescla as características do centralizado e do distribuído. Estas características mescladas podem resultar benefícios para certos controles da plataforma de gerenciamento; por exemplo, questões relacionadas à escalabilidade podem ser equacionadas em funções distribuídas, bem como, questões relacionadas a falhas do ponto mestre. Por sua vez, as questões deficientes do modelo distribuído, voltadas às atualizações da plataforma de gerenciamento, podem ser tratadas no modelo centralizado.

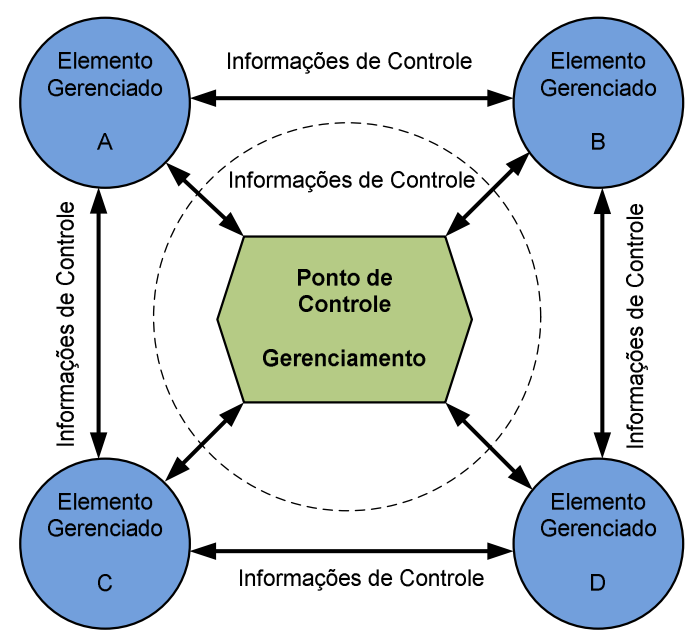

Figura 24 - Modelo híbrido de arquitetura de gerenciamento de rede sem fio. 
O modelo centralizado foi escolhido para a plataforma. Este modelo cria facilidades de atualização e controle, já que vários scripts foram construídos e adaptados para a realização da coleta das informações relevantes.

\subsection{Descrição do cenário para avaliação de redes de baixa a média complexidade e densidade.}

A função deste cenário é a extração de dados para avaliar os problemas de vazão das redes WLANs quando elas são submetidas às interferências espectrais de outras redes padrão 802.11b/g. Neste sentido, a plataforma foi instalada em um Campus Universitário, considerado adequado, por ser composto por 1200 usuários distribuídos em 23.300 metros quadrados de área territorial, além de apresentar um cenário real e em atividade. Via de regra, os acessos acontecem por membros da própria comunidade, através de associação à rede WLAN por um dos 13 Pontos de Acesso geograficamente distribuídos no ambiente (Figura 25). Contudo, a dinâmica de utilização da rede é mais complexa se comparada aos ambientes corporativos, por exemplo. As dificuldades estão em: $i$ ) mobilidade do usuário (normalmente estudantes e professores) pelo ambiente que fazem uso da rede em diversos blocos (salas de aula, auditórios, sala de professor etc.); ii) dificuldade em prever a demanda de acesso nos AP's devido ao deslocamento em massa (e.g. em uma aula com 100 alunos tentando acesso no mesmo AP ou, ainda, em uma apresentação com centenas de pessoas na platéia). Estas áreas têm carga de tráfego oscilante, com alto tráfego durante o dia e quase ínfimo durante a madrugada - isto comparado a ambientes como aeroportos, eventos em hotéis, congressos etc. Para caracterizar este cenário ele será rotulado como de baixa a média densidade e complexidade. 


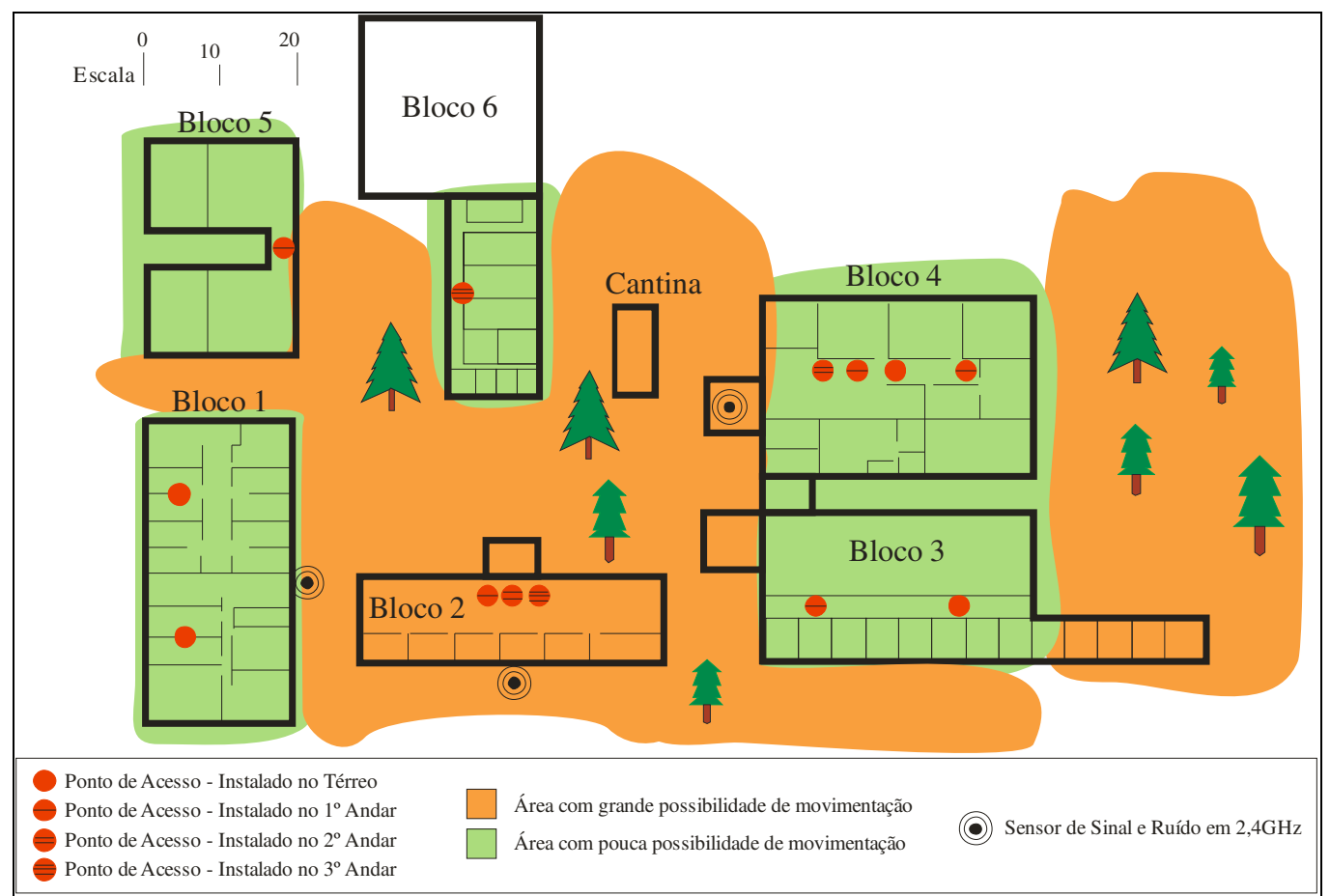

Figura 25 - Distribuição dos Pontos de Acesso do ambiente do Campus Universitário. A escala apresenta valores em metros.

\subsection{Descrição do cenário de alta complexidade e densidade.}

A proposta desta investigação foi projetar e construir um cenário que reproduzisse um ambiente denso e complexo para comparar o impacto da perda de vazão, causada pela interferência espectral, de ambientes de baixa a média com ambientes de alta densidade e complexidade. Para conseguir este propósito, o cenário foi construído em um laboratório na forma de testbed (Figura 26). Este testbed foi totalmente isolado de interferências externas ao laboratório, o que garantiu um ambiente livre de sinais oriundos de outras fontes $802.11 \mathrm{~b} / \mathrm{g}$. O principal intuito deste cenário foi caracterizar o impacto das interferências quando há densidade de sinais de dispositivos $802.11 \mathrm{~b} / \mathrm{g}$ no mesmo canal ou canais adjacentes. $\mathrm{O}$ testbed exemplifica os ambientes que possuem redes WLANs e sofrem alterações repentinas de associações dos clientes aos pontos de acesso. Estas alterações são provocadas por eventos de grande magnitude, que atraem a atenção dos usuários para um ponto mais concentrado. Por exemplo, eventos do tipo "music show" podem atrair uma grande concentração de usuários e, consequentemente, vários pontos de acesso. A análise dos sinais de RF mostra que essas aglomerações deixam o ambiente consideravelmente denso e complexo. 


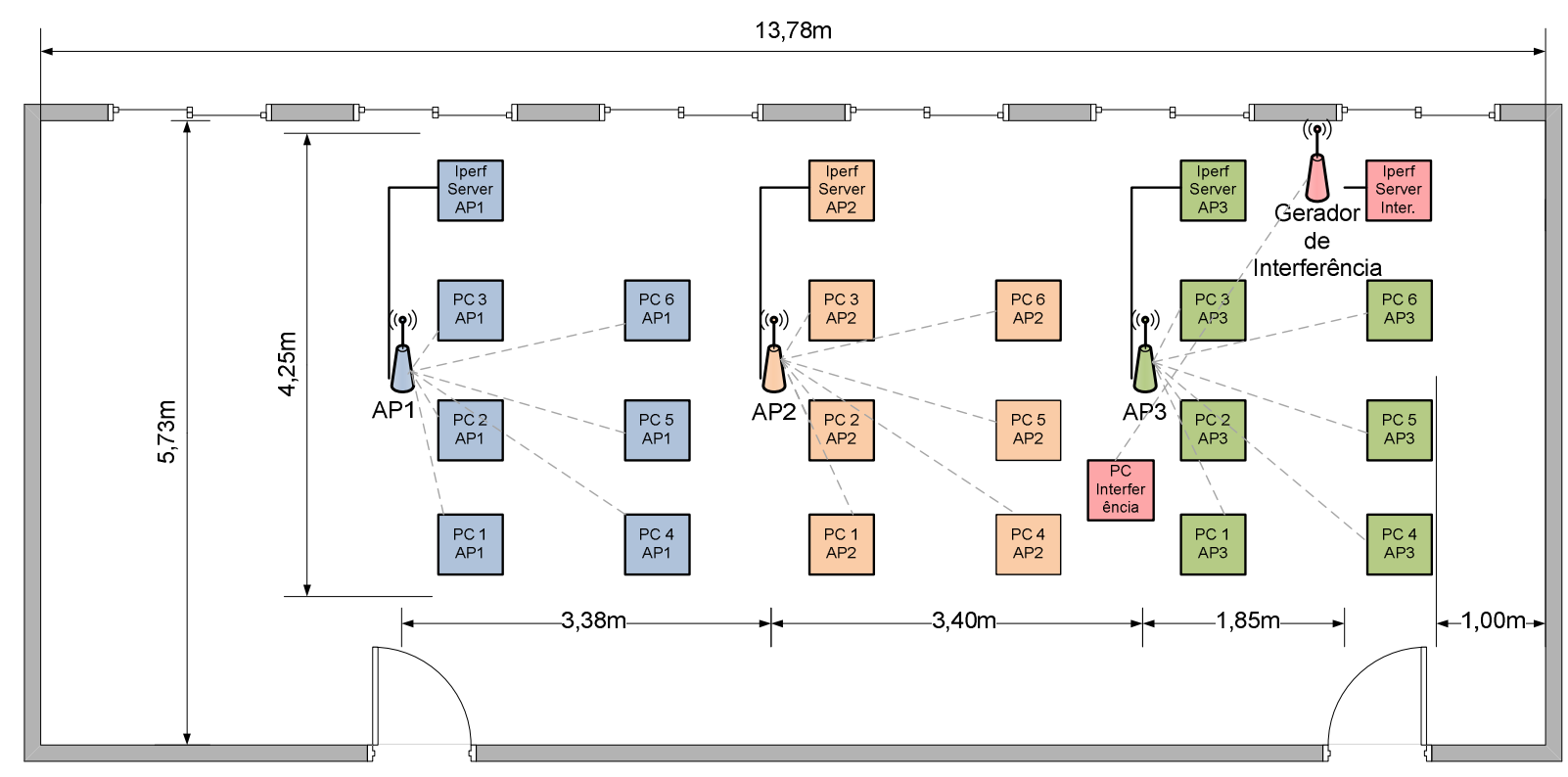

Figura 26 - Cenário com alta densidade de dispositivos 802.11b/g.

Para a classificação dos cenários, em baixa a média ou alta complexidade e densidade, a quantificação de metros quadrados foi diretamente relacionada com o número de Pontos de Acesso distribuídos no ambiente. Estes valores são apresentados na Tabela 5.

Tabela 5 - Relação entre metros quadrados e números de APs.

\begin{tabular}{l|l|l|l}
\hline $\begin{array}{l}\text { Cenário } \\
\text { (Complexidade e } \\
\text { Densidade) }\end{array}$ & Metros Quadrados & Número de APs & $\begin{array}{l}\text { Relação em Metros Quadrados } \\
\text { por Ponto de Acesso }\end{array}$ \\
\hline Baixa a média & 23.300 & 13 & 1792 \\
\hline Alta & 79 & 3 & 26 \\
\hline
\end{tabular}

\subsection{Descrição dos experimentos e ferramentas utilizadas}

Os experimentos ou coletas de informações, para os dois cenários anteriormente mencionados, foram executados em período de plena atividade do Campus Universitário. As férias, os períodos de recesso, os feriados prolongados e outros momentos que pudessem trazer inatividade ou hiperatividade no ambiente foram desprezados.

As informações de contexto foram fundamentais para análises e conclusões deste trabalho. O modelo de plataforma proposto coleta informações dos agentes dos pontos de acesso e informações sobre as redes WLANs disponíveis no ambiente e as centraliza na estação de processamento. As informações reportam a situação atual da rede WLAN e do ambiente, fato que cria uma perspectiva da vazão da rede no tempo e espaço. 
Para coletar as informações sobre a vazão dos pontos de acesso foi utilizado o protocolo SNMP. A partir da estação de processamento foram enviados pedidos de informações sobre a interface de rede sem fio do ponto de acesso, mais especificamente, a quantidade de dados trafegados (vazão) e a quantidade de usuários associados à rede WLAN (Figura 27). A coleta das informações do ponto de acesso é facilitada pela baixa complexidade do SNMP. O SNMP trabalha com o protocolo User Datagram Protocol (UDP) que passa as informações aos coletores e agentes sem necessidade de manter uma conexão estabelecida (connectionless) (Figura 28).

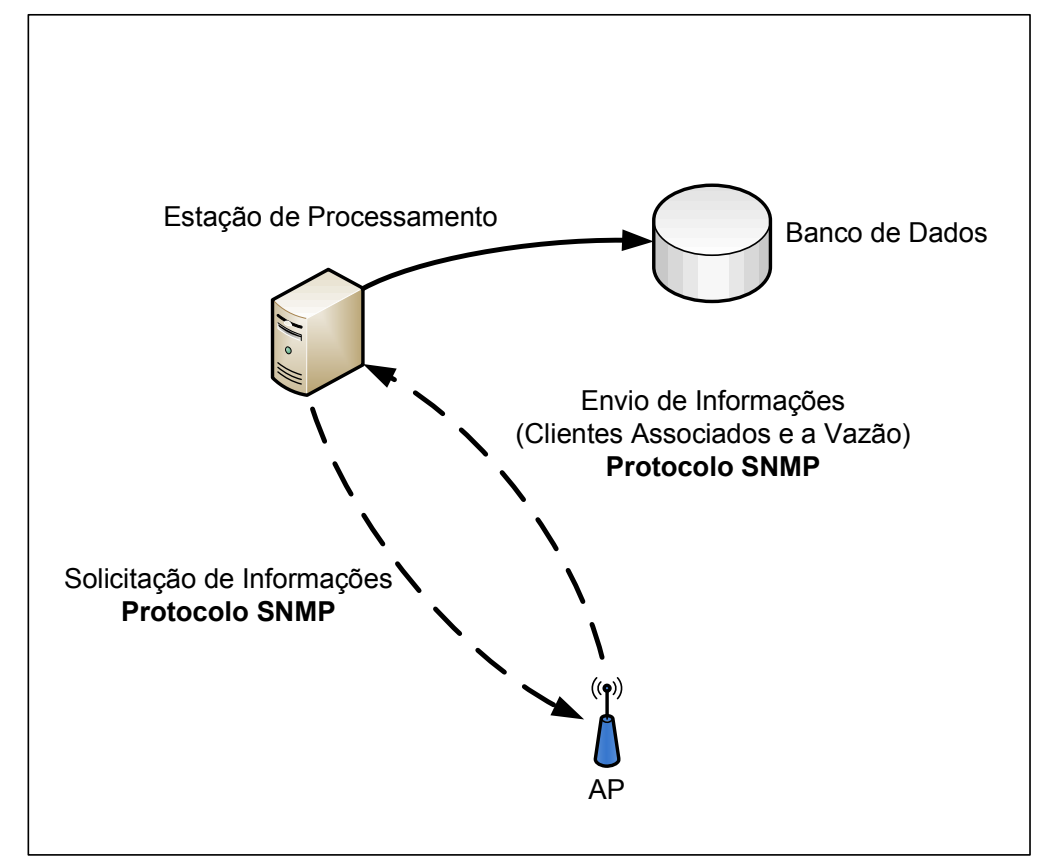

Figura 27 - Fluxo da solicitação e resposta do protocolo SNMP na plataforma.

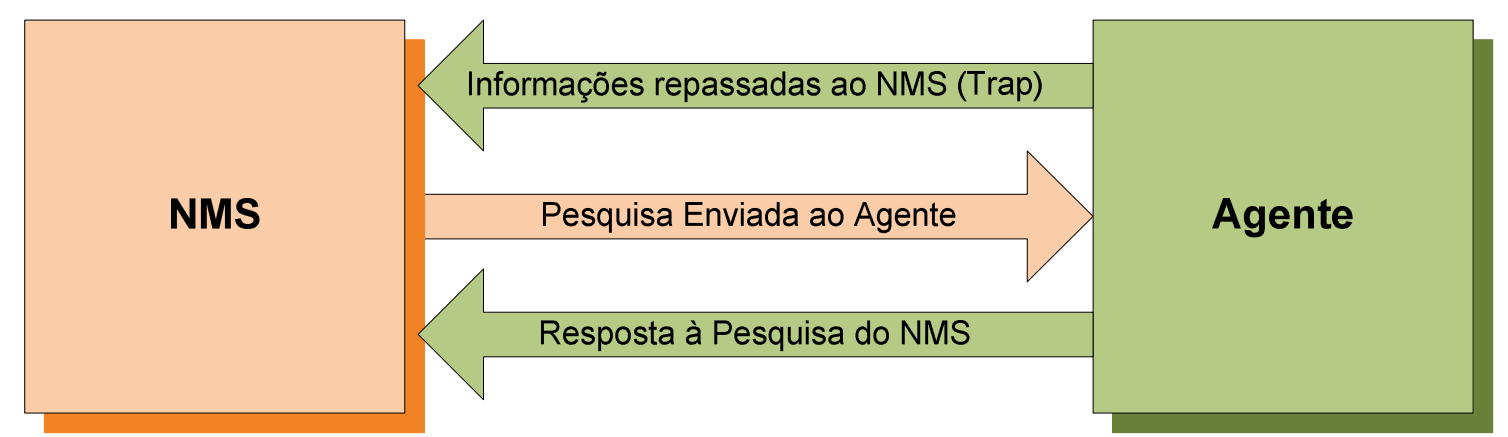

Figura 28 - Relacionamento entre o NMS e o agente (adaptado de MAURO e SCHMIDT, 2005). 


\subsubsection{O Simple Network Management Protocol - SNMP}

O Simple Network Management Protocol (SNMP) é o protocolo padrão em gerenciamento e monitoramento de redes e, frequentemente, é utilizado para funções que exijam coleta de informações e inserções de parâmetros (STALLINGS, 1999), (PAGUREK, WANG e WHITE, 2000), (KANTOROVITCH e MAHONEN, 2002). Diversos dispositivos de rede utilizam o protocolo SNMP, modens, switches, routers entre outros, como o principal instrumento de gerenciamento. O largo uso do protocolo SNMP é decorrente de sua padronização, pois opera em redes que utilizam a pilha TCP/IP como instrumento de comunicação. Enquanto seu precursor, o Simple Gateway Management Protocol (SGMP) era responsável apenas por gerenciar roteadores, o SNMP pode gerenciar vários dispositivos que operam com IP (MAURO e SCHMIDT, 2005). O Internet Engineering Task Force (IETF) é responsável pela gestão do SNMP e Requests for Comments (RFCs) são publicadas para garantir boa proposta de padronização. Atualmente existem três versões do SNMP: a versão 1 (SNMPv1), a 2 (SNMPv2) e a 3 (SNMPv3). Entre as versões existem diferenças que vão desde o método de busca de informações até fatores de segurança.

A funcionalidade do SNMP é bastante simples, duas grandes entidades são classificadas no modelo SNMP, o gerenciador e o agente (MAURO e SCHMIDT, 2005). Os gerenciadores são responsáveis por requisitar ou receber informações de gerenciamento dos agentes. Por sua vez, os agentes são softwares específicos para prover o gerenciamento do dispositivo e estes softwares são embarcados nos dispositivos que suportem o gerenciamento SNMP, como: roteadores, ponto de acesso, comutadores entre outros. Os agentes podem repassar informações aos gerenciadores de duas formas - a primeira quando houver requisição do gerenciador (Query) ou quando há um valor que extrapola o limiar estipulado no próprio equipamento, fato que o agente informa ao gerenciador de forma espontânea (Trap), sem necessidade de uma Query. O gerenciador também é conhecido por Network Management Station (NMS). A Figura 29 ilustra o relacionamento entre o NMS e o agente.

O SNMP define uma estrutura de gerenciamento de informações que provê definições de objetos e comportamentos. $\mathrm{O}$ agente possui uma lista de objetos que ele pode gerenciar no dispositivo; assim, existem dispositivos com mais objetos que outros. Por exemplo, um ponto de acesso pode conter um objeto, chamado modo de operação, que poderá ter como conteúdo a string $802.11 \mathrm{~b} / \mathrm{g}, 802.11 \mathrm{~b}$ e $802.11 \mathrm{~g}$. Para gerenciamento da rede existem vários objetos; os mais comuns tratam basicamente da velocidade de interfaces, Maximum Transmission Unit 
(MTU), octetos enviados, octetos recebidos, entre outros. Para que os objetos tenham estrutura definida e de certa forma organizada, uma estrutura chamada Management Information Base (MIB) é responsável pela classificação e gerenciamento dos objetos do agente. Existem várias MIBs implantadas, muitos agentes trabalham com MIBs relativamente comuns, como por exemplo, MIB-II (RFC 1213). Porém, existem MIBs específicas para determinadas situações de gerenciamento, algumas são produzidas pelos próprios fabricantes dos equipamentos que serão gerenciados pelo SNMP.

A concepção de gerenciamento através do SNMP é focada no gerenciamento de diversas classes. As classes que podem ser gerenciadas pelo SNMP estão divididas da seguinte forma: gerenciamento de falhas, de configuração, de controle de contas, de desempenho e de segurança.

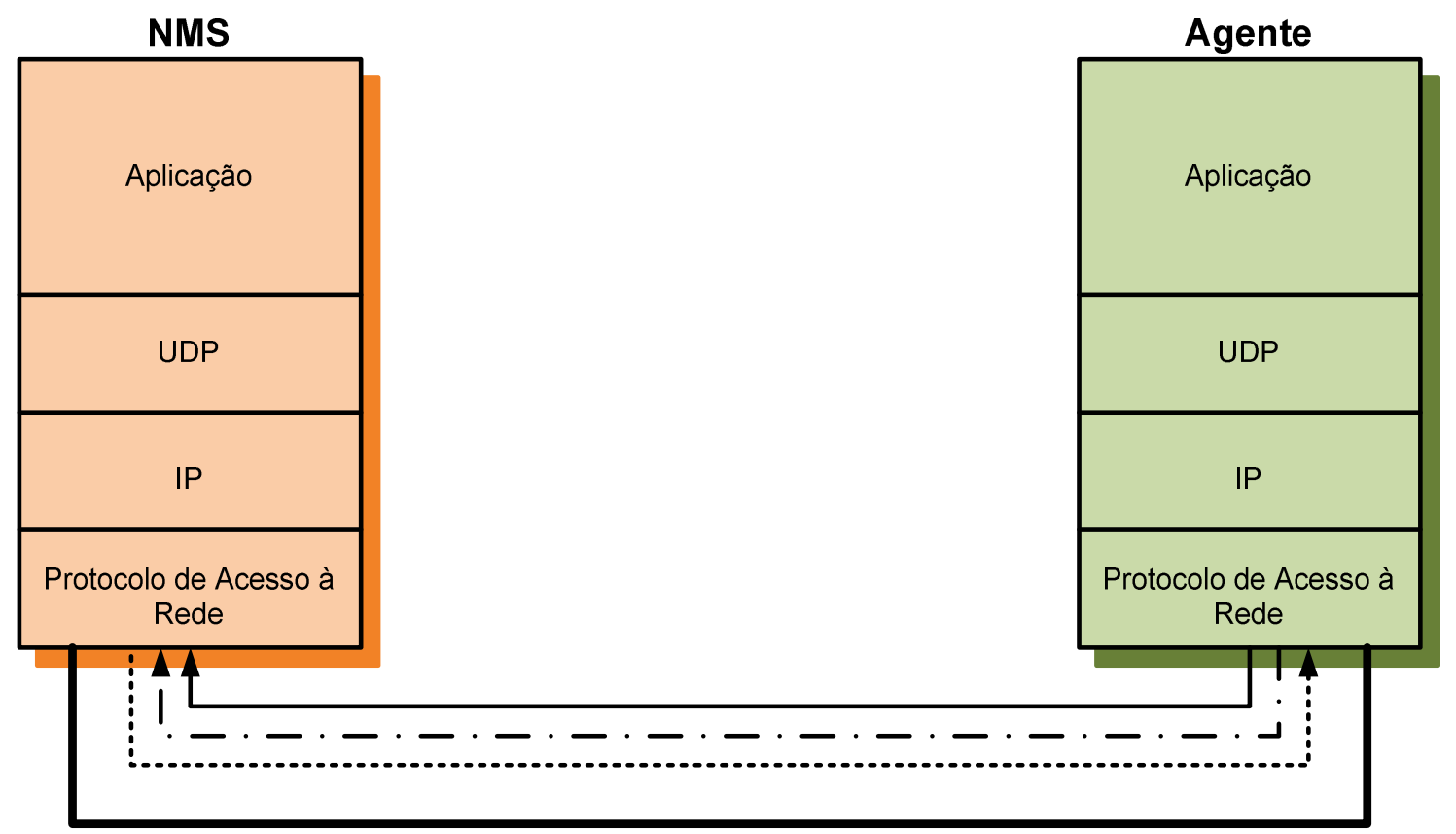

Comunicação entre o NMS e o Agente através de uma rede.

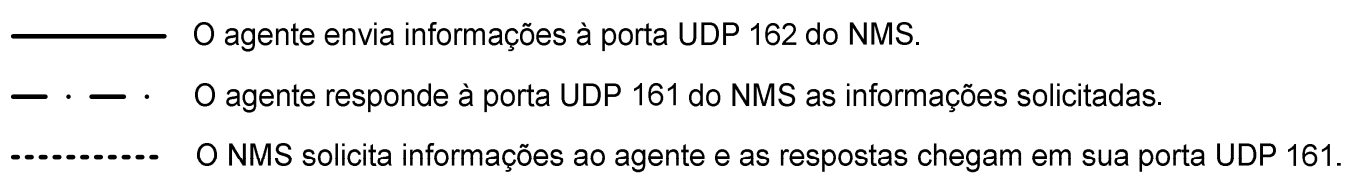

Figura 29 - Padrão de comunicação entre o NMS e o agente (adaptado de MAURO e SCHMIDT, 2005).

Para conseguir retornar às informações que são específicas para o gerenciamento, é importante conhecer como a MIB é organizada e estruturada. Três definições criam um esquema de árvore que definem a Structure of Management Information (SMI), sendo as definições: name, type e syntax e encoding. 
Objetos nomeados são organizados em uma hierarquia de árvores (Figura 30), e são identificados com um identificador (OID), serializados através de números inteiros separados por ponto (.). Desta forma, através das suas separações através do caractere ponto, criam uma árvore estruturada que representa a base de informações de gerenciamento do dispositivo na qual o agente está instalado.

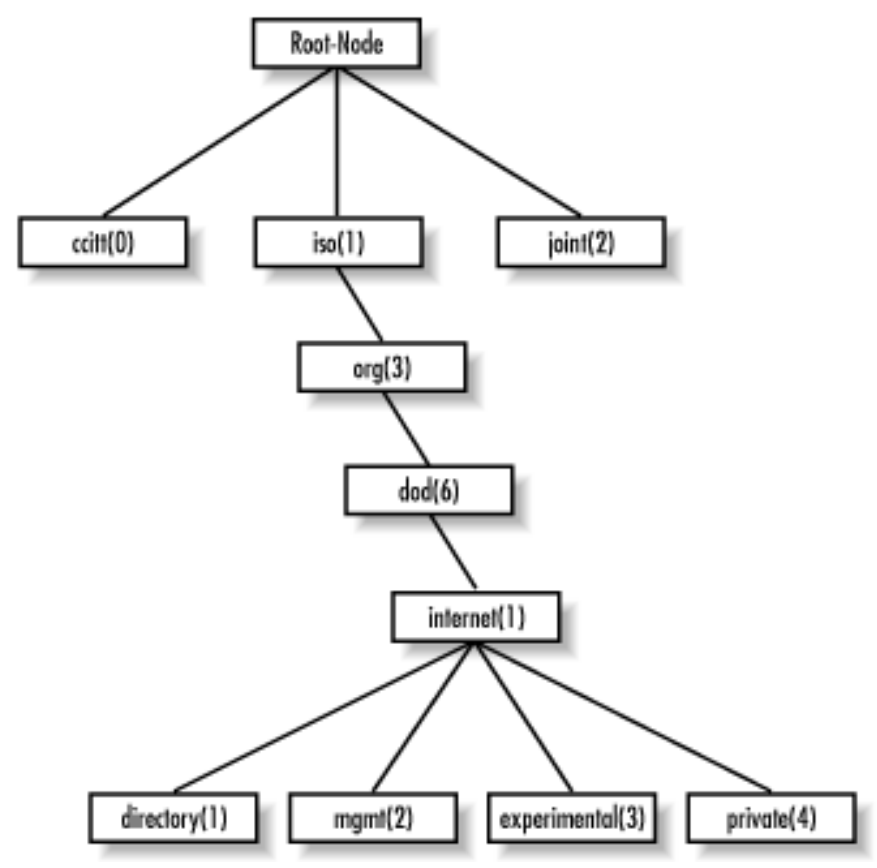

Figura 30 - Estrutura de árvore de objetos, o nó no topo é chamado de root e os nós subsequentes são chamados de filhos, todos os nós filhos fazem parte da sub-árvore (STALLINGS, 1999).

Por exemplo, para representar Iso (1). Org (3). Dod (6). Internet (1) a notação decimal com ponto é a mais comum, uma vez que diversos programas que gerenciam agentes através do SNMP utilizam esta notação, consequentemente, o OID seria 1.3.6.1.

\subsubsection{Passive/Active Scan e a ferramenta iwlist}

Além das informações contextuais conseguidas através do SNMP, informações relativas às interferências causadas por pontos de acesso devem ser coletadas pela plataforma. Para esta função foi utilizado um microcomputador contendo uma interface de rede sem fio 802.11b/g. Este microcomputador é chamado Sensor na plataforma (Figura 31). O processo de descoberta de sinais, de outras redes WLANs no ambiente, é composto por duas diretivas: a passiva e a ativa. A diretiva passiva, conhecida como passive scan, é a mais utilizada para redes que anunciam o SSID (Service Set Identifier) correspondente. O SSID é responsável pela escolha de associação do cliente, na qual o cliente pode escolher a associação na rede A ou $\mathrm{B}$, apenas com base na etiqueta SSID. O processo do passive scan é composto de uma 
varredura de canais, feita através da interface do cliente móvel, que espera receber informações enviadas em tempos cíclicos pelos pontos de acesso (Figura 32). Estas informações são distribuídas em frames conhecidos por beacons que, normalmente, são enviados de 100 em 100 ms pelos pontos de acesso. (GEIER, 2001) (LI, TSENG e CHAO., 2007).

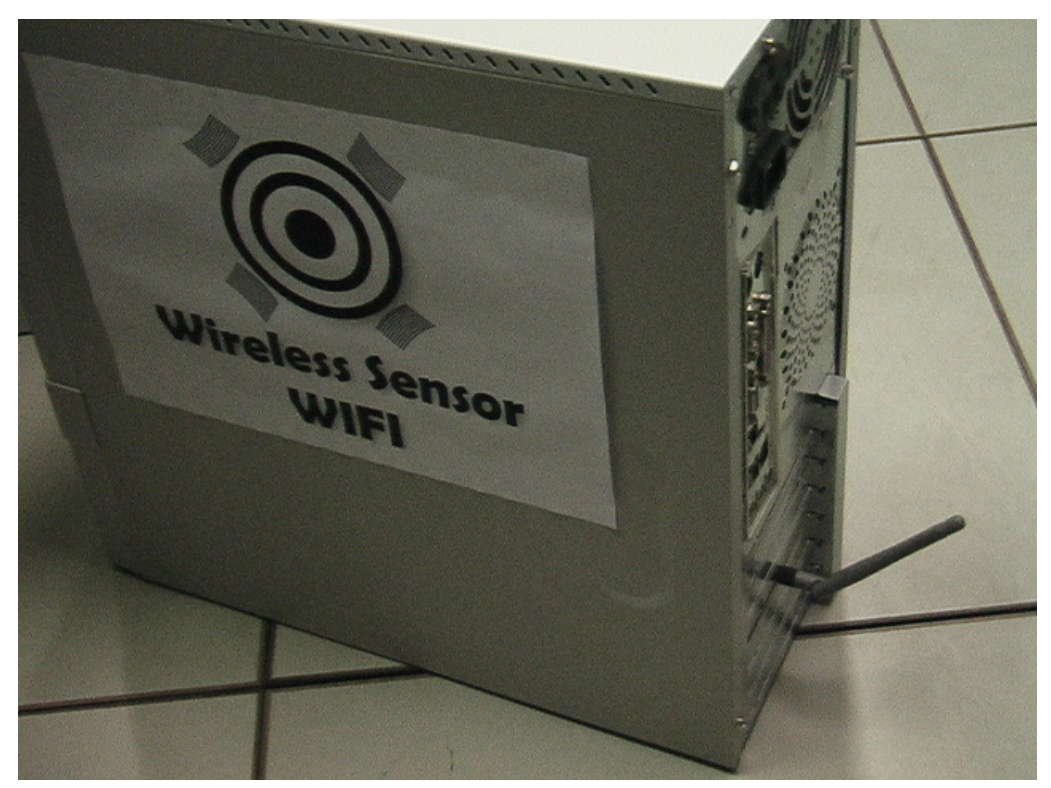

Figura 31 - Imagem do sensor utilizado no experimento.
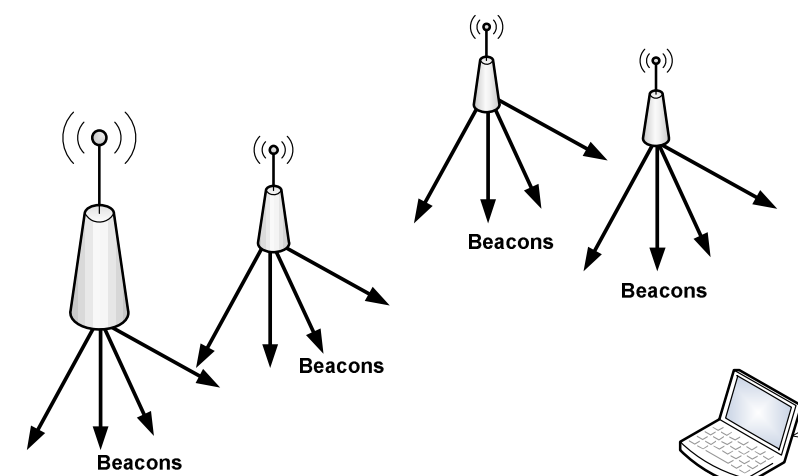

Processo de Varredura
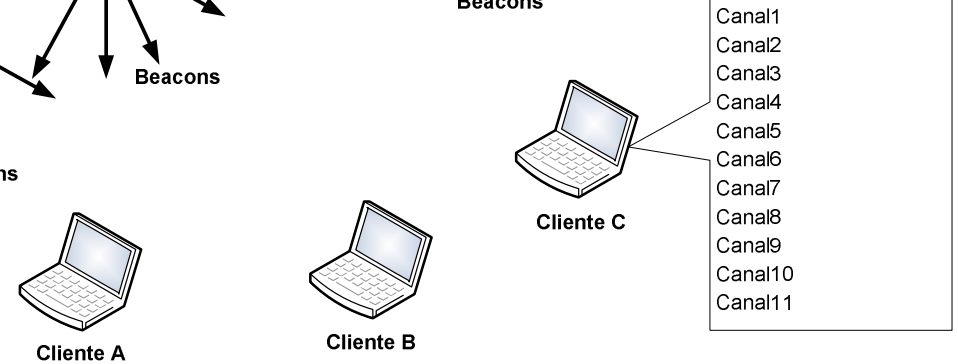

Figura 32 - Processo passive scan, APs anunciam beacons frames.

A descoberta em modo ativo (Active Scan) é utilizada de forma inversa. A diretiva de descoberta de informações dos pontos de acesso parte do cliente móvel. No modo active scan, 
os clientes em tempos cíclicos enviam uma mensagem de Probe Request para cada canal ou para todos os canais. O Probe Request é respondido pelo AP através de uma mensagem de Probe Response. Este método possibilita que o cliente móvel seja proativo no processo de descoberta de informações (Figura 33).

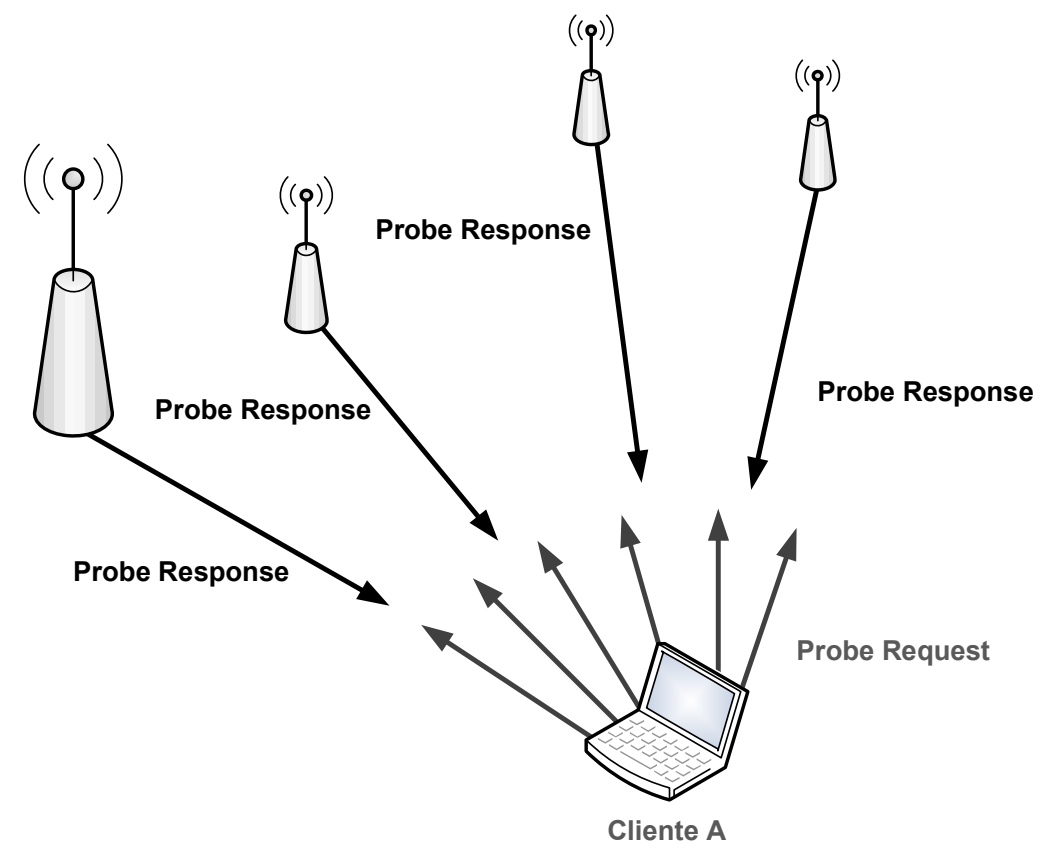

Figura 33 - Cliente requisita informações dos APs através de Probe Request. A resposta dos APs é através de mensagens de Probe Response.

O comando iwlist, do pacote de ferramentas wireless do Linux (LINUX WIRELESS LAN, http://www.hpl.hp.com/personal/Jean_Tourrilhes/Linux/), vai ser utilizado para recuperar informações de outras redes que irradiam sinais no ambiente. O iwlist foi instalado nos sensores e as informações são enviadas à estação de processamento (Figura 34). O iwlist utiliza o método ativo de descoberta (active scan). Quando o comando é executado, ele dispara mensagens de Probe Request para todos os canais e espera o retorno das informações (Figura 35) dos pontos de acesso que estão no ambiente (ROHRIG e KUNEMUND, 2007). 


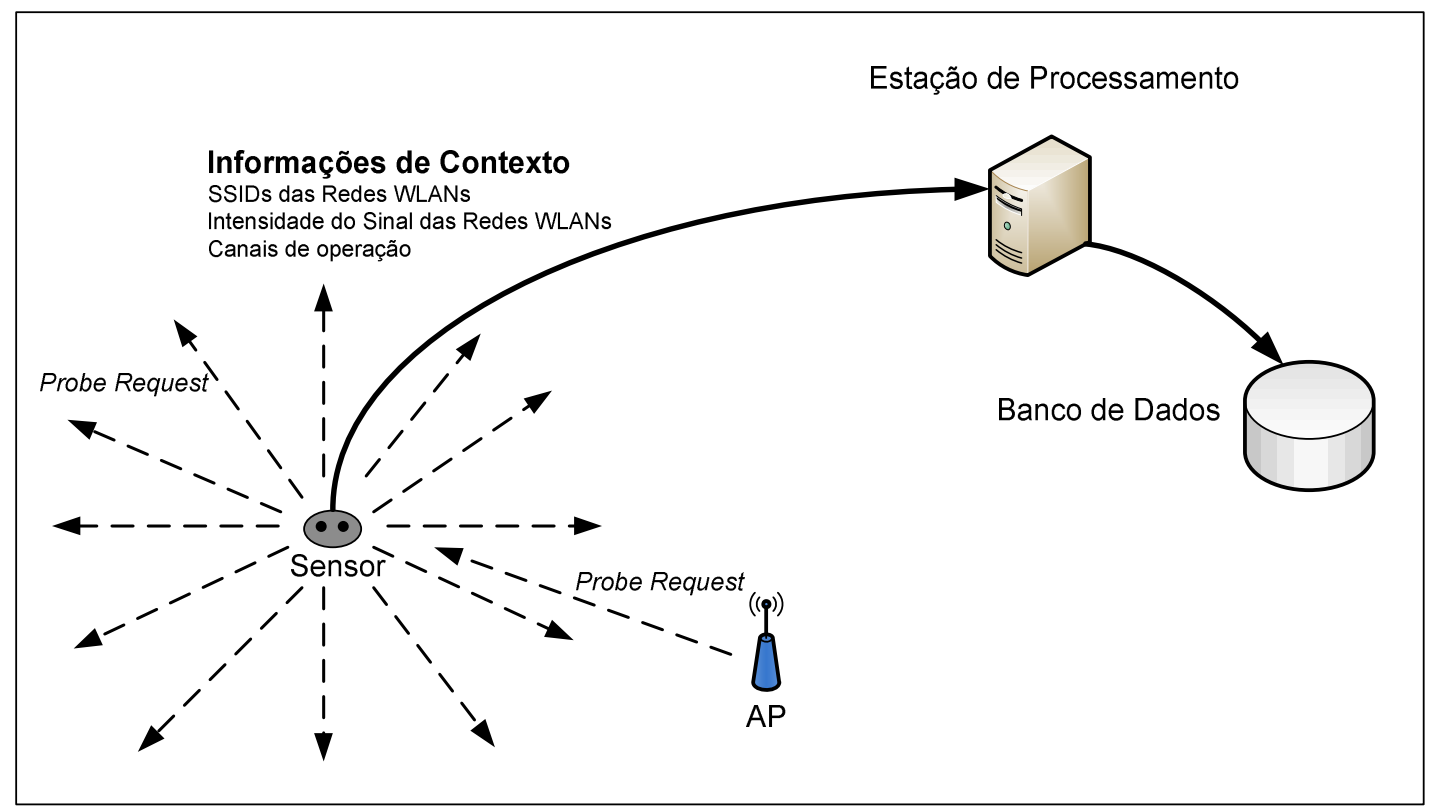

Figura 34 - Fluxo da solicitação e resposta da ferramenta iwlist na plataforma.

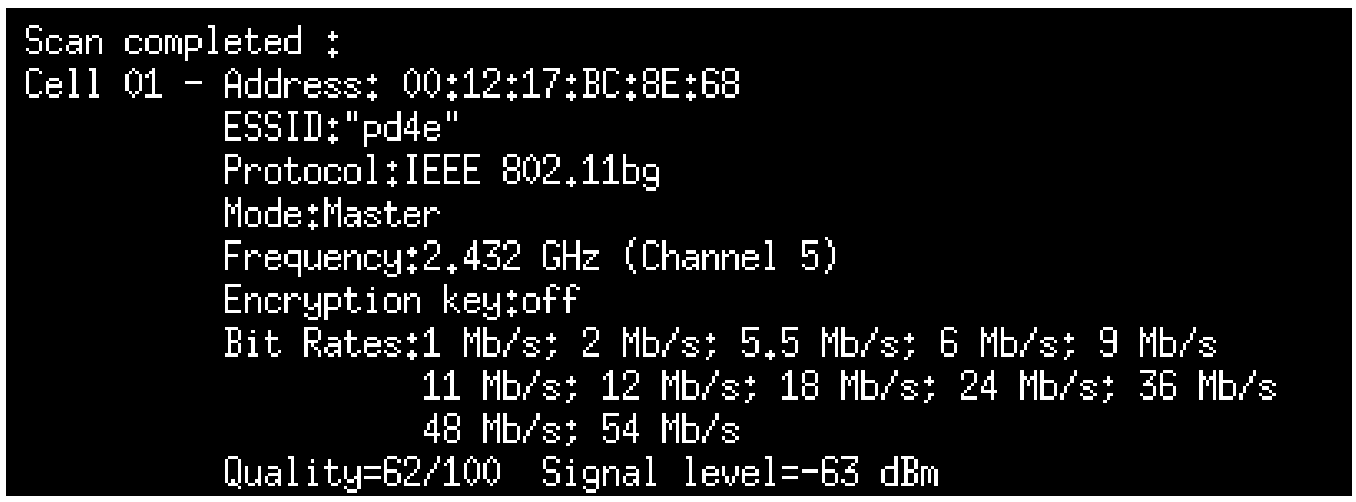

Figura 35 - Resultado do comando iwlist executado em Linux.

\subsubsection{Gerador de Interferência e o Iperf}

Tanto no cenário de baixa a média, quanto no de alta densidade e complexidade, foi preciso mensurar os efeitos da degradação de desempenho causados por interferência espectral, oriundas de outras redes WLAN. Para isto, um conjunto formado por um ponto de acesso e dois microcomputadores, denominado Gerador de Interferência, foi instalado para ambos os cenários. Com o intuito de gerar atividade espectral, foi instalada a ferramenta iperf nos microcomputadores do Gerador de Interferência (IPERF - UNIVERSITY OF CENTRAL FLORIDA). O iperf é uma ferramenta utilizada para analisar o comportamento das redes, por exemplo, medir o jitter e a perda. No entanto ele pode ser utilizado apenas para gerar tráfego, tanto em UDP quanto em TCP. Em ambos os casos, o Iperf comporta-se como uma aplicação cliente-servidor. Uma máquina deve ser instanciada como servidor (Figura 36) e outra como 
cliente (Figura 37) e a conexão entre as duas é estabelecida através do protocolo IP e porta UDP ou TCP.

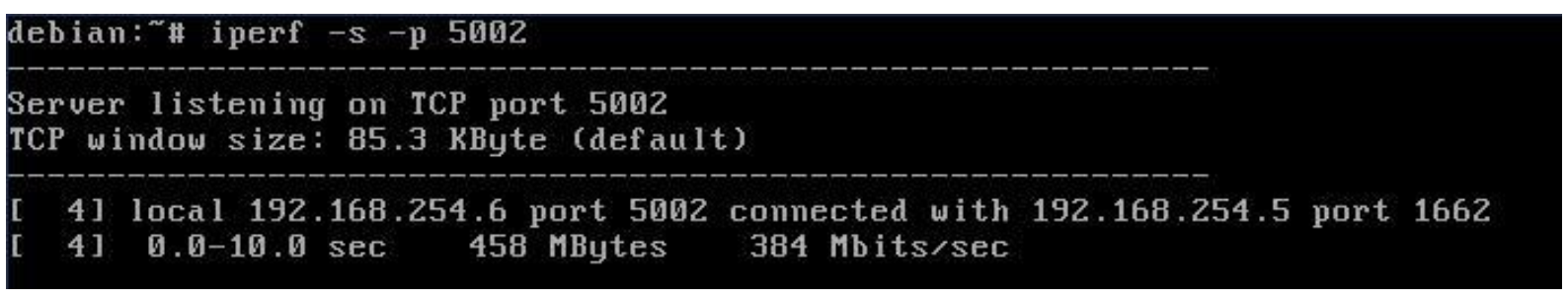

Figura 36-Iperf como servidor.

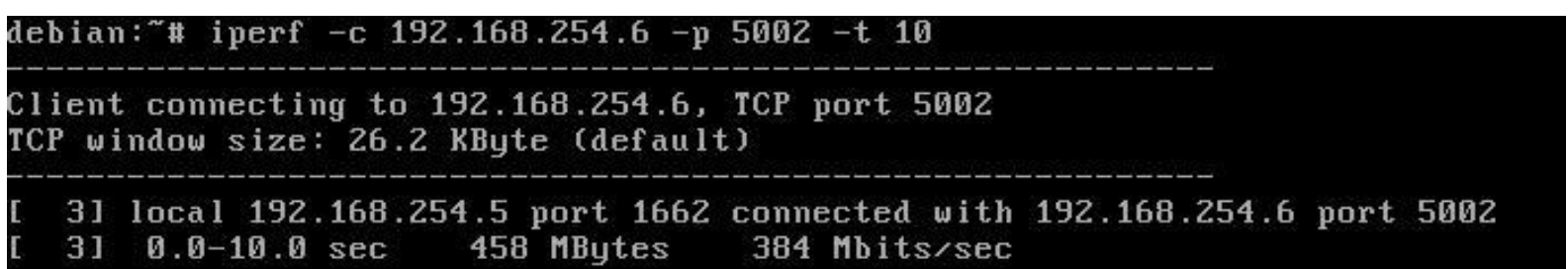

Figura 37 -Iperf como cliente.

Analisando a Figura 38 podemos entender o Gerador de Interferências utilizado nos experimentos, tanto no cenário de baixa a média complexidade e densidade (campus universitário), quanto no de alta (testbed).

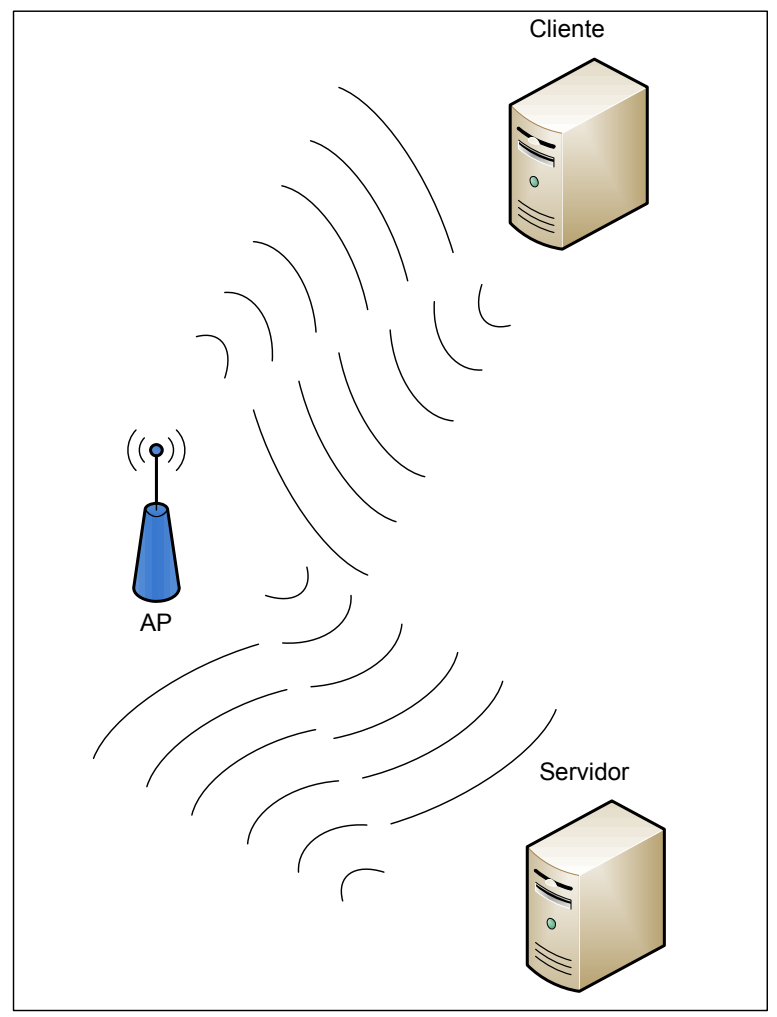

Figura 38 - Gerador de Interferência, utilizado para geração de cargas de rede em ambos os cenários. 


\subsection{As Configurações de Hardware e Software}

\subsubsection{Descrição de hardware e software do cenário de baixa a média complexidade e densidade.}

O cenário de baixa a media complexidade e densidade, formado pela rede sem fio do campus universitário, possui 13 pontos de acesso. Estes pontos de acesso são da marca Cisco Systems, modelos 1100 e 1250. Em todos estes pontos de acesso foi habilitada a MIB “802dot11”, da própria empresa.

Neste mesmo cenário foram utilizados 3 sensores. Cada sensor foi montado sobre um microcomputador Pentium 4 de 2,4GHz, com 512 MB de RAM. Estes sensores analisavam os sinais padrão 802.11, através de uma interface PCI (Peripheral Component Interconnect) padrão $802.11 \mathrm{~b} / \mathrm{g}$, com chipset Atheros AR2413. A estação de processamento possuía o mesmo hardware dos sensores, porém não estava equipada com interface de rede sem fio.

O gerador de interferência foi criado através de 1 ponto de acesso marca Linksys, modelo WRT54G e 2 microcomputadores, ambos Pentium 4 de 2,4GHz, com 512 MB de RAM. Os microcomputadores geraram carga de rede através de interface PCI padrão 802.11b/g, com chipset Atheros AR2413.

Na Tabela 6 apresenta um resumo dos hardwares utilizados no cenário de baixa a média complexidade e densidade.

Tabela 6 - Resumo dos hardwares utilizados no cenário de baixa a média complexidade e densidade.

\begin{tabular}{l|l|l|l|l}
\hline Quantidade & Descrição & Marca & Modelo & Acessórios \\
\hline 08 & $\begin{array}{l}\text { Ponto de Acesso } \\
\text { (Produção) }\end{array}$ & Cisco & 1100 & \\
\hline 05 & $\begin{array}{l}\text { Ponto de Acesso } \\
\text { (Produção) }\end{array}$ & Cisco & 1250 & \\
\hline 03 & Sensores & Genérico & Pentium 4-2,4GHz & Interface PCI 802.11b/g \\
\hline 01 & $\begin{array}{l}\text { Ponto de Acesso } \\
\text { (Gerador de } \\
\text { Interferência) }\end{array}$ & Linksys & WRT54G & \\
\hline 02 & $\begin{array}{l}\text { Microcomputadores } \\
\text { (Gerador de } \\
\text { Interferência) }\end{array}$ & Genérico & Pentium 4-2,4GHz & Interface PCI 802.11b/g \\
\hline
\end{tabular}

O sistema operacional instalado nos microcomputadores, sensores e gerador de interferência, foi o Linux Ubuntu com kernel 2.6.31-14, com os pacotes iperf e net-SNMP. 


\subsubsection{Descrição de hardware e software do cenário de alta densidade e complexidade.}

No ambiente de testbed, criado para analisar as degradações na vazão da rede sem fio em ambientes densos e complexos, foram utilizados 3 pontos de acesso, sendo todos da marca Dlink, modelo DIR-655.

Os 18 microcomputadores que simulavam os clientes associados à rede sem fio, 6 máquinas por ponto de acesso, possuíam processadores Pentium $4 \mathrm{HT}$ de $3.4 \mathrm{GHz}$ e $1 \mathrm{~GB}$ de RAM. Estes clientes estavam associados à rede sem fio através de uma interface PCI (Peripheral Component Interconnect) padrão 802.11b/g, com chipset Atheros AR2413. As cargas de rede geradas nos clientes foram direcionadas para 3 microcomputadores. Estes 3 microcomputadores, chamados servidores, possuíam as mesmas características de hardware dos clientes.

O gerador de interferência utilizou 1 ponto de acesso marca Linksys, modelo WRT54G e 2 microcomputadores, ambos Pentium 4 HT de 3.4GHz, com 1GB de RAM. Os microcomputadores geraram carga de rede através de interface PCI padrão $802.11 \mathrm{~b} / \mathrm{g}$, com chipset Atheros AR2413.

$\mathrm{Na}$ Tabela 7 encontramos um resumo dos hardwares utilizados no cenário de alta densidade e complexidade.

Tabela 7 - Resumo dos hardwares utilizados no cenário de baixa a média complexidade e densidade.

\begin{tabular}{l|l|l|l|l}
\hline Quantidade & Descrição & Marca & Modelo & Acessórios \\
\hline 03 & Ponto de Acesso & Dlink & DIR-655 & \\
\hline 01 & $\begin{array}{l}\text { Ponto de Acesso } \\
\text { (Gerador de } \\
\text { Interferência) }\end{array}$ & Linksys & WRT54G & \\
\hline 18 & $\begin{array}{l}\text { Microcomputadores } \\
\text { (Clientes) }\end{array}$ & Genérico & Pentium 4-3,4GHz & Interface PCI 802.11b/g \\
\hline 03 & $\begin{array}{l}\text { Microcomputadores } \\
\text { (Servidores) }\end{array}$ & Genérico & Pentium 4-3,4GHz & Interface PCI 802.11b/g \\
\hline 02 & $\begin{array}{l}\text { Microcomputadores } \\
\text { (Gerador de } \\
\text { Interferência) }\end{array}$ & Genérico & Pentium 4-3,4GHz & Interface PCI 802.11b/g \\
\hline
\end{tabular}

O sistema operacional instalado nos microcomputadores, clientes, servidores e gerador de interferência, foi o Linux Ubuntu com kernel 2.6.31-14, com o pacote iperf. 


\section{Resultados e Discussões}

\subsection{Avaliações do Ambiente de Baixa a Média Densidade e}

\section{Complexidade}

Para avaliar os efeitos das interferências espectrais no campus, causadas por outras fontes 802.11, os sensores coletaram informações de redes vizinhas durante 90 dias consecutivos. A periodicidade das coletas foi de 5 minutos, totalizando: 12 coletas a cada hora, 288 ao dia, 8640 ao mês e $\mathbf{2 5 9 2 0}$ no total geral. O período de analise não sobrepôs os períodos de inatividade do campus.

Após compilação dos dados, a média geral de associações durante o período de 1 dia (24 horas) foi de 112 clientes associados. Dividindo a média geral de associações pelo número de pontos de acesso instalados, que neste caso é 13, a média de clientes associados, por ponto de acesso, foi de $\mathbf{8}$ dispositivos (Figura 39).

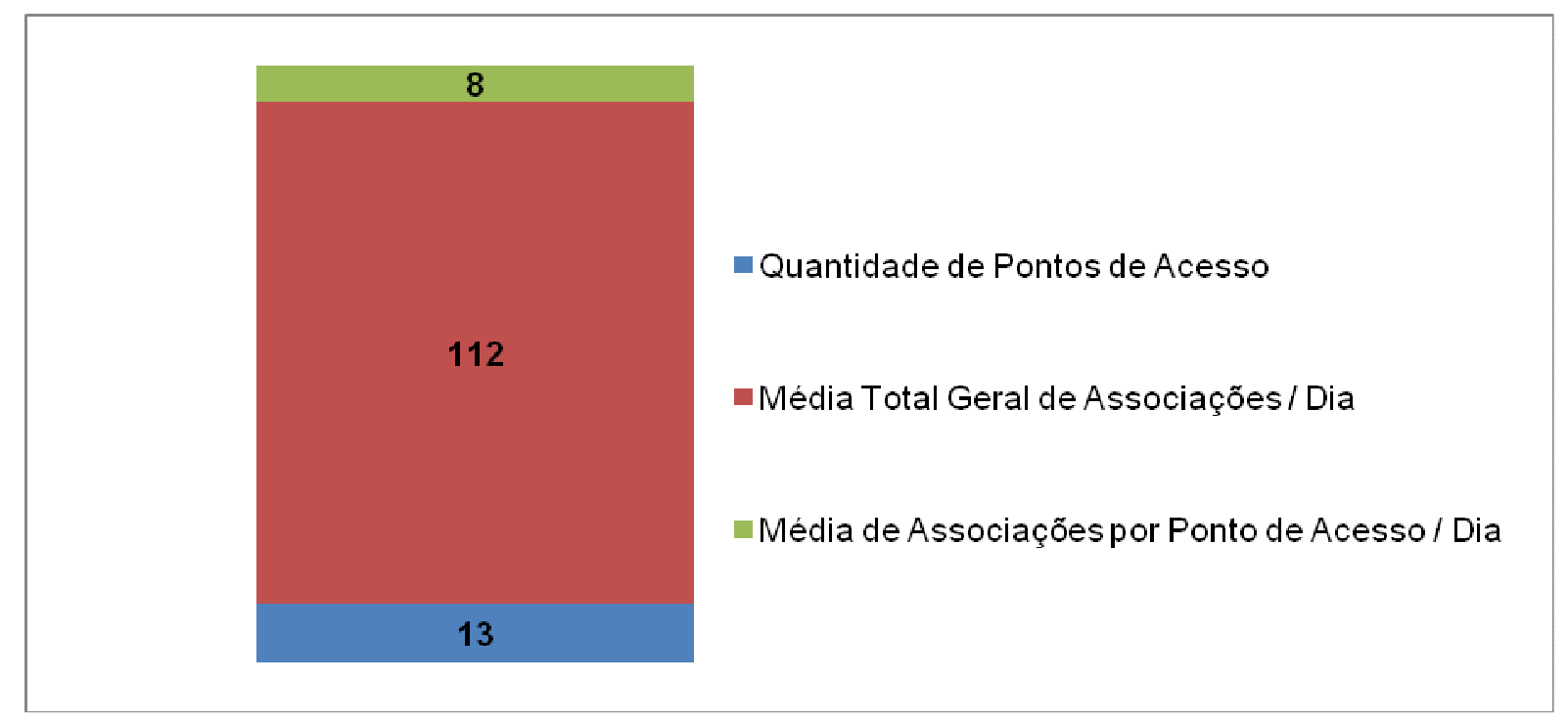

Figura 39 - Total de pontos de acesso, média total geral de associações por dia e média de associações por ponto de acesso no período de 24 horas.

\subsubsection{Avaliações dos Sinais Coletados no Espaço e no Tempo}

A análise dos sinais oriundos de outras redes $\mathrm{WiFi}$, coletados pelos sensores, permite observar alguns pontos interessantes: i) a Figura 40 ilustra as divisas do Campus Universitário; a saber, a divisa norte divide o Campus de uma área residencial - com muitas repúblicas dos alunos do Campus - e a divisa sul divide o Campus de um clube poliesportivo. Neste contexto, muitas repúblicas e casas residenciais instalaram redes WiFi em seus 
aposentos, propagando uma quantidade substancial de sinais 802.11. No clube poliesportivo as condições são diferentes, pois, as redes anunciadas são mais controladas pela gerência operacional da própria instituição; ii) a análise dos resultados coletados pelo sensor, posicionado no bloco 1 (Figura 41),permite verificar que a diversidade espectral é menor, quando comparada com a diversidade dos demais sensores; iii) os sinais coletados pelo sensor posicionado no bloco 2 (Figura 42) fornecem subsídios para uma análise diferenciada. $\mathrm{O}$ sensor do bloco 2 foi alocado mais próximo à divisa; desta forma, mais sinais foram coletados, porém, os sinais estão mais distribuídos nos 11 canais disponíveis; iv) o resultado da análise do sensor do bloco 4 aponta um aumento substancial nos sinais dissipados no período de sexta a domingo. Este aumento substancial pode ter ocorrido pelo fato de os alunos migrarem seus dispositivos móveis para as suas respectivas repúblicas ou residências (Figura $43)$.

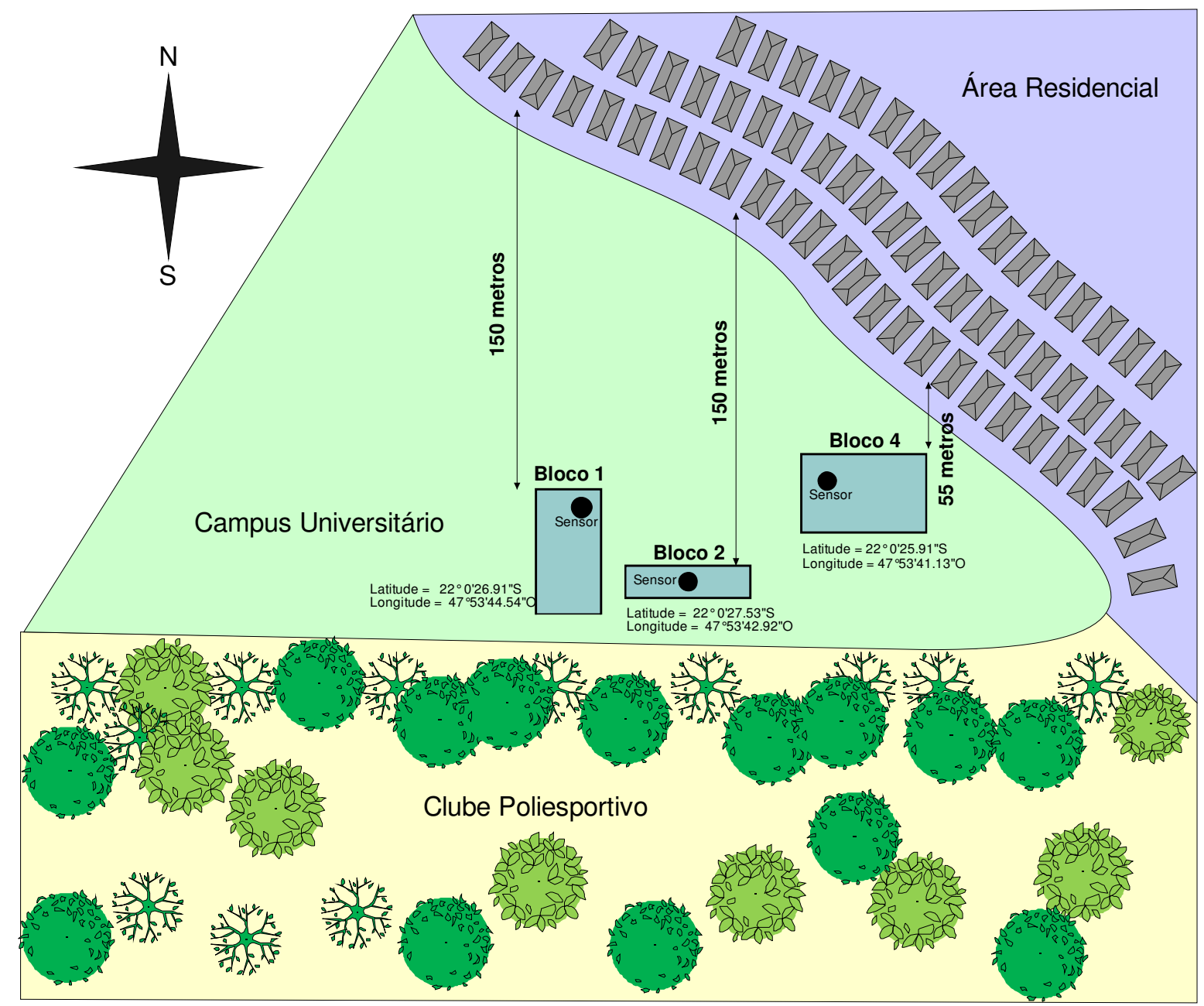

Figura 40 - Mapa do Campus Universitário e suas divisas, com o posicionamento preciso dos sensores e suas respectivas distâncias. 


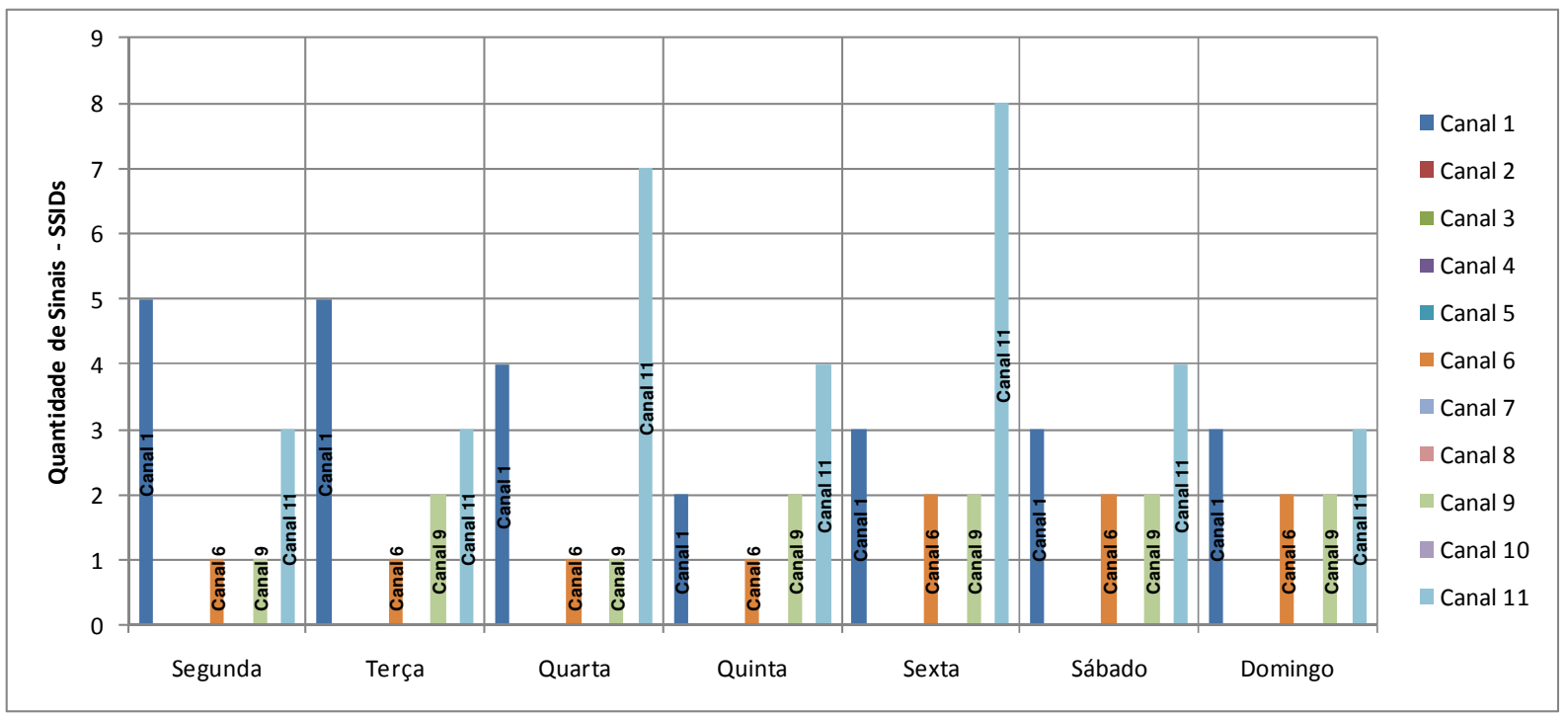

Figura 41 - Quantidade de sinais coletados pelo sensor posicionado no bloco 1, distribuídos em dias e qualificados pelos canais de operação $\left(\right.$ Latitude $=22^{\circ} 0^{\prime} 26.911^{\prime \prime} \mathrm{S}$ e Longitude $=47^{\circ} 53^{\prime} 44.54$ " $\mathrm{O}$ ).

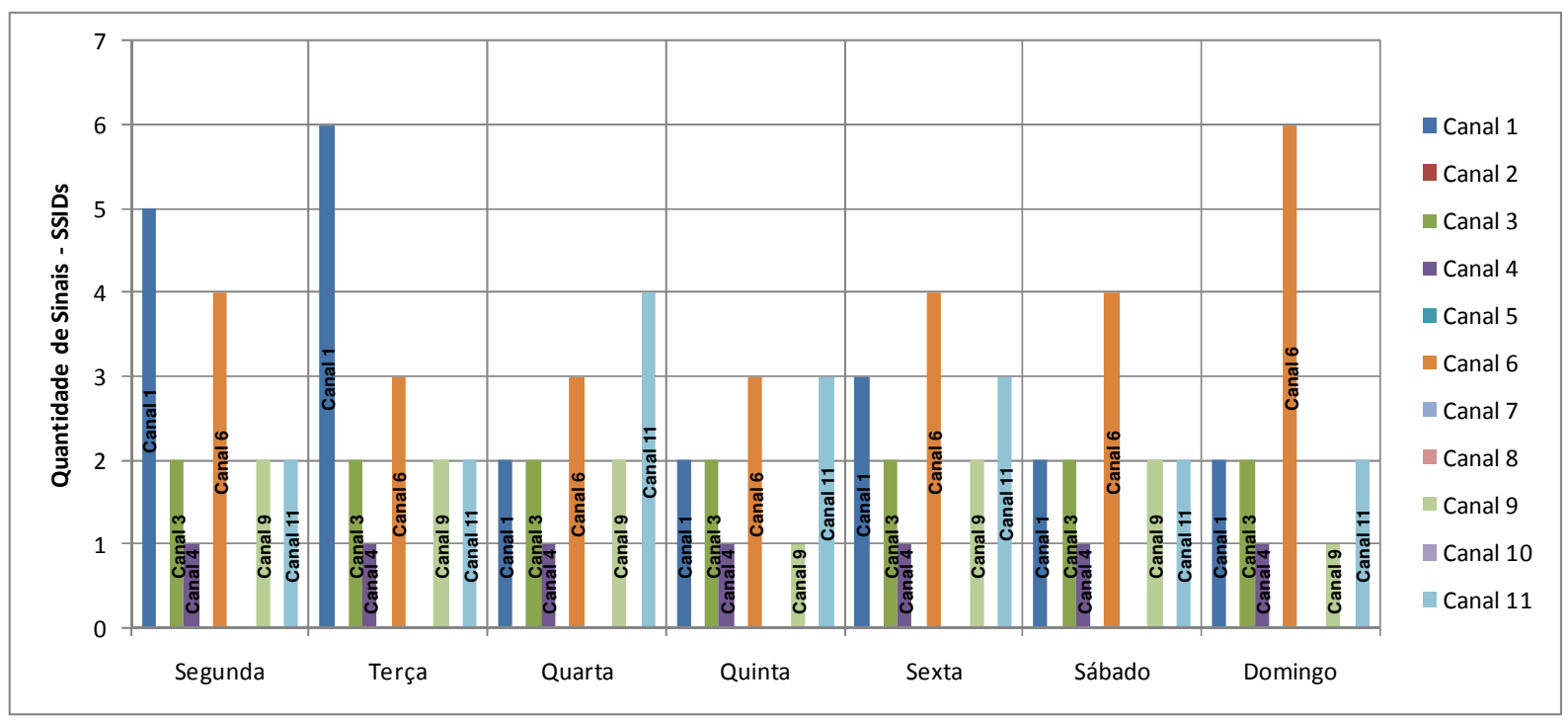

Figura 42 - Quantidade de sinais coletados pelo sensor posicionado no bloco 2, distribuídos em dias e qualificados pelos canais de operação (Latitude $=22^{\circ} 0^{\prime} 27.53$ ' $\mathrm{S}$ e Longitude $=47^{\circ} 53^{\prime} 42.92^{\prime \prime} \mathrm{O}$ ). 


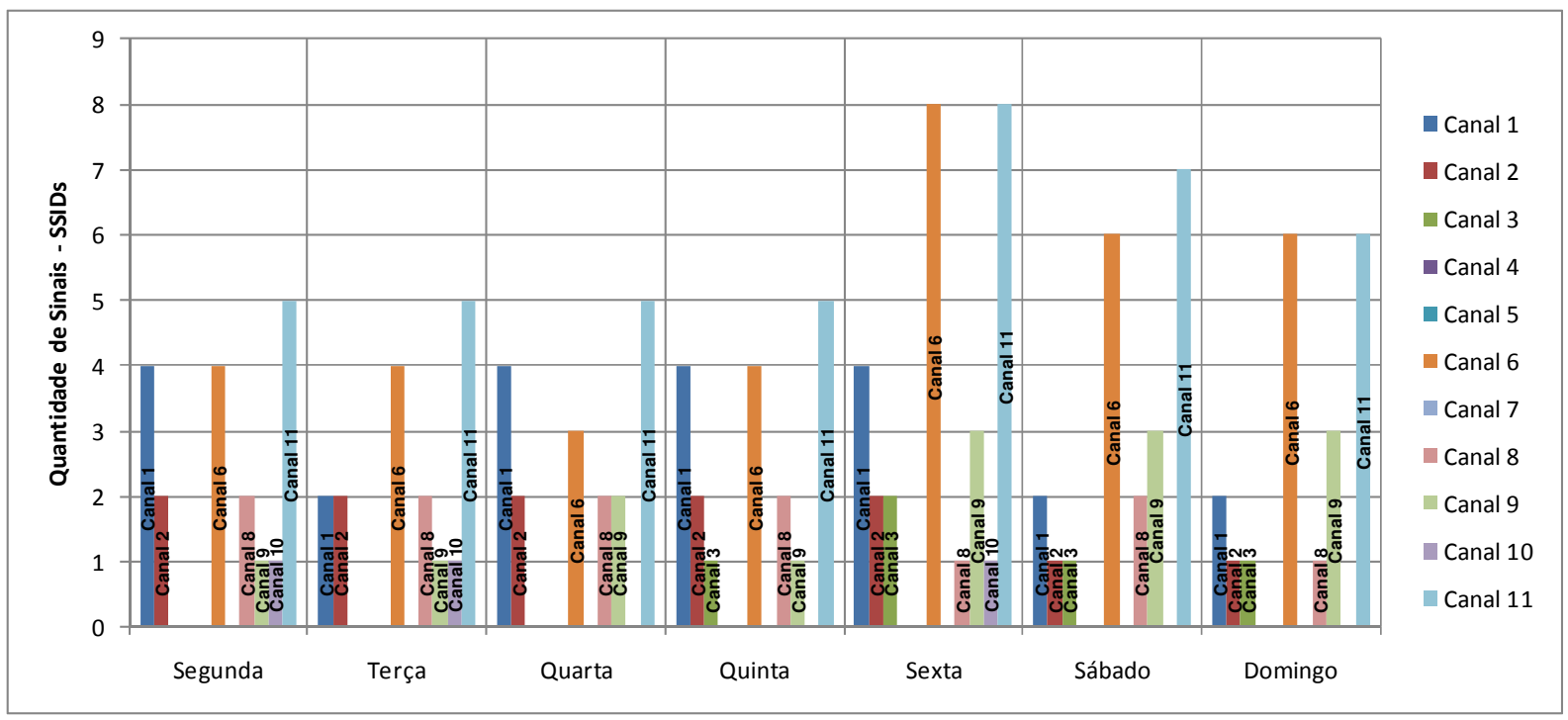

Figura 43 - Quantidade de sinais coletados pelo sensor posicionado no bloco 4, distribuídos em dias e qualificados pelos canais de operação (Latitude $=22^{\circ} 0^{\prime} 25.91{ }^{\prime \prime} \mathrm{S}$ e Longitude $=47^{\circ} 533^{\prime} 41.13$ ' $O$ ).

Os sinais coletados pelos sensores não contabilizam os sinais disponibilizados pelos APs do próprio campus. Todos os sinais coletados foram gerados por fontes desconhecidas. A Figura 44 apresenta a soma dos sinais coletados nos três sensores. As somas foram distribuídas em dias da semana e qualificadas através dos canais de operação. É possível verificar visualmente, através da Figura 44, que o canal mais concorrido é o canal 11, seguido pelos canais 6 e 1 .

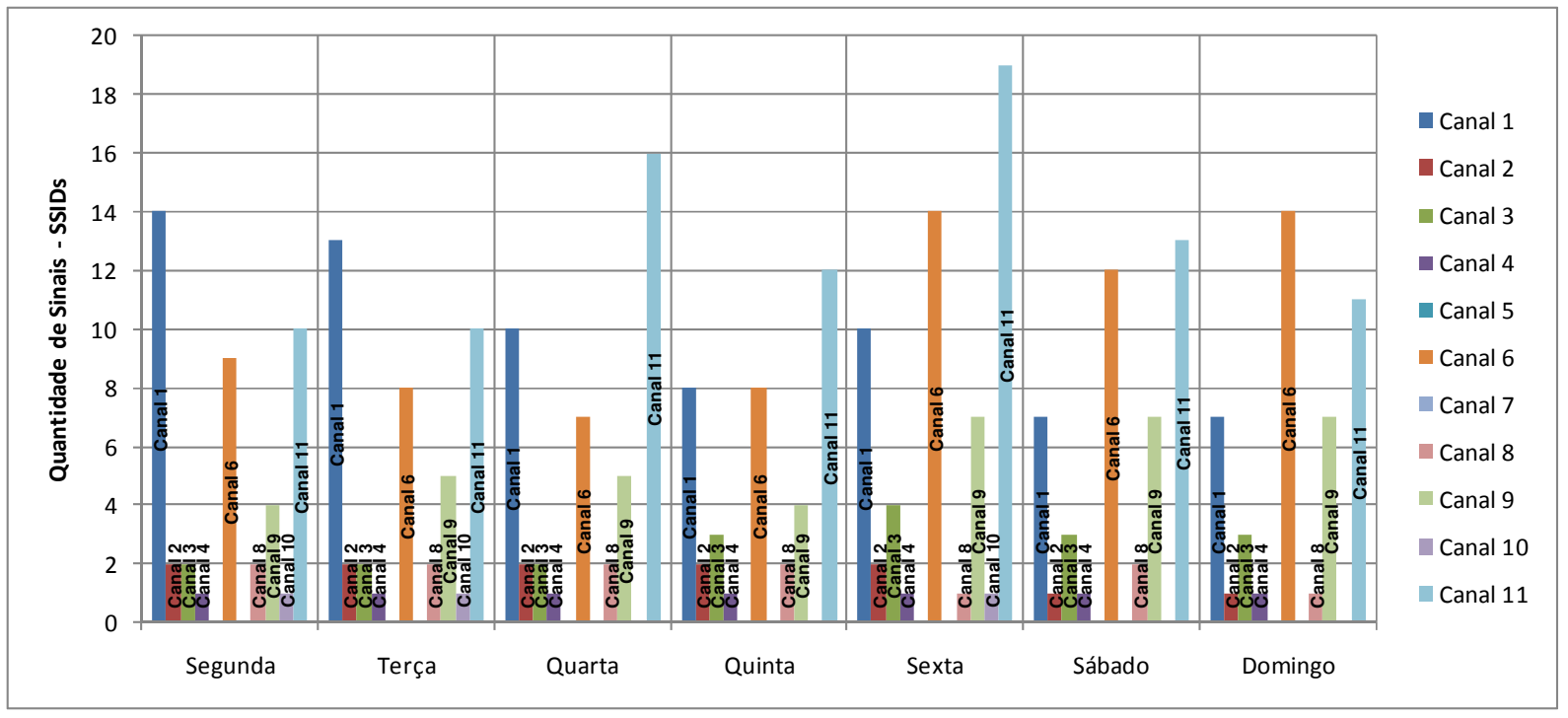

Figura 44 - Quantidade de sinais coletados pelos sensores posicionados nos blocos 1, 2 e 4, distribuídos em dias e qualificados pelos canais de operação. 
As médias das somas dos sinais, coletados nos três sensores, qualificadas apenas por canais, são apresentadas na Figura 45. Os canais 1, 6 e 11 são claramente identificados como os mais utilizados.

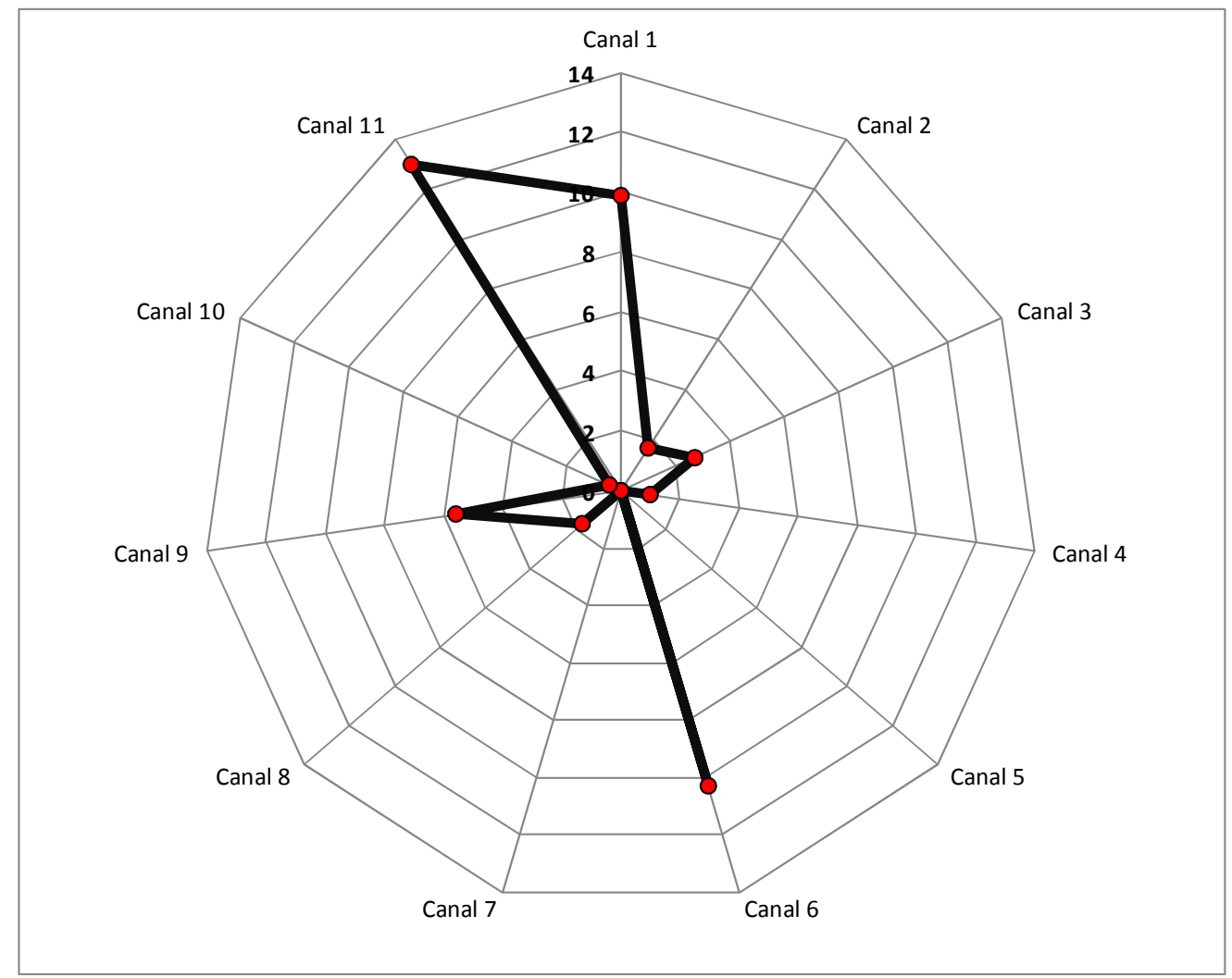

Figura 45 - Média dos sinais coletados pelos sensores posicionados nos blocos 1, 2 e 4, qualificados pelos canais de operação.

A Figura 46 apresenta visualmente os dados coletados pelos três sensores. Esta apresentação é composta por três eixos, a saber, um para os dias da semana, outro para a distribuição dos canais e o último a quantidade de sinais coletados. Através da análise visual dos três eixos, é possível verificar a dinâmica de propagação de sinais. O canal 1, por exemplo, tem sua utilização diminuída nos finais de semana. A utilização do canal 6 tem comportamento divergente, quando comparado ao canal 1, pois existe elevação substancial na utilização deste canal nos finais de semana. Os canais 2, 5, 7 e 10 têm comportamento estável de utilização - quase não são utilizados. 


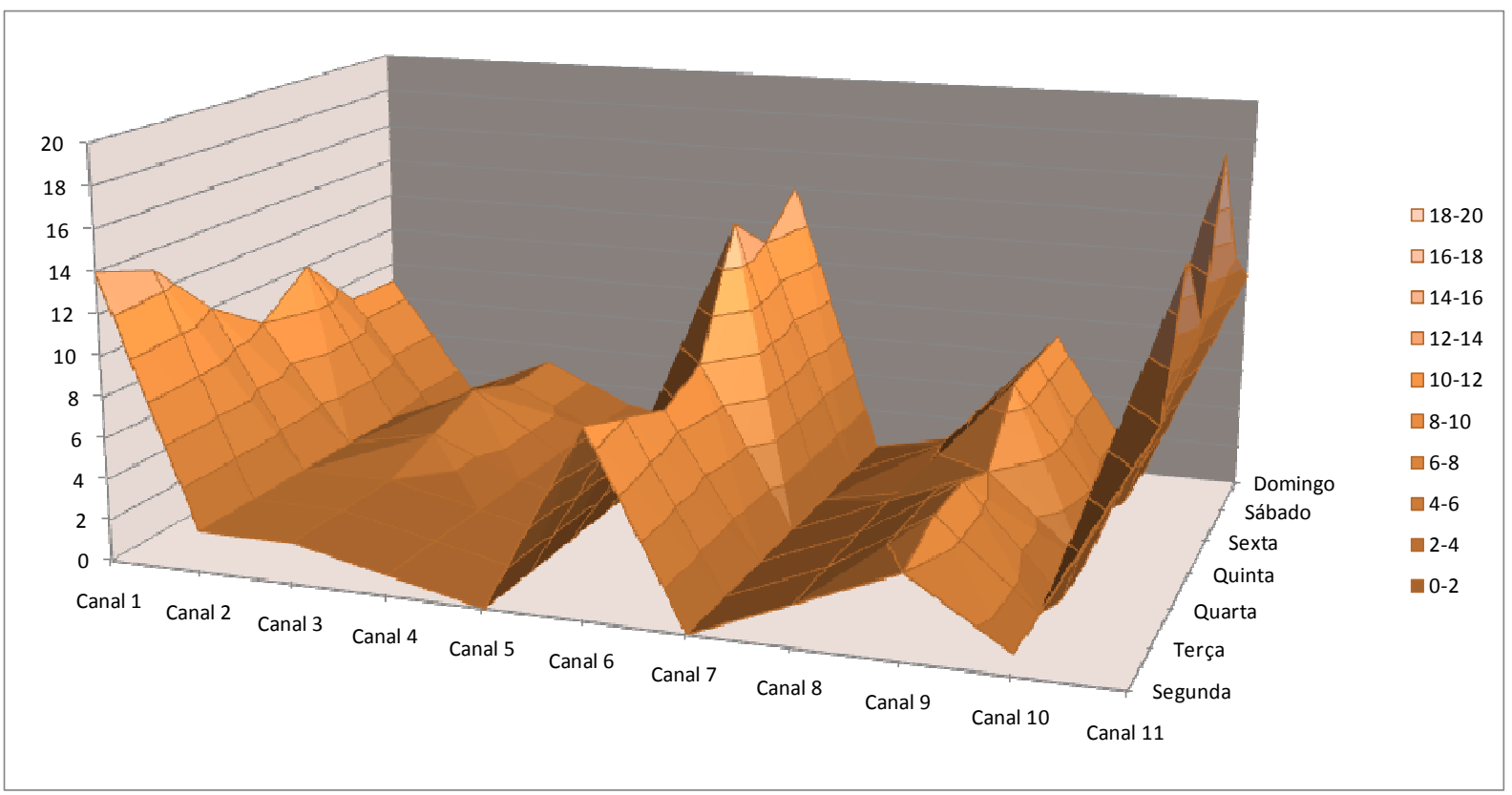

Figura 46 - Distribuição dos sinais coletados no tempo, qualificados por canais e dias da semana.

\subsubsection{Avaliação da diminuição da vazão quando expostos à interferências}

A sobreposição parcial ou total de canais em redes WLANs é um problema existente. Os dados, apresentados na seção anterior, comprovam que o espectro de radio frequência está concorrido, no contexto de uma rede Campus. A probabilidade de sobreposição total ou parcial no canal 1 é de $\mathbf{2 1 \%}$, no canal 6 é de $\mathbf{2 2 \%}$ e no canal 11 é de $\mathbf{2 8 \%}$. A probabilidade de sobreposição parcial ou total concebida através dos canais que estão entre 1 a 6 e 6 a 11, revela que os índices são menores; estão entre 0 a $6 \%$ de probabilidade (Tabela 8 ).

Tabela 8 - Distribuição dos sinais coletados e o percentual de ocupação espectral.

\begin{tabular}{l|r|r|r|r|r|r|r|r|r} 
& Segunda & Terça & Quarta & Quinta & Sexta & Sábado & Domingo & $\begin{array}{c}\text { Média de } \\
\text { Sinais }\end{array}$ & $\begin{array}{c}\text { Percentual } \\
\text { de Ocupação }\end{array}$ \\
\hline Canal 1 & 14 & 13 & 10 & 8 & 10 & 7 & 7 & 9,9 & $21 \%$ \\
\hline Canal 2 & 2 & 2 & 2 & 2 & 2 & 1 & 1 & 1,7 & $4 \%$ \\
\hline Canal 3 & 2 & 2 & 2 & 3 & 4 & 3 & 3 & 2,7 & $6 \%$ \\
\hline Canal 4 & 1 & 1 & 1 & 1 & 1 & 1 & 1 & 1,0 & $2 \%$ \\
\hline Canal 5 & 0 & 0 & 0 & 0 & 0 & 0 & 0 & 0,0 & $0 \%$ \\
\hline Canal 6 & 9 & 8 & 7 & 8 & 14 & 12 & 14 & 10,3 & $22 \%$ \\
\hline Canal 7 & 0 & 0 & 0 & 0 & 0 & 0 & 0 & 0,0 & $0 \%$ \\
\hline Canal 8 & 2 & 2 & 2 & 2 & 1 & 2 & 1 & 1,7 & $4 \%$ \\
\hline Canal 9 & 4 & 5 & 5 & 4 & 7 & 7 & 7 & 5,6 & $12 \%$ \\
\hline Canal 10 & 1 & 1 & 0 & 0 & 1 & 0 & 0 & 0,4 & $1 \%$ \\
\hline Canal 11 & 10 & 10 & 16 & 12 & 19 & 13 & 11 & 13,0 & $28 \%$ \\
\hline
\end{tabular}


Com o intuito de analisar o impacto da interferência total de canal, no contexto de uma rede de baixa a média complexidade, foi inserida uma fonte de interferência determinística. A metodologia, para a geração da interferência, já foi amplamente discutida na seção de metodologias deste trabalho.

O comportamento da vazão da rede sem fio no Campus, para os APs localizados no bloco 1, 2 e 4, está descrito na Figura 47. Próximos a estes pontos de acesso estão os três sensores responsáveis pelas coletas dos resultados mencionados anteriormente. O comportamento da vazão da rede sem fio, ilustrado na Figura 47, foi mapeado através das 25920 medidas, coletadas durante 90 dias. O comportamento da Figura 47 não teve a interferência da fonte geradora.

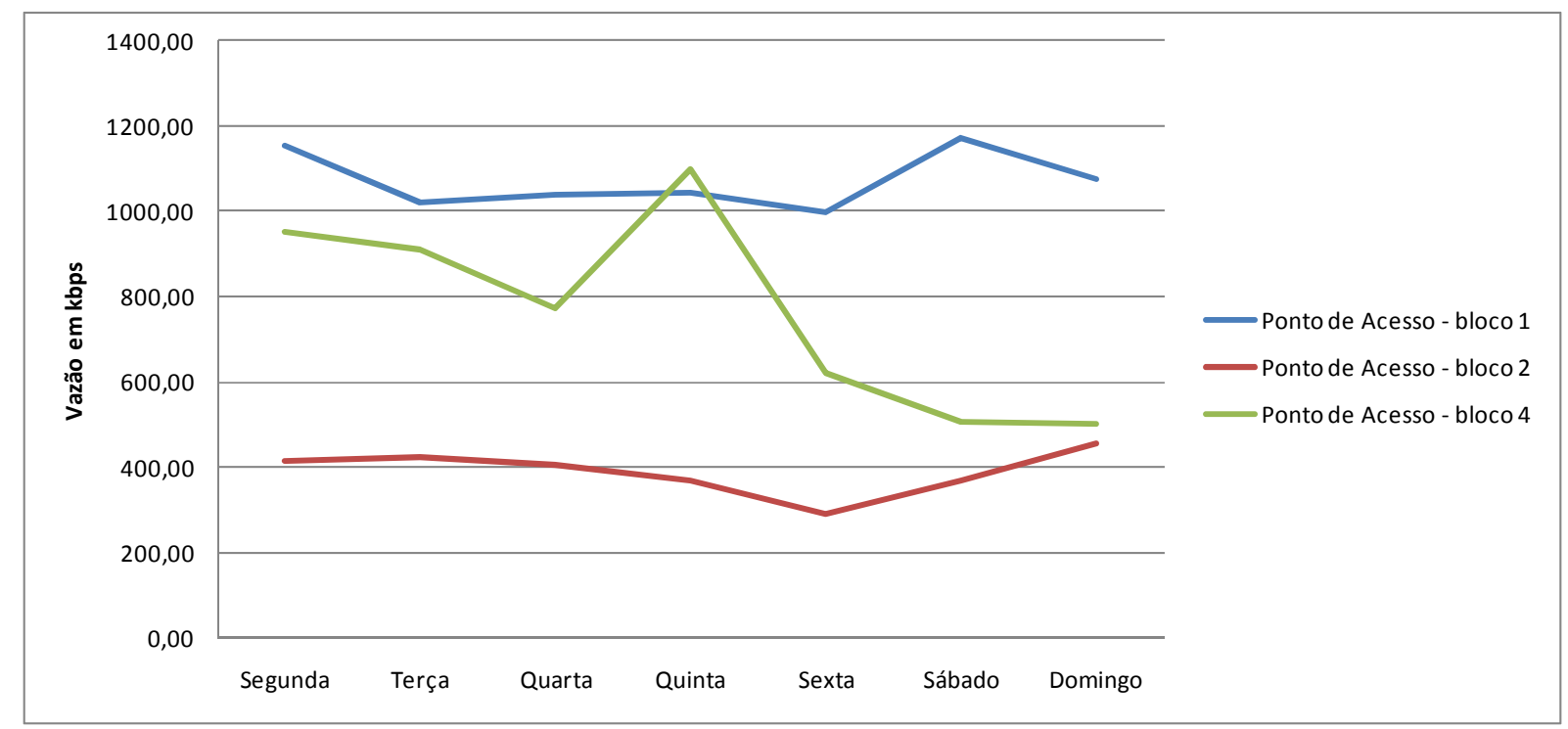

Figura 47 - Comportamento da vazão da rede sem fio no Campus Universitário, Ponto de Acesso bloco1, bloco2 e bloco4.

Por ter comportamento mais estável, a fonte geradora foi inserida próxima ao ponto de acesso do bloco 1, com o mesmo canal de operação. A carga de rede, injetada no meio pela fonte geradora de interferência, foi de $11 \mathrm{mbps}$. O protocolo TCP foi utilizado para a geração da carga.

Após uma semana de geração de tráfego de interferência, não foram encontradas evidências substanciais de degradação de vazão no ponto de acesso do bloco 1 . A análise do percentual de pacotes perdidos, no ponto de acesso do bloco 1, com e sem a interferência, aponta a média de $\mathbf{0 , 0 1 2 \%}$ de pacotes perdidos sem a fonte de interferência e de $\mathbf{0 , 0 6 6 \%}$ com a fonte de interferência (Figura 48). 


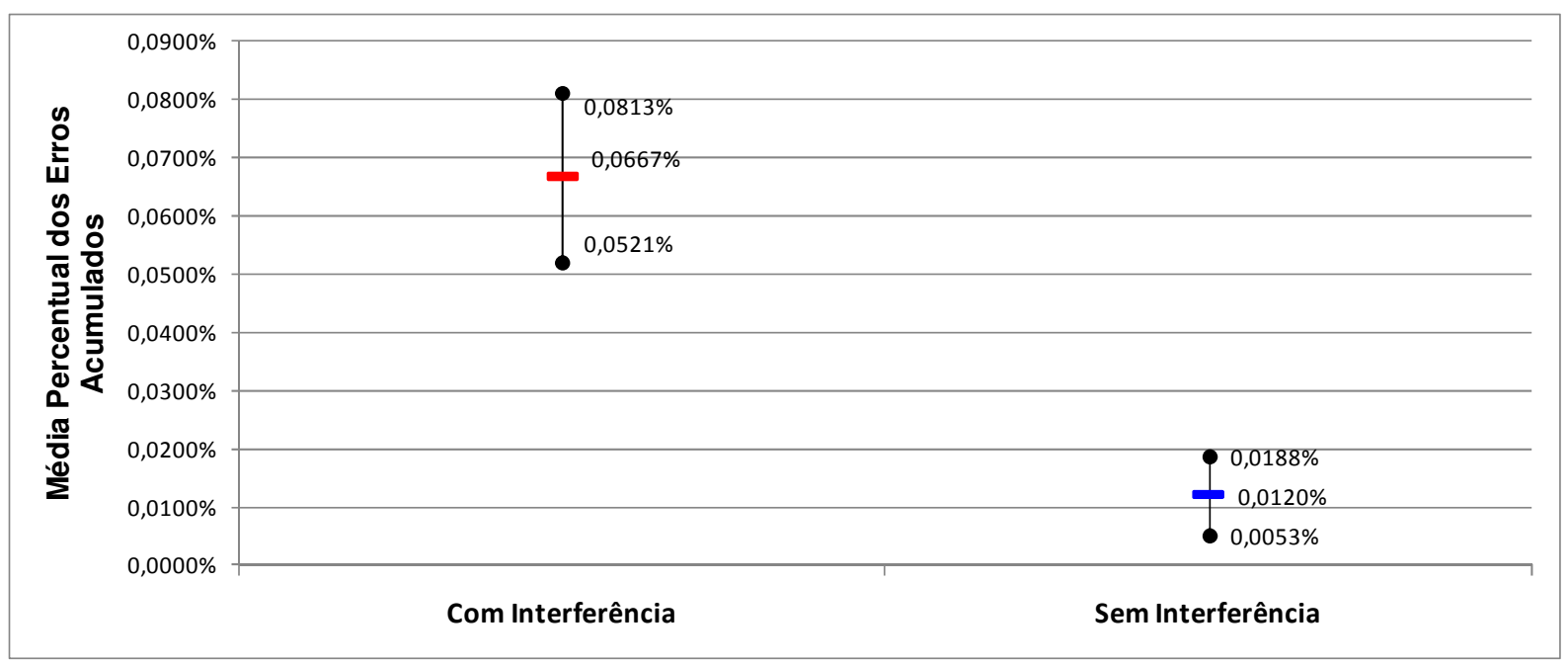

Figura 48 - Média percentual dos erros (pacotes perdidos), com e sem interferência da fonte geradora. Intervalo de confiança de $5 \%$ para mais e para menos.

A projeção do percentual de perdas de pacotes, desprezando quaisquer fatores adicionais no comportamento da vazão dos APs, permite perceber que a degradação não foi substancial (Figura 49).

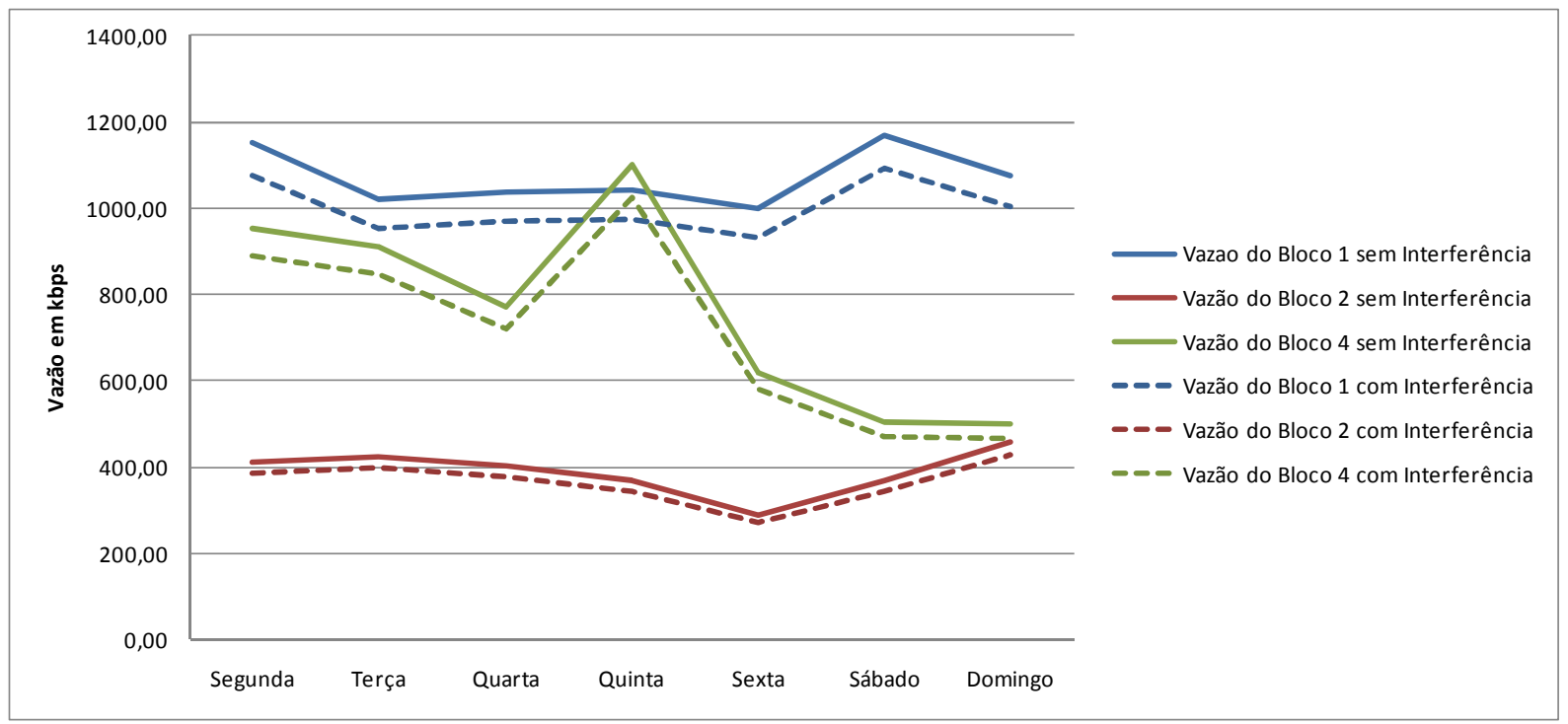

Figura 49 - Projeção da média percentual dos erros sobre o comportamento da vazão dos pontos de acesso. 


\subsection{Avaliações do Ambiente de Alta Densidade e Complexidade}

A interferência espectral total, causada pela sobreposição do canal, não causou evidentes perturbações da vazão na rede Campus. No entanto, é preciso avaliar as situações que levam à sobreposição total e parcial, ambas geradas por vários APs, no mesmo tempo e espaço.

O testbed, criado para experimentar as interferências em ambientes com alta densidade e complexidade de utilização, foi amplamente discutido na seção de metodologias.

\subsubsection{Resultado e Avaliação do Experimento número 1}

No experimento número 1 foram gerados 40 fluxos $\mathrm{TCP}^{5}$ dos clientes PC 1 , PC 2, PC 3, PC 4, PC 5 e PC 6, todos associados ao AP1 (canal 1), para o Iperf Server do AP1. Simultaneamente foram gerados fluxos TCP dos clientes PC 1, PC 2, PC 3, PC 4, PC 5 e PC 6, todos associados no AP2 (canal 6), para o Iperf Server do AP2 e dos clientes PC 1, PC 2, PC 3, PC 4, PC 5 e PC 6, todos associados no AP3 (canal 11), para o Iperf Server do AP3. O AP gerador de interferência não estava ligado.

A Figura 50 apresenta os resultados das coletas. O comportamento da vazão dos três APs é semelhante; desta forma, quando não há sobreposição, o comportamento da vazão dos APs tende a ser igual. Este comportamento confirma a teoria do espaçamento espectral ${ }^{6}$, pois, existe evidente mitigação das interferências causadas por fontes próximas.

\footnotetext{
${ }^{5}$ Os fluxos foram gerados sem limite de vazão.

${ }^{6}$ Os canais 1, 6 e 11, em redes padrão 802.11 b/g, não se sobrepõem. A técnica de espaçamento espectral pode ser utilizada para mitigar os problemas de sobreposição de canais (RAPPAPORT, 2009).
} 


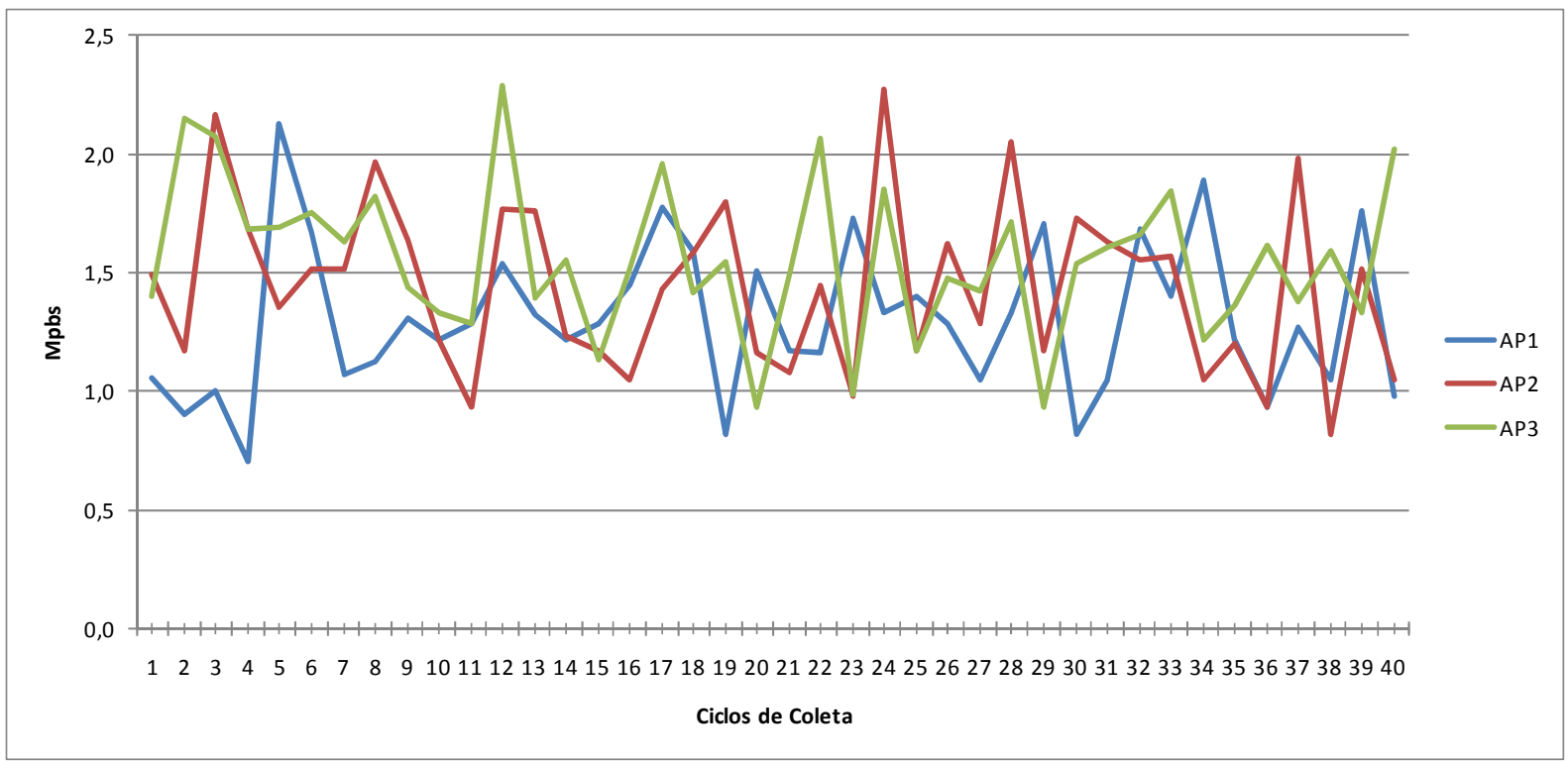

Figura 50 - Comportamento da vazão nos três APs no cenário de alta densidade e complexidade. O AP1 operava no canal 1, o AP2 no canal 6 e o AP3 no canal 11.

\subsubsection{Resultado e Avaliação do Experimento número 2}

No experimento número 2 , o objetivo era verificar se havia alteração de comportamento de vazão sem que houvesse uma carga geradora de interferência. No primeiro momento, o Gerador de Interferência foi inserido no ambiente com o canal 11, mesmo canal do AP3. Foram disparados 40 fluxos TCP, da mesma forma que no experimento número 1. Neste experimento o Gerador de Interferência ficou inativo, ele não gerou ou recebeu fluxos.

A sobreposição do canal do Gerador de Interferência ocorreu com o AP3 pois, ambos estavam configurados para o canal 11. O fato importante é de não ter havido alteração substancial no comportamento da vazão do AP3, comparado aos do AP1 e AP2 (Figura 51). Este comportamento comprova não ser suficiente haver a sobreposição de canal. As fontes configuradas no mesmo canal deverão receber e enviar sinais, simultaneamente, para que haja impacto na vazão. 


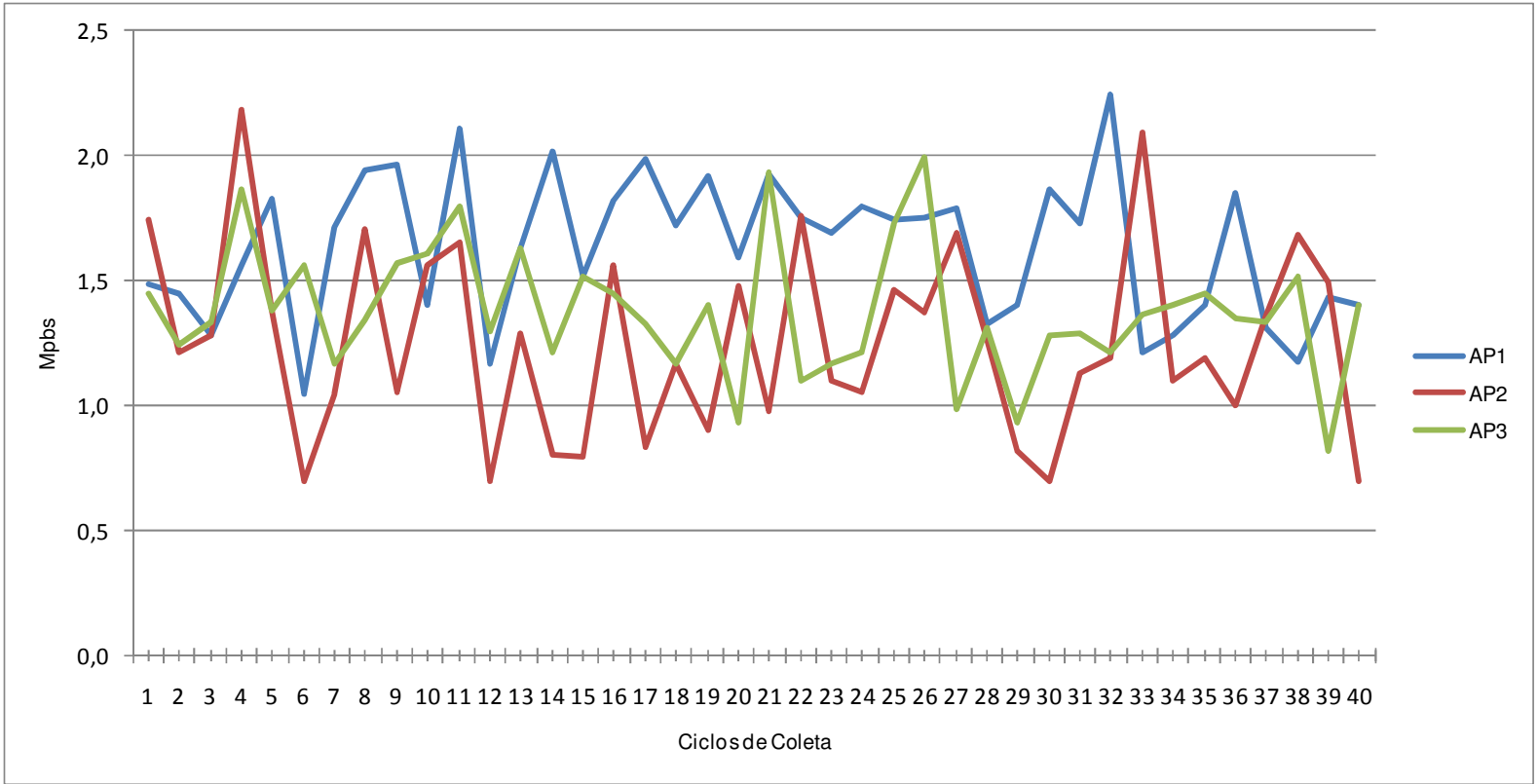

Figura 51 - Comportamento da vazão do AP3 quando exposto a uma fonte geradora de interferência sem atividade, alocada no mesmo canal.

Quando o Gerador de Interferência foi submetido à geração e recebimento de fluxos TCP o comportamento da vazão do AP3 foi alterado. Houve uma queda média de vazão no AP3 de 53\%, quando comparado aos fluxos dos APs 1 e 2 (Figura 52).

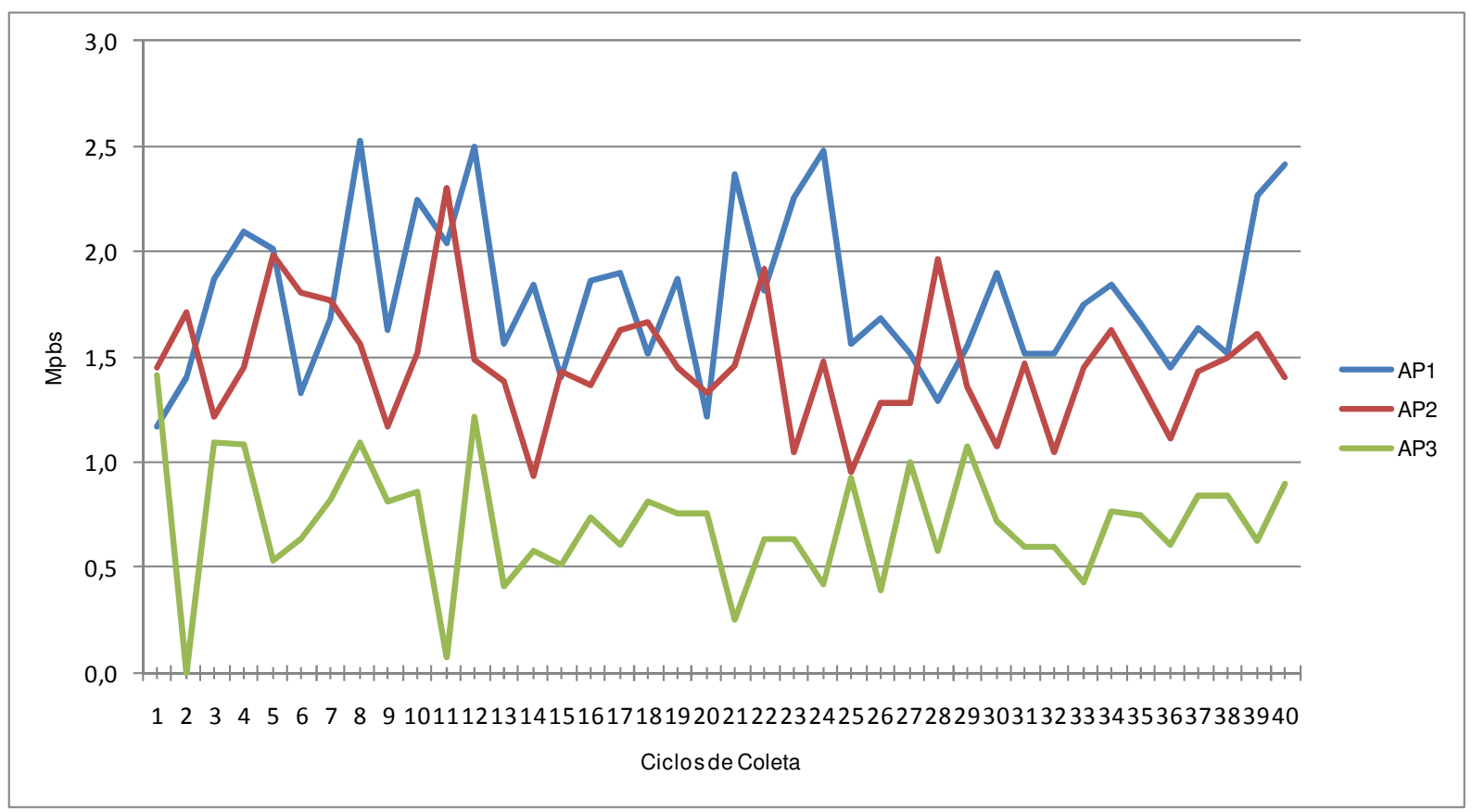

Figura 52 - Comportamento da vazão do AP3 quando exposto a uma fonte geradora de interferência com atividade, alocada no mesmo canal. 


\subsubsection{Resultado e Avaliação do Experimento número 3}

O experimento número 3 foi configurado para expor os APs à interferências mútuas. Estas interferências ocorrem em ambientes densos e complexos. Em ambientes com estas características não é possível aplicar a separação espectral, devido ao número excessivo de sinais em uma pequena área geográfica.

De forma sincronizada e simultânea foram gerados 40 fluxos TCP. Estes fluxos partiram dos clientes dos APs número 1, 2 e 3 com destino aos IPerf Servers respectivos ${ }^{7}$.

O AP1 teve o canal 1 alocado, o AP2 o canal 6 e o Gerador de Interferência o canal 11, estes permaneceram fixos. Porém, o AP3 teve seu canal variado no tempo. Foram disparados 40 fluxos TCP para cada um de seus onze canais ${ }^{8}$, totalizando 11 testes de degradação de vazão. A Tabela 9 apresenta as combinações de canais dos APs - uma combinação para cada fluxo. Para entendimento do experimento número 3, suas ações foram subdividas em coletas, que vão da coleta 3.1 a 3.11 .

Tabela 9 - Combinações de canais nos APs 1, 2, 3 e Gerador de Interferência, no experimento número 3.

\begin{tabular}{l|l|l|l|l}
\hline Coleta & Canal do AP1 & Canal do AP2 & Canal do AP3 & Gerador de Interferência \\
\hline $\mathbf{3 . 1}$ & 1 & 6 & 1 & 11 \\
\hline $\mathbf{3 . 2}$ & 1 & 6 & 2 & 11 \\
\hline $\mathbf{3 . 3}$ & 1 & 6 & 3 & 11 \\
\hline $\mathbf{3 . 4}$ & 1 & 6 & 4 & 11 \\
\hline $\mathbf{3 . 5}$ & 1 & 6 & 5 & 11 \\
\hline $\mathbf{3 . 6}$ & 1 & 6 & 6 & 11 \\
\hline $\mathbf{3 . 7}$ & 1 & 6 & 7 & 11 \\
\hline $\mathbf{3 . 8}$ & 1 & 6 & 8 & 11 \\
\hline $\mathbf{3 . 9}$ & 1 & 6 & 9 & 11 \\
\hline $\mathbf{3 . 1 0}$ & 1 & 6 & 10 & 11 \\
\hline $\mathbf{3 . 1 1}$ & 1 & 6 & 11 & 11 \\
\hline
\end{tabular}

Na Figura 53 por ser verificado o resultado compilado do experimento. Foi variado no tempo o canal do AP3, sendo que na coleta 3.1 o canal do AP3 estava configurado para o canal 1 , na coleta 3.2 no canal 2 e assim respectivamente.

Os resultados apresentados foram extraídos através da média aritmética dos 40 fluxos. Com a análise dos dados alguns fatores chamaram a atenção: i) na coleta 3.1 a degradação da vazão ocorreu no AP1 e no AP3, ambos estavam operando no mesmo canal; ii) na coleta 3.6 a

\footnotetext{
${ }^{7}$ Mais informações sobre o cenário procurar na seção "Descrição do cenário de alta complexidade e densidade"

${ }^{8}$ Foram utilizados os 11 canais conforme a FCC.
} 
degradação da vazão ocorreu no AP2 e no AP3, ambos estavam operando no canal 6; iii) na coleta 3.11 a degradação da vazão ocorreu no AP3, ele estava operando no mesmo canal do Gerador de Interferência; iv) nas coletas 3.3, 3.4, 3.9 e 3.10 a degradação da vazão do AP3 foi considerável. As quedas ocorreram quando havia duas sobreposições parciais, uma originada dos canais inferiores e outra dos canais superiores. Por exemplo, na coleta 3.4 o AP1 estava operando no canal 1, o AP2 no canal 6 e o AP3 no canal 4. Neste caso, o AP3 recebeu interferência de $7 \mathrm{MHz}$ vinda do AP1 e $12 \mathrm{MHz}$ vinda do AP3; v) a sobreposição total do canal é menos prejudicial que as sobreposições parciais, quando comparada ao contexto dos três APs $^{9}$. As sobreposições parciais, vinda de duas fontes de interferência, uma abaixo e outra acima, apresentaram degradações severas. O AP que operou na região central da faixa de interferência recebeu uma degradação substancial. Os outros dois APs sofreram degradações menores ${ }^{10}$.

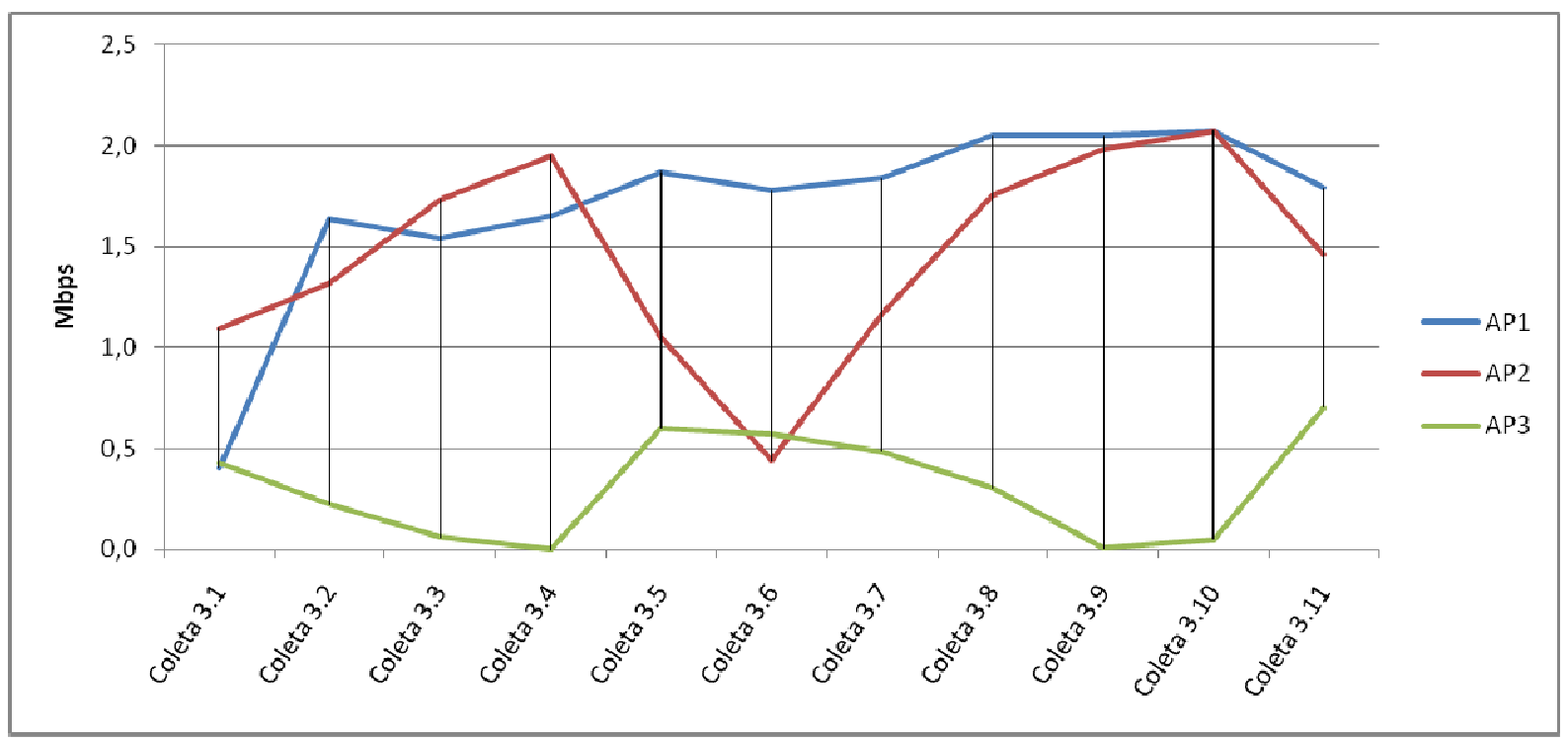

Figura 53 - Comportamento compilado das vazões dos APs 1, 2 e 3 . O canal de operação do AP3 variou no tempo.

\section{Conclusões, Propostas e Sugestões para Trabalhos Futuros}

\subsection{Conclusões}

A sobreposição total ou parcial de canais, em redes $802.11 \mathrm{~b} / \mathrm{g}$, apresenta problemas de queda de vazão da rede WLAN, conforme os experimentos comprovaram. Em redes com

\footnotetext{
${ }^{9}$ Verificar os resultados das coletas 3.1 e 3.6.

${ }^{10}$ Verificar os resultados das coletas $3.3,3.4,3.9$ e 3.10 .
} 
baixa a média densidade e complexidade, de acordo com o modelo deste trabalho, as degradações derivadas das interferências espectrais não se mostraram acentuadas.

Por sua vez, as redes classificadas como de alta densidade e complexidade podem sofrer impactos severos de degradação de vazão, visto que a proximidade dos pontos de acesso não possibilita a organização dos canais no espaço. Outro fator é a potência dos sinais, nos ambientes densos e complexos os sinais são recepcionados com potência elevada.

O gerenciamento do espectro, no tempo e no espaço, é fundamental. A plataforma proposta foi capaz de coletar informações importantes para a análise comportamental da rede. As informações coletadas pela plataforma possibilitam criar um escopo de classificação das redes, em densas, não densas, complexas e não complexas. Esta realimentação da plataforma é muito importante para o administrador da rede sem fio, pois, uma rede que no momento v0 era classificada como de baixa a média complexidade, em um momento v1 poderá vir a ser classificada como de alta densidade e complexidade.

\subsection{Propostas}

Por conta da elasticidade da densidade e complexidade, das redes sem fio padrão 802.11, é apresentada uma proposta de ciclo de vida (Figura 54). Esta proposta é adaptada dos quesitos de gerenciamento de espectro, utilizados pelos administradores de rede sem fio. Normalmente os administradores utilizam quatro etapas para realizar o gerenciamento de espectro das WLANs: pré-instalação ou expansão, instalação e verificação, descoberta de erros e otimização. Através da plataforma proposta, que foi amplamente experimentada, foi concluído que a adição de dois outros processos no ciclo de vida é importante. O primeiro processo a ser inserido, no ciclo de vida proposto, é o contexto espectral. O contexto espectral tem por objetivo entender as variações das redes no espaço e no tempo. Este processo possibilita, ao administrador, classificar e reclassificar a densidade e complexidade das redes sem fio no ambiente. Outro processo inserido no modelo tradicional é a adaptação. A adaptação é um processo que proporciona ações variadas, de acordo com a situação da rede. O processo possibilita, por exemplo, o desligamento de um determinado AP. Os resultados obtidos através dos experimentos apontam para alguns momentos de total inatividade da rede sem fio. Nestes momentos os APs inativos poderiam ser desligados, a fim de economizar o espectro de RF e a energia elétrica. O uso racionalizado do espectro é importante para não aumentar a complexidade e densidade dos sinais, minimizando as possibilidades de degradação de vazão. 


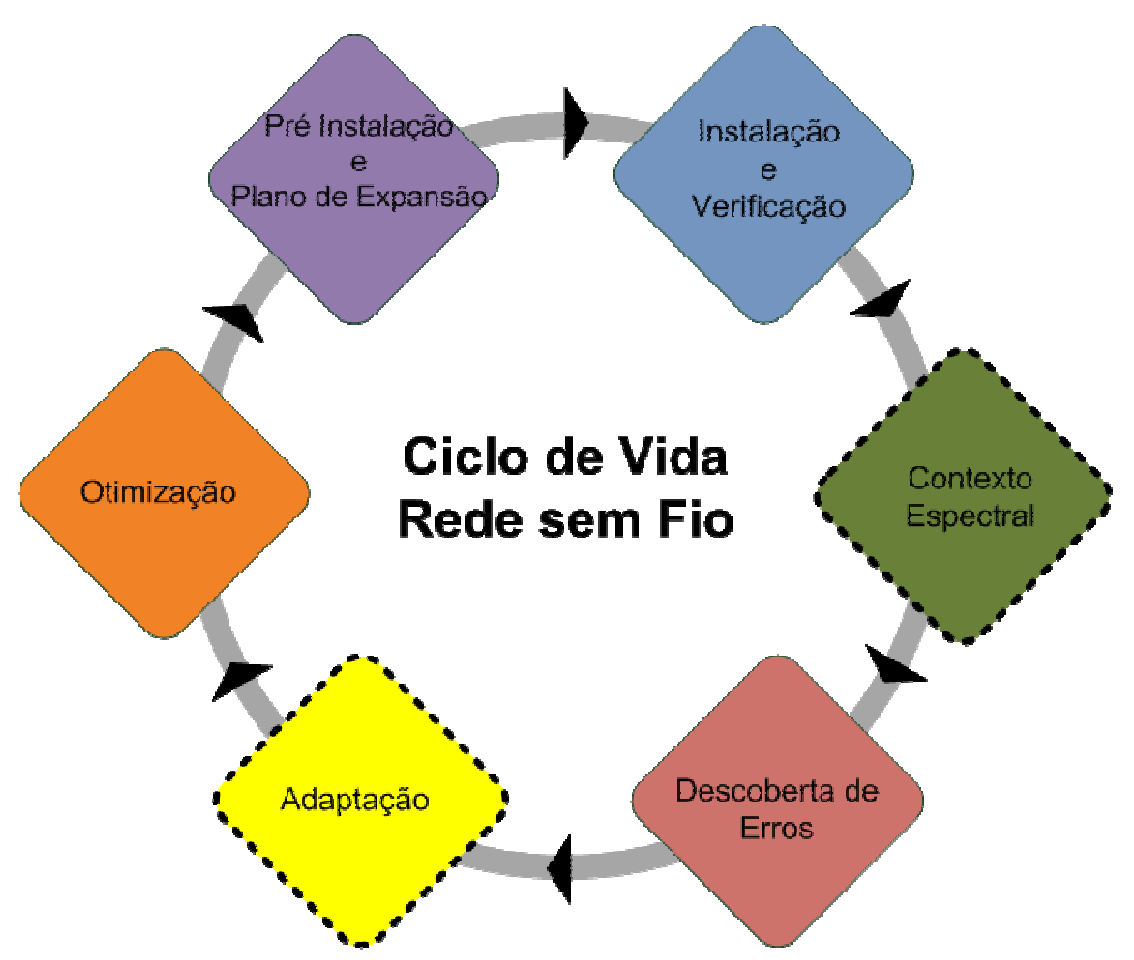

Figura 54 - Proposta de um ciclo de vida da rede sem fio, padrão 802.11.

\subsection{Sugestões para Trabalhos Futuros}

Com os recentes estudos em Cognitive Radio (MITOLA, 1993), (GANESAN e LI, 2005), (NIYATO e HOSSAIN, 2009), as informações do contexto espectral e de utilização das redes sem fio são importantes. Essas informações podem melhorar a adequação de alocação do espectro, além de propiciar despoluição espectral em momentos de inatividade. Este tema possibilita contribuições de ordem inédita, visto que vários grupos de pesquisa trabalham e publicam em congressos de temas relacionados.

Para melhorar o processo da coleta e conseguir maior precisão nas informações de contexto, algumas etapas futuras deverão ser desenvolvidas. Essas poderão contribuir para a concatenação da plataforma ao Cognitive Radio:

- Ampliação da cobertura da plataforma, através do acréscimo de mais sensores;

- Transformar os sensores em micro-hardwares, através de software embarcado;

- Criação de uma MIB para coleta de informações dos sensores, através do protocolo SNMP;

- Entender a dinâmica do comportamento dos usuários através de séries temporais;

- Simular quedas de vazão e analisar o comportamento dos usuários; 


\section{Referências}

ARAUJO, R. B. Computação Ubíqua: princípios, tecnologias e desafios. XXI - Simpósio Brasileiro de Redes de Computadores, Natal, 19 maio 2003. 1-71.

BROADCOM. 802.11n: Next-Generation Wireless LAN Technology. Broadcom Corporation. [S.1.], p. 13. 2006.

CHENG, Y.-C. et al. Jigsaw: solving the puzzle of enterprise 802.11 analysis. SIGCOMM Comput. Commun. Rev., New York, NY, USA, v. 36, n. 4, p. 39-50, 2006. ISSN 01464833.

CHOI, S.; PARK, K.; KIM, C.-K. On the performance characteristics of WLANs: revisited. SIGMETRICS Perform. Eval. Rev., New York, NY, USA, 2005. 97-108.

CISCO SYSTEMS. Radio Resource Management under Unified Wireless Networks. Cisco Systems. [S.1.], p. 37. 2010. (Document ID: 71113).

DRIESSEN, P. F.; FOSCHINI, G. J. On the capacity formula for multiple input-multiple output wireless channels: a geometric interpretation. Communications, IEEE Transactions on, v. 47, p. 173-176, Fevereiro 1999. ISSN 0090-6778.

E.BENJAMIN, H. Throughput Measurements and Empirical Prediction Models for IEEE 802.11b Wireless LAN (WLAN) Installations. Blacksburg: Master's Thesis Virginia Tech University, 2001.

ERIKSSON, J. et al. Feasibility study of mesh networks for all-wireless offices. MobiSys '06: Proceedings of the 4th international conference on Mobile systems. New York, NY, USA: ACM. 2006. p. 69-82.

FRATTASI, S. et al. Defining 4G technology from the users perspective. Network, IEEE, v. 20, p. 35-41, janeiro 2006. ISSN 0890-8044.

GANESAN, G.; LI, Y. Cooperative spectrum sensing in cognitive radio networks. New Frontiers in Dynamic Spectrum Access Networks, 2005. DySPAN 2005. [S.1.]: IEEExplore. 2005. p. 137-143. 
GAST, M. 802.11 Wireless Networks: The Definitive Guide, Second Edition. $2^{\mathrm{a}}$ Edição. ed. [S.1.]: O'Reilly, v. 1, 2005.

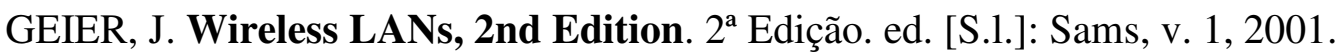

HALPERT, B. J. Interference effects on wireless link availability. SoutheastCon, 2005. Proceedings. IEEE, abril 2005. 537-541.

HO, L. T. W.; SAMUEL, L. G.; PITTS, J. M. Applying Emergent Self-Organizing Behavior for the Coordination of $4 \mathrm{G}$ Networks Using Complexity Metrics. Bell Labs Technical Journal - Wiley Periodicals, v. 8, n. 1, p. 5-25, 2005.

HUI, S. Y.; YEUNG, K. H. Challenges in the migration to $4 \mathrm{G}$ mobile systems. Communications Magazine, IEEE, v. 41, n. 12, p. 54-59, dezembro 2003. ISSN 0163-6804.

IEEE STANDARD. IEEE 802.11 WG, Part 11: Wireless LAN Medium Access Control (MAC) and Physical Layer (PHY) specifications. IEEE. [S.1.]. 1999.

IPERF - UNIVERSITY OF CENTRAL FLORIDA. Iperf. Disponivel em: <http://www.noc.ucf.edu/Tools/Iperf/>. Acesso em: 10 abril 2010.

KANTOROVITCH, J.; MAHONEN, P. Case studies and experiments of SNMP in wireless networks. IP Operations and Management, 2002 IEEE Workshop on. [S.1.]: IEEEXplore. 2002. p. 179-183.

KIRCHNERI, R. M.; SOUZA, R. C.; ZIEGELMANN, F. A. Identificação de estruturas nãolineares de séries temporais através de regressão linear local e modelos aditivos. Pesquisa Operacional, Rio de Janeiro, v. 28, Abril 2008. ISSN 0101-7438.

LI, C.-S.; TSENG, Y.-C.; CHAO., H.-C. A Neighbor Caching Mechanism for Handoff in IEEE 802.11 Wireless Networks. Multimedia and Ubiquitous Engineering, 2007. MUE '07. International Conference on. [S.1.]: IEEEXplore. 2007. p. 48-53.

MARY, P. et al. Performance Analysis of Mitigated Asynchronous SpectrallyOverlapping WLAN Interference. Wireless Communications and Networking Conference, 2007.WCNC 2007. IEEE. [S.1.]: IEEEXplore. 2007. p. 2097-2102. 
MATEUS, G. R.; LOUREIRO, A. A. F. Introdução à Computação Móvel. $2^{\mathrm{a}}$ Edição. ed. Rio de Janeiro: Escola de Computação, v. v1, 2005. 1-199 p.

MAURO, D.; SCHMIDT, K. Essential SNMP, Second Edition. 2 ${ }^{\mathrm{a}}$ Edição. ed. [S.1.]: O'Reilly, v. I, 2005.

MITOLA, J. Software radios: Survey, critical evaluation and future directions. Aerospace and Electronic Systems Magazine, IEEE, 1993. 25-36.

MOREIRA, E. D. S. et al. Exploiting contextual handover information for versatile services in NGN environments. Digital Information Management, 2007. ICDIM '07. 2nd International Conference. [S.1.]: 2007. p. $506-512$.

MULLANY, F. J. et al. Self-deployment, Self-configuration:Critical Future Paradigms for Wireless Access Networks. Autonomic Communication - Lecture Notes in Computer Science - Springer, Berlin / Heidelberg, v. 3457, p. 58-68, 2005.

NIYATO, D.; HOSSAIN, E. Cognitive radio for next-generation wireless networks: an approach to opportunistic channel selection in ieee 802.11-based wireless mesh. Wireless Communications, IEEE, fevereiro 2009. 46-54.

PAGUREK, B.; WANG, Y.; WHITE, T. Integration of mobile agents with SNMP: why and how. Network Operations and Management Symposium - NOMS. [S.1.]: IEEEXplore. 2000. p. 609-622.

PERAHIA, E.; STACEY, R. Next Generation Wireless LANs Throughput, Robustness, and Reliability in 802.11n. [S.1.]: Cambridge University Press, v. 1, 2008.

PETROVA, M. et al. Interference Measurements on Performance Degradation between Colocated IEEE 802.11g/n and IEEE 802.15.4 Networks. Networking, 2007. ICN '07. Sixth International Conference on. [S.1.]: IEEEXplore. 2007. p. 93-93.

RAMAKRISHNA, G. et al. Understanding and mitigating the impact of rf interference on 802.11 networks. In Proc. of Sigcomm'07. [S.1.]: [s.n.]. 2007. p. 385-396.

RAPPAPORT, T. Comunicações sem fio: princípios e práticas. $2^{\mathrm{a}}$ Edição. ed. [S.1.]: Pearson, v. I, 2009. ISBN 9788576051985. 
ROHRIG, C.; KUNEMUND, F. Mobile Robot Localization using WLAN Signal Strengths. Intelligent Data Acquisition and Advanced Computing Systems: Technology and Applications, 2007. IDAACS 2007. 4th IEEE Workshop on. [S.1.]: [s.n.]. 2007. p. 704-709.

SHEN, C.; PESCH, D.; IRVINE, J. A framework for self-management of hybrid wireless networks using autonomic computing principles. Communication Networks and Services Research Conference, 2005. Proceedings of the 3rd Annual. [S.1.]: IEEEXplore. 2005. p. 261266.

SKORDOULIS, D. et al. IEEE 802.11n MAC frame aggregation mechanisms for nextgeneration high-throughput WLANs. Wireless Communications, IEEE, v. 15, p. 40-47, Fevereiro 2008. ISSN 1536-1284.

SPYMODEX. Cell Phone Jammer. Disponivel em: <http://www.spymodex.com/>. Acesso em: 20 janeiro 2009.

STALLINGS, W. SNMP, SNMPv2, SNMPv3, and RMON 1 and 2. [S.1.]: Addison-Wesley, v. $1,1999$.

TANENBAUM, A. S. Redes de Computadores. 4ª Edição. ed. [S.1.]: Campus, 2003.

VIDALES, P. et al. A practical approach for 4G systems: deployment of overlay networks. Testbeds and Research Infrastructures for the Development of Networks and Communities, fevereiro 2005. 172-181.

WANG, Y.; CUTHBERT, L. G.; BIGHAM, J. Intelligent radio resource management for IEEE 802.11 WLAN. Wireless Communications and Networking Conference, 2004. WCNC. 2004 IEEE. [S.1.]: IEEE. 2004. p. 1365-1370.

WEISER, M. The Computer for the 21st Century. In: WEISER, M. Human-computer interaction: toward the year 2000. San Francisco, CA, USA: Morgan Kaufmann Publishers Inc., 1995. p. 933-940. ISBN 1-55860-246-1.

WI-FI ALLIANCE. College students say Wi-Fi has become a fixture on campus; 73 percent say Wi-Fi helps them get better grades. Wi-Fi Alliance, 6 outubro 2008. Disponivel em: http://www.wi-fi.org. Acesso em: 20 janeiro 2009. 
WIGLE. Wireless Geographic Logging Engine - Plotting WiFi on Maps. Disponivel em: $<$ http://wigle.net>. Acesso em: 28 Setembro 2010.

ZIMMERMANN, K. et al. Autonomic wireless network management. Workshop on autonomic communication No2. Atenas: Springer, Berlin. 2005. p. 57-70. 